\title{
COMPUTATIONAL AND EXPERIMENTAL MODELING OF THREE-PHASE SLURRY-BUBBLE COLUMN REACTOR
}

\author{
Grant No.: DE-FG-98FT40117 \\ University Coal Research
}

\section{ANNUAL REPORT}

September 1999

\author{
Professor Isaac K. Gamwo \\ Principal Investigator \\ Department of Mechanical Engineering \\ University of Akron \\ Akron, Ohio 44326-3906 \\ Tel.: 330-972-7256 \\ Fax: 330-972-6027 \\ E-mail: gamwo@uakron.edu
Professor Dimitri Gidaspow Co-Principal Investigator Department of Chemical and Chicago, IL 60616 Ph. 312-567-3045 Fax 312-567-8874
E-mail: Gidaspow @iit.edu \\ Environmental Engineering
}

Program Manager: Donald Krastman

U.S. Department of Energy

National Energy Technology Laboratory 


\title{
COMPUTATIONAL AND EXPERIMENTAL MODELING OF THREE-PHASE SLURRY-BUBBLE COLUMN REACTOR
}

\author{
DE-PS26-98FT98200 \\ UCR \\ ANNUAL REPORT \\ September 1999
}

\author{
Professor Isaac Gamwo \\ PI \\ University of Akron \\ Akron, Ohio 44326-3906
}

\author{
Professor Dimitri Gidaspow \\ Co-PI \\ Department of Chemical and \\ Environmental Engineering \\ Chicago, IL 60616 \\ Ph. 312-567-3045 \\ Fax 312-567-8874 \\ Email GIDASPOW@ IIT.EDU
}

\begin{abstract}
Considerable progress has been achieved in understanding three-phase reactors from the point of view of kinetic theory. In a paper in press for publication in Chemical Engineering Science (Wu and Gidaspow, 1999) we have obtained a complete numerical solution of bubble column reactors.

In view of the complexity of the simulation a better understanding of the processes using simplified analytical solutions is required. Such analytical solutions are presented in the attached paper, Large Scale Oscillations or Gravity Waves in Risers and Bubbling Beds. This paper presents analytical solutions for bubbling frequencies and standing wave flow patterns. The flow patterns in operating slurry bubble column reactors are not optimum. They involve upflow in the center and downflow at the walls. It may be possible to control flow patterns by proper redistribution of heat exchangers in slurry bubble column reactors.

We also believe that the catalyst size in operating slurry bubble column reactors is not optimum. To obtain an optimum size we are following up on the observation of George Cody of Exxon who reported a maximum granular temperature (random particle kinetic energy) for a particle size of 90 microns. The attached paper, Turbulence of Particles in a CFB and Slurry Bubble Columns Using Kinetic Theory, supports George Cody's observations. However, our explanation for the existence of the maximum in granular temperature differs from that proposed by George Cody. Further computer simulations and experiments involving measurements of granular temperature are needed to obtain a sound theoretical explanation for the possible existence of an optimum catalyst size.
\end{abstract}




\section{Table of Contents}

Objective

Accomplishment to Date

Large Scale Oscillations or Gravity Waves in Risers and Bubbling Bed - paper

Turbulence of Particles in a CFB and Slurry Bubble Columns Using Kinetic Theory - paper

Measurement of Thermal Conductivity of FCC Particles - paper

Improved CFB at IIT

Model for Vaporization 


\section{Objective}

The overall objective of this research is to develop predictive hydrodynamic models for gasliquid-solid catalyst reactors using momentum balances for each phase. The unique feature of our approach is the modeling of turbulence of the catalyst particles using kinetic theory.

This project is a collaborative effort between the University of Akron, Illinois Institute of Technology and two industries: UOP and Energy International.

The tasks involve the development of transient two and three dimensional computer codes for Fischer-Tropsch synthesis in slurry bubble column reactors, optimization, comparison to data, and measurement of input parameters, such as the catalyst viscosity and effective restitution coefficients. Heat and mass transfer rates will be measured in the IIT two-story riser by injection of liquid nitrogen into an air-catalyst stream.

\section{Accomplishment to Date}

Our paper describing the basic approach using kinetic theory to predict the turbulence of catalyst particles in a slurry bubble column reactor, based mainly on the work accomplished in a previous UCR grant, has been accepted for publication in a refereed journal (Wu and Gidaspow, 1999).The simulation predicted the existence of multiple vortices in the LaPorte Air Products methanol reactor.

In view of the complexity of the simulation a better understanding of the processes using simplified analytical solutions is required. Such analytical solutions are presented in the attached paper, Large Scale Oscillations or Gravity Waves in Risers and Bubbling Beds. This paper presents analytical solutions for 
bubbling frequencies and standing wave flow patterns. The flow patterns in operating slurry bubble column reactors are not optimum. They involve upflow in the center and downflow at the walls. It may be possible to control flow patterns by proper redistribution of heat exchangers in slurry bubble column reactors.

We also believe that the catalyst size in operating slurry bubble column reactors is not optimum. To obtain an optimum size we are following up on the observation of George Cody of Exxon who reported a maximum granular temperature (random particle kinetic energy) for a particle size of 90 microns. The attached paper, Turbulence of Particles in a CFB and Slurry Bubble Columns Using Kinetic Theory, supports George Cody's observations. However, our explanation for the existence of the maximum in granular temperature differs from that proposed by George Cody. Further computer simulations and experiments involving measurements of granular temperature are needed to obtain a sound theoretical explanation for the possible existence of an optimum catalyst size.

We measured the thermal conductivity of catalyst particles in the IIT riser. Similarly to the viscosity it is approximately a linear function of the solid volume fraction. The Prandtl number has a reasonable value of 4.2. The details are presented in this report.

We are instrumenting our riser with two movable gamma ray densitometers which will give us volume fractions of the catalyst in a section of the riser where liquid nitrogen will be injected. In order to obtain symmetrical flow we replaced the bend with a splash plate. These measurements will give us evaporation rates of the liquid and sonic velocities that are needed for estimates of circulation cells in a slurry bubble column reactor.

A simple collisional kinetic theory model for vaporization was derived. It gives large but reasonable vaporization rates. 


\title{
Large Scale Oscillations or Gravity Waves in Risers and Bubbling Beds
}

\author{
Dimitri Gidaspow, Lu Huilin and Reza Mostofi \\ Department of Chemical and Environmental Engineering \\ Illinois Institute of Technology \\ Chicago, IL. 60616
}

\begin{abstract}
An important characteristic of fluidized beds is that they never reach a steady state. To explain the behavior, the classical wave theory is applied to fluidization by replacing the acoustic sonic velocity with the square root of the derivative of the solids pressure with respect to density. This pseudo-sonic velocity is obtained from measurements of granular temperature and an equation of state for the cracking catalyst that has been established in an earlier publication.

The wide range of granular temperature is explained in terms of a new analytical solution of the problem. The wave theory gives a resonant frequency and shows the possibility of the existence of standing waves which set up systems of steady vortices sometimes computed in the complete numerical solution of the Navier-Stokes type equations for fluidization.

A gamma ray densitometer was used to measure axial porosity oscillations in a two story circulating fluidized bed for flow of $75 \mu \mathrm{m}$ cracking catalyst particles. In the upper portion of the riser, there was a distinct dominant frequency of less than 0.2 Hertz which decreases with increasing porosity. In the lower portion of the tube the behavior was more chaotic and the dominant frequency was less defined. It approached one Hertz for porosity of 0.6.

To explain these data and the bubbling bed frequencies an analytical expression for the dominant frequency of oscillations was developed starting with conservation of mass and momentum. In agreement with riser measurement it decreases to zero, as the solid volume fraction decreases. It agrees with the decrease of the bubbling bed frequency with bed height. For incompressible flow, the large scale oscillation is simply the classical gravity wave obtained from the transient Bernoulli equation.
\end{abstract}




\section{Introduction}

The understanding and prediction of large scale oscillations of gas-solid flow, sometimes referred to as hydrodynamic instability (Jackson, 1985), is of interest in nature, such as in the explosive volcanic eruptions (Neri, et al 1998), industrially in coal combustors and in fluidized catalytic cracking (FCC) reactors (Squires, et al., 1985) and in the control of solid propellant rockets (Culik, 1994). Fluidized bed reactors are widely used industrially due to their excellent heat and mass transfer characteristics, which are caused by oscillations of particles. One can group these oscillations into large-scale oscillations, which are of the order of equipment size, reactor height or diameter, and small-scale oscillations that are of the order of particle size.

\section{1a. Solids Viscosity and Kinetic Theory Models}

Recent reviews (Gidaspow, 1994; Jackson, 1993; Sinclair, 1997; Kuipers, et al, 1998) show that two types of Navier-Stokes type models were developed to simulate fluidized beds and compared with experiments. The model with solids viscosity as an input was used by Tsuo and Gidaspow (1989), Benyahia, et al (1998) and by Sun and Gidaspow (1999) to model riser (vertical pipe) flow. Bubbling flow was modeled similarly by Lyckowski, et al (1993) and by Anderson, et al (1995). These models compute the large-scale density oscillations which we refer to as gravity waves. However, for riser flow they have not been compared to experimental density fluctuations due to absence of such data. This paper presents such data.

The second Navier-Stokes type model is based on the granular theory of Savage and co-workers (Lun, et al 1984; Savage 1988). It was applied to steady, developed riser flow in a pioneering paper by Sinclair and Jackson (1989) using the Johnson and Jackson (1987) boundary conditions. Developed flow requires the solids pressure to be constant. For an ideal type equation of state for particles, verified experimentally by Gidaspow and Huilin (1998) for FCC particles, this approximation states that the product of the granular temperature (essentially, oscillating kinetic energy of particles) and the solids volume fraction is a constant. But with a restitution coefficient of near unity and the Johnson and Jackson (1987) boundary conditions the granular temperature equation shows that the maximum in the granular temperature is at the center of the riser. In view of the constancy of the granular pressure, the solids volume fraction is a minimum at the pipe center. This leads to the observed core-annular flow for both riser flow and for the co-current down flow. The viscosity input riser model also leads to the core-annular flow regime. In this transient model the transfer of particles to the wall is due to the large-scale oscillations. The accumulation of particles at the wall is due to the low gas velocity at the wall which is insufficient to maintain the upward flow of particles.

It was only a decade ago that the oil industry using gamma ray techniques (Sun and Koves, 1998) learned that their large diameter risers operate in the core-annular flow regime: the core is very dilute. The core-annular structure leads to two main problems: (1) insufficient gas-solids contact, and (2) back-mixing due to non-uniform radial distributions (Jin, et al 1997). This unfavorable radial volume fraction distribution of solids in the riser has led to consideration of new schemes of contacting for a refinery of the $21^{\text {st }}$ century.

The transient kinetic theory model (Gidaspow, 1994; Samuelsberg and Hjertager, $1996 \mathrm{a} \&$ b) also requires some experimental input. For gas-solid flow the main input is the restitution coefficient which is a function of velocity at impact. At the present time there is no 
way of accurately estimating the restitution coefficient. Hence the granular temperature was experimentally measured for FCC particles using a CCD camera and the equation of state for particles was constructed using the measured solids pressure and the radial distribution functions of statistical mechanics (Gidaspow and Huilin, 1996 \& 1998). The kinetic theory model clearly explains why fluidized beds are such good heat transfer devices. Their thermal conductivity, $k$ can be expressed in terms of mean free path, $l$, the average of fluctuating velocity, $\langle v\rangle$ which is essentially the square root of the granular temperature and the density and the specific heat of particles as follows.

$$
k=l\langle v\rangle \rho C_{p}
$$

where $\rho=$ density and $C_{p}=$ heat capacity of particles.

The mean free path, $l$ is essentially the particle diameter divided by the solids volume fraction. For dense systems it is of the order of particle diameter. For dilute conditions it will approach the size of equipment. The granular temperature rises with the particle concentration, reaches a maximum near about five percent solids and then decreases due to a decrease in the mean free path. Cody's data (Buyevich and Cody, 1998) suggest that the granular temperature have a maximum for a particle size of about 90 microns, close to the size of FCC particles. Hence the thermal conductivity should have a maximum at this particle size, as indeed it appears to have. We see that the kinetic theory model has the potential to explain why fluidized beds are such good contacting devices.

\section{1b. Sonic Velocity of Particles}

The granular flow kinetic theory also helps to explain the mechanism of large-scale wave propagation. From the work of Savage (1988) and others we know that density waves move with the pseudo sonic velocity, the derivative of solids pressure with respect to the density. Hence we present our data for sonic velocities for FCC particles.

The large-scale oscillation frequency is the sonic velocity divided by the equipment size. Near five percent solids and less the collisional and the cohesive contributions in the equation of state are negligible. Then the sonic velocity is simply the square root of the granular temperature. For FCC particles it is of the order of one meter per second versus about $300 \mathrm{~m} / \mathrm{s}$ for gases. Hence for particles the oscillations associated with the hydrodynamic instability are of the order of one Hertz for particles versus 300 for air for a one meter length.

\section{1c. Resonant Vibrations}

Resonant vibrations that are vibrations whose natural frequency equals the forced frequency are known to set up large amplitudes of oscillations. The natural frequency can be interpreted to be as the frequency obtained from the sonic velocity discussed above. The forced frequency is the gravity wave obtained in this paper. It agrees with literature bubbling bed data and with the riser data presented here.

The scale-up of the circulating fluidized bed reactor for making liquids from synthesis gas, the Synthol reactor was delayed by two years due to vibrations caused by the dense iron catalyst not encountered in the much smaller pilot plant (Matsen, 1997; Shingles and Mc Donald, 1988). We may speculate that resonance was set up when the length was made larger, 
since the catalyst concentration was probably the same in the pilot plant and in the commercial unit.

\section{IIT Circulating Fluidized Bed}

The experimental set-up is shown in Figure 1a. The riser is an acrylic tube of $0.07 \mathrm{~m} \mathrm{ID}$ and a height of $6.58 \mathrm{~m}$. Fluid cracking catalyst particles of a density of $1654 \mathrm{~kg} / \mathrm{m}^{3}$ and an average diameter of $75 \mu \mathrm{m}$ were used. The CFB and the particles are identical to those used by Miller and Gidaspow (1992). Charge is removed by a metallic wire along the wall of the tube. Figure $1 \mathrm{~b}$ shows a sketch of time average particle concentration and flux profiles obtained by Miller and Gidaspow (1992). A video made previously by Miller (1992) shows that in the dense regime of interest in this study the particles at the wall undergo a vigorous up and down motion. It is basically this random particle motion that we measured with our CCD camera and converted into granular temperature (Gidaspow and Huilin, 1996). From it we had obtained a collisional viscosity that matched Miller and Gidaspow's (1992) reported viscosity obtained from pressure drop-radial particle velocity measurements.

Porosity measurements across the whole tube were made at a height of $1.83 \mathrm{~m}$ on the first floor and the second floor at a height of $4.4 \mathrm{~m}$ with a gamma ray densitometer with a collimation diameter of about one centimeter.

\section{Gamma Ray Densitometer}

A gamma ray densitometer has been successfully used to understand the dynamics of bubbling fluidized beds for at least the last 34 years (Baumgarten et. al, 1960; Weimer et al., 1985; Ding et. al., 1990). It has surprisingly not been applied to understand the dynamics of a CFB despite its potential use in industrial risers and high pressure combustors. In this study a gamma ray densitometer equipped with a scintillation detector was used to measure porosity oscillations in the IIT CFB, shown in Fig. $1_{\mathrm{a}}$, at two locations. In the bubbling bed study of Tsinontides and Jackson (1993), they used a radioactive beam of only a few millimeter diameter to have a good spatial resolution. Such a small beam does not allow the transient determination of porosities. The beam in this experiment was one centimeter.

The gamma ray densitometer was used to measure instantaneous averaged crosssectional porosities. The source is a $500 \mathrm{mCi}-\mathrm{Cs}-137$ source having a single gamma ray of 667 Kev and a half life of 30 years. The Cs- 137 was sealed in a welded stainless steel capsule. The source holder was welded, filled with lead, and provided with a shutter to turn off the source. The detector is a NaI (Ti) crystal scintillation detector (Teledyne, ISOTOPESS-44-I/2). It consisted of a $2 \mathrm{~mm}$ thick, $5.08 \mathrm{~cm}$ diameter tube with a $0.14 \mathrm{~mm}$ thick Beryllium window. The transmitted radiation was converted to electrical pules by photo-multiplier (Model 266, EG\&G Ortec). The converted electrical signals were passed through a series of data conditions including a preamplifier (Model 113, EG\&G), an amplifier and a double channel analyzer (model 778). The DCA has been used to remove low energy level noises. A DCA produces an output logic pulse only if the peak amplitude of this input signal falls within the energy window that is established with two preset threshold levels. The output of DCA connects to a modular data acquisition and control system (ISAAC 91-I) which was used as the interface between the 
densitometer and personal computer. The output signal of DCA is sent into a counter device. The counter counts down from 65535 to zero and reinitializes automatically. The counting number is sent to computer in binary form and managed by a PC computer. An IBM PC with a $20 \mathrm{MB}$ hard disk and a Math coprocessor has been used to store and analyze data. The data analysis consisted of transient state porosity and steady state porosity measurement. The power spectrum is calculated by using the fast Fourier transform (FFT) method. The intensity of transmitted radiation follows Beer's law. The attenuation coefficient for the particles was $0.02477 \mathrm{~cm} / \mathrm{g}$. A calibration curve was obtained by measuring radiation counts for an empty tube and one filled with particles. At a porosity of 0.4 the count was 22400 while for the empty tube it was 23800 per second.

\section{Oscillations in the Dilute Regime}

Figure 2 shows the experimental porosity oscillations in the upper portion of this riser. As in the computation of the Pyropower system (Therdthianwong and Gidaspow, 1994), we see wild porosity oscillations depicted in Figure 2. Similar data were obtained at other gas velocities and solid fluxes. Figure 3 shows the spectral representation of the data in Figure 2. As in the simulation for the Pyropower type CFB (Gidaspow et al., 1995) there are two distinct peaks with little noise. Figure 4 shows a summary of spectra for other flow conditions. Figure 5 shows a plot of the dominant frequency as a function of porosity. The frequency is well below one Hertz, typical of bubbling beds. It increases linearly from $0.05 \mathrm{Hertz}$ at a superficial gas velocity of $1.6 \mathrm{~m} / \mathrm{s}$ and a flux of $27.8 \mathrm{~kg} / \mathrm{m}^{2}$-s to 0.128 at a velocity of $2.6 \mathrm{~m} / \mathrm{s}$. It also increases linearly with solid flux from $0.06 \mathrm{Hertz}$ at a flux of $18.5 \mathrm{~kg} / \mathrm{m}^{2}$-s at a velocity of $2.67 \mathrm{~m} / \mathrm{s}$ to 0.2 Hertz at a flux of $34 \mathrm{~kg} / \mathrm{m}^{2}$-s. Such low frequencies were also obtained for pressure oscillations and analyzed by Bouillard and Miller (1994). The numerical simulation for the large scale unit (Gidaspow et al., 1995) operating at an order of magnitude larger flux shows that linear extrapolations of these data are not valid. The trend is in the right direction, however. The frequency increases to one Hertz for the higher gas and solid flows.

\section{Oscillations in the Dense Regime}

Figure 6 shows typical density fluctuations in the lower portion of the IIT CFB, $1.83 \mathrm{~m}$ above the inlet. In agreement with computations for the Pyropower system (Gidaspow et al., 1995) for an instant of time the average porosity in this region is near 0.8 . The corresponding power spectrum depicted in Figure 7 shows a much more chaotic behavior. Other data show more pronounced dominant peaks summarized in Figure 8. The large scatter of the data is due to the absence of a distinct structure of flow in the bottom section of the CFB.

\section{Wave Propagation in Dense Flow}

The theory of fluidization, as described by Gidaspow (1994), shows that the mechanism of large scale oscillations is a coupled pressure and density non-linear wave propagation phenomenon. The small scale turbulence is described by the granular temperature, for which an additional conservation equation is written. For a very dense bed, such as a bubbling bed, a simplified theory shows that the density and the flux obey a simple wave equation with densities 
propagating at pseudo-sonic velocities of solids, $\mathrm{C}_{\mathrm{S}}$. The kinetic theory of granular flow shows that $\mathrm{C}_{\mathrm{S}}$ is the oscillating velocity of the particles.

For the dense riser flow of interest here, the more complete equations must be considered. A Reynolds number criterion shows that it is sufficient to consider the particle equations only. For pipe flow with small catalyst particles the slip between the gas and the particles is small. Then the mixture equations show that the characteristic group is a mixture Reynolds number (Gidaspow, 1994). A useful Reynolds number, $R_{e}$ is one based on some average velocity, $\mathrm{v}$ and, say, the pipe diameter, $\mathrm{D}$,

$$
R_{e}=\frac{D \rho_{m} v}{\mu_{p}+\mu_{g}}
$$

where $\mu_{p}$ is the particle viscosity which exceeds the fluid viscosity, $\mu_{g}$ by several orders of magnitude. The mixture density, $\rho_{m}$ is

$$
\rho_{m}=(1-\varepsilon) \rho_{s}+\varepsilon \rho_{g}
$$

For dense flow

$$
(1-\varepsilon) \rho_{s}>>\varepsilon \rho_{g}
$$

For $\rho_{s} / \rho_{g}=1000$

$$
1-\varepsilon>0.001
$$

for $\varepsilon_{s}$, the volume fraction of solids of much greater than $0.1 \%$. Thus for particle concentration of much greater than $0.1 \%$, the Reynolds number criterion is

$$
R_{e}=\frac{D(1-\varepsilon) \rho_{s} v}{\mu_{p}}
$$

It does not involve gas properties. Hence it is sufficient to consider the particle equations only. The one dimensional particle mass and momentum balances are as follows:

Solid Mass Phase Balance:

$$
\frac{\partial}{\partial t}\left(\varepsilon_{s} \rho_{s}\right)+\frac{\partial}{\partial x}\left(\varepsilon_{s} \rho_{s} v_{s}\right)=0
$$

Inviscid Momentum Balance:

$$
\frac{\partial}{\partial t}\left(\varepsilon_{s} \rho_{s} v_{s}\right)+\frac{\partial}{\partial x}\left(\varepsilon_{s} \rho_{s} v_{s} v_{s}\right)=-\frac{\partial p_{s}}{\partial x}
$$

The theory of characteristics (Gidaspow, 1994) shows that the characteristic directions are

$$
v_{s} \pm C_{s}
$$

where the pseudo-sonic velocity (Savage, 1988) is

$$
C_{s}=\left(\frac{\partial p_{s}}{\rho_{s} \partial \varepsilon_{s}}\right)^{\frac{1}{2}}
$$

Ocone and Astarita (1994) obtained a similar expression of the pseudo-sonic velocity assuming a reversible and pseudo-adiabatic process. Particle waves move with velocities given by Eq. 
(8). The difficulty with this theory is that the particle sonic speed must be known. In the next section we will show that it can be obtained from measurements of granular temperature.

For more dilute flow, as in pneumatic transport, the more complete equations must be considered. Gidaspow (1994) shows that the characteristic paths for density, pressure, etc. wave propagation are:

$$
\begin{gathered}
v_{g} \pm C_{g} \\
\text { and } \\
v_{s} \pm C_{s}
\end{gathered}
$$

\section{Particle Sonic Velocity}

Particle sonic velocity can be estimated based on kinetic theory derived equation of state and measurements of granular temperature in the CFB. Granular temperatures were measured in the IIT CFB using a CCD camera (Gidaspow and Huilin, 1996). The technique involves a measurement of particle velocity distribution, in principle similar to that obtained much earlier by Carlos and Richardson (1968) using a photographic method. A particle makes a streak on a computer screen for a millisecond or so. The distances traveled divided by time give two velocity components. Many such measurements give distribution curves of the axial and radial velocities. Table A listed the experimental data in the dilute region. Since the radial velocities are small compared with the axial velocities, isotropy is a reasonable assumption in the radial direction. Such calculations and measurements give us the granular temperature depicted in Figure 9 (Gidaspow and Huilin, 1996).

The sonic velocity, $C_{s}$, as defined by Equation (9) is then obtained from the derivative of the equation of state for the particles originally derived by Lun et al. (1984):

$$
p_{s}=\varepsilon_{s} \rho_{s} \theta\left[1+2 \varepsilon_{s}(1+e) g_{0}\right]
$$

where we used Bagnold 's relation of $g_{0}$ given by (Bagnold, 1954):

$$
g_{0}=\left[1-\left(\frac{\varepsilon_{s}}{\varepsilon_{s, \max }}\right)^{\frac{1}{3}}\right]^{-1}
$$

Figure 10 shows the computed sonic velocities in our CFB. They are of the order of magnitude estimated by Gidaspow (1994) from measurements of discharge of particles from orifices. Figure 10 also shows the measured average particle velocities obtained using our digital video camera.

\section{Compressible Large Scale One Dimensional Oscillation}

In this section we derive an equation for the observed large scale low frequency oscillation in the vertical pipe. We begin with the momentum balance for the solids Equation (7.2) in Gidaspow's book. To obtain an analytical solution for the frequency, a number of approximations are necessary. First, we neglect the velocity square terms. This simplification will immediately lead to the neglect of $\mathrm{V}_{\mathrm{s}}$ compared to $\mathrm{C}_{\mathrm{s}}$ in the wave propagation analysis. Next we neglect the small contribution, for one dimensional analysis, of wall friction caused by solids viscosity. We further restrict the analysis to flow of particles above minimum fluidization. This leads to the neglect of 
solids stress caused by particle contact except those caused by collisions. With these simplifications the solids momentum balance for phase $\mathrm{s}$ becomes as follows.

$$
\begin{array}{ccc}
\frac{\partial\left(\varepsilon_{s} \rho_{s} v_{s}\right)}{\partial t}= & -\frac{\partial P_{s}}{\partial x}-\varepsilon_{s} g\left(\rho_{s}-\rho_{g}\right)-\beta\left(v_{s}-v_{g}\right) \\
\begin{array}{c}
\text { Acceleration of } \\
\begin{array}{c}
\text { Momentun } \\
\text { of Phase s }
\end{array}
\end{array} & \begin{array}{c}
\text { Solids Pressure due } \\
\text { to Collisions }
\end{array} & \text { Buoyancy } \\
\text { Drag }
\end{array}
$$

Note that for a steady state with a negligible solids pressure, Equation (13) is the conventional balance of buoyancy and drag. Here, however, we emphasize the time variation. Hence we need the transient conservation of particles equation, which is as follows in one dimension.

$$
\frac{\partial\left(\varepsilon_{s} \rho_{s}\right)}{\partial t}+\frac{\partial\left(\varepsilon_{s} \rho_{s} v_{s}\right)}{\partial x}=0
$$

A wave equation for the bulk density $\rho_{B}=\rho_{s} \varepsilon_{s}$ or for the flux, $F=\rho_{s} \varepsilon_{s} v_{s}$ can be obtained by following the procedure in chapter 7 in Gidaspow's book. Differentiation of Equation (14) with respect to time gives

$$
\frac{\partial^{2} \rho_{B}}{\partial t^{2}}=-\frac{\partial^{2} F}{\partial t \partial x}
$$

while differentiation of Equation (13) with respect to $\mathrm{x}$ for $\rho_{s}>>\rho_{g}$ gives

$$
\frac{\partial^{2} F}{\partial x \partial t}=-C_{s}^{2} \frac{\partial^{2} \rho_{B}}{\partial x^{2}}-g \frac{\partial \rho_{B}}{\partial x}-\beta\left(\frac{\partial v_{s}}{\partial x}-\frac{\partial v_{g}}{\partial x}\right)
$$

Combination of Equations (15) and (16) produces the one dimensional wave equation for bulk density, where $\mathrm{C}_{\mathrm{s}}$ was defined by Equation (9).

$$
\begin{aligned}
& \frac{\partial^{2} \rho_{B}}{\partial t^{2}}=C_{s}^{2} \frac{\partial^{2} \rho_{B}}{\partial x^{2}}+g \frac{\partial \rho_{B}}{\partial x}-\beta\left(\frac{\partial v_{g}}{\partial x}-\frac{\partial v_{s}}{\partial x}\right) \\
& \text { Wave Propagation }=\quad \text { Source } \quad-\quad \text { Drag } \\
& \text { (Zero for Developed Flow) }
\end{aligned}
$$

Equation (17) shows that the density wave propagates with the pseudo-wave velocity $\mathrm{C}_{\mathrm{s}}$, that gravity acts as a source for wave formation and that drag dampens the waves, when the relative velocity is positive. Generalization of Equation (17) to two and three dimensions shows that there will be additional source terms due to gradients of $\left(\mathrm{v}_{\mathrm{g}}-\mathrm{v}_{\mathrm{s}}\right)$ in the multiple dimensions. These terms may give additional peaks in the spectral analysis of bulk density. For developed flow the axial variation of the relative velocity becomes zero in Equation (17). Further, if we neglect the solids pressure effect, the sonic velocity, Equation (17) simplifies to a diffusion equation

$$
\frac{\partial^{2} \rho_{B}}{\partial t^{2}}=g \frac{\partial \rho_{B}}{\partial x}
$$

The variation of bulk density with height, $\mathrm{x}$ is obtained from an additional momentum balance. For developed one dimensional flow the pressure drop is balanced approximately by the weight of the bed, expressed by 


$$
\frac{\partial P}{\partial x}=g \rho_{B}
$$

The pressure drop itself is given by the Ergun equation which for small relative velocities is as follows.

$$
-\frac{d P}{d x}=\frac{150 \mu_{g}}{\left(\phi d_{p}\right)^{2}} \frac{\varepsilon_{s}^{2}}{\varepsilon^{3}} U_{o}
$$

We now relate the pressure drop to relative bed expansion using the method of Thompson (1978) who obtained a formula for frequency similar to that derived here. Thompson did not use conventional fluidization equations, but constructed a flow model of his own. First we note that for an expanded bed, the conservation of particles balance is as follows

$$
\varepsilon_{s o} x_{o}=\varepsilon_{s} x
$$

where $\varepsilon_{\mathrm{so}}$ and $\mathrm{x}_{\mathrm{o}}$ are some initial bed volume fraction and height of bed filled with particles. Using calculus, Equation (21) gives the differential expression as

$$
\frac{d x}{x}=-\frac{d \varepsilon_{s}}{\varepsilon_{s}}
$$

We now estimate the relative differential change of pressure using Equation (20), as the volume fraction, $\varepsilon_{\mathrm{s}}$ changes during the passage of a wave for a constant superficial velocity $U_{o}$. By calculus only,

$$
\frac{d\left(\frac{d P}{d x}\right)}{\frac{d P}{d x}}=-\left[3 \varepsilon_{s} / \varepsilon+2\right] \frac{d \varepsilon_{s}}{\varepsilon_{s}}
$$

Using the differential particle balance, Equation (22), the differential change of pressure drop can then be expressed as follows

$$
\frac{d\left(\frac{d P}{d x}\right)}{d x}=-\left[3 \varepsilon_{s} / \varepsilon+2\right] \frac{\varepsilon_{s}\left(\frac{d P}{d x}\right)}{\varepsilon_{s o} x_{o}}
$$

The above expression allows an estimate of the density gradient to be made.

Differentiation of Eq. (19) and substitution into Eq. (18) gives

$$
\frac{\partial^{2} \rho_{B}}{\partial t^{2}}=\frac{\partial^{2} P}{\partial x^{2}}
$$

But

$$
\frac{\partial^{2} P}{\partial x^{2}} \approx \frac{\Delta\left(\frac{d P}{d x}\right)}{\Delta x}
$$

Using Eq. (19) and (24), Eq. (25) becomes an ordinary differential equation

$$
\frac{d^{2} \rho_{B}}{d t^{2}}+\left[\frac{\left(3 \varepsilon_{s} / \varepsilon+2\right) \varepsilon_{s} g}{\varepsilon_{s o} x_{o}}\right] \rho_{B}=0
$$


Equation (27) is the equation for the vibration of a spring of a unit mass with the brackets representing a spring constant. Treating the bracket as a constant, the solution is

$$
\rho_{B}=A \cos \omega t+B \sin \omega t
$$

where

$$
\omega=\left(\frac{g}{x_{o}}\right)^{\frac{1}{2}}\left[\frac{\left(3 \varepsilon_{s} / \varepsilon+2\right) \varepsilon_{s}}{\varepsilon_{s o}}\right]^{\frac{1}{2}}
$$

The frequency of oscillations, $f$ is

$$
f=\frac{\omega}{2 \pi}
$$

We see that the basic frequency is that caused by gravity, $\left(g / x_{o}\right)^{\frac{1}{2}}$ and that the frequency becomes very small as the volume fraction of particles becomes small.

Verloop and Heertjes (1974) were the first to derive a frequency relation that has the basic term $\left(g / x_{o}\right)^{1 / 2}$ by treating a fluidized bed as a vibrating column. However their relation does not have the correct compressibility term achieved by using some key steps contained in Thompson's (1978) analyses. In Equation (27) the "elasticity" per unit mass is proportional to the volume fraction of solid. A denser bed has a greater elasticity.

\section{Comparison of Dominant Frequency Formula to Experiments}

Fig. 11 shows a comparison of the expanded bed dominant frequency, Equations (29) and (30), to the experimental data. Very low frequencies predicted by Equation (29) were also obtained by Sun and Gidaspow (1999) in the simulation of the PSRI riser in the challenge problem presented at the Eighth International Fluidization Conference in France. Fig. 11 and Equation (29) also suggest that for very dilute systems the frequency will vanish giving a steady state. This is the situation observed numerically. In such a situation the frequency jumps to a value of the order of 100 Hertz (Plasynski, et al ; 1993).

In Figure 11 the data obtained on the first floor is in the inlet section of the riser. There is more than one peak, as suggested by Equation (17). Gradients of velocity produce additional peaks in the bulk density. We have seen such a behavior earlier at IIT in bubbling beds (Seo, 1985; Gidaspow; et al,1989; Gidaspow,1994 Fig. 10.5). We have measured porosity with the gamma ray densitometer described here and pressure with a transducer. Fig. 12 shows several peaks near the inlet of a two dimensional bed but only one distinct peak in the region of bubble formation. Fig. 13 shows that the dominant peak obtained from pressure measurements, $f_{p}$, is the same as that due to the porosity measurement, $f_{\varepsilon}$, expect in the entrance region, for $\mathrm{h}<12$ $\mathrm{cm}$. This follows from Equation (19), which is valid in the developed region. This equation also shows that if the density varies as the sine wave, then the pressure will be a cosine wave. Since $\cos (\omega t)=\sin \left(\omega t+\frac{\pi}{2}\right)$, there is the observed displacement of the two waves. Note also that 
the pressure waves (Gidaspow, 1994) move with the velocity $\left(\frac{\rho_{g}}{\rho_{s}}\right)^{\frac{1}{2}} \cdot C_{g} /\left(\varepsilon \varepsilon_{s}\right)^{\frac{1}{2}}$, where $\mathrm{C}_{\mathrm{g}}$ is the sonic velocity of the gas when $\rho_{s} \varepsilon_{s} \gg \varepsilon \rho_{g}$. At atmospheric pressure this velocity is of the order of $10 \mathrm{~m} / \mathrm{sec}$, considerably higher than $\mathrm{C}_{\mathrm{s}}$. Since in the developed region the dominant frequencies are the same for pressure and porosity, we can compare our experimental frequency equation to early bubbling bed data of Geldart and Baeyens (1974) who obtained dominant pressure peaks for several bed diameters. A comparison of the expanded bed equation to IIT and Geldart data is shown in Fig. 14. There is excellent agreement between the simplified theory and the data.

\section{Two Dimensional Oscillations: Gravity Waves}

The classical analysis of gravity waves (Elmore and Heald, 1969) can be used to understand two dimensional effects observed in fluidized beds. This analysis begins with the transient Bernoulli's equation made at the top of the bed. With a constant pressure and negligible velocity head, this equation reduces itself to

$$
g \Delta x=\frac{\partial \Phi}{\partial t}+\text { constant } \quad \text { at } \quad \mathrm{x}=\mathrm{h}
$$

where $\Phi$ is the velocity potential used by Davidson (1961) in his classical bubble model. Such a potential exists in the absence of voidage gradients, as shown in Gidaspow's book (1994). This is a severe restriction. Nevertheless, it yields some useful approximate solutions. Thus for irrotational flow,

$$
\nabla^{2} \Phi=0
$$

and

$$
\vec{v}=-\nabla \Phi
$$

Then in the direction of flow, $x$, Equations (31) and (33) give the balance

$$
g \frac{\partial \Phi}{\partial x}=\frac{\partial^{2} \Phi}{\partial t^{2}} \quad \text { at } \quad x=h
$$

At $\mathrm{x}=0$, the velocity is zero.

The solution to Equation (32) is obtained by separation of variables

$$
\Phi=X(x) Y(y) T(t)
$$

to be

$$
\frac{d^{2} T}{d t^{2}}+(g K \tanh K h) T=0
$$

where $\mathrm{K}$ is the separation constant having units of reciprocal length.

Equation (36) shows that the angular frequency $\omega$ is

$$
\omega=(g K \tanh K h)^{\frac{1}{2}}
$$

Compare this to the compressible one dimensional case, Eq. (29).

The wave velocity, $\mathrm{C}$ is 


$$
C=\frac{\omega}{K}=\left(\frac{g}{K} \tanh K h\right)^{\frac{1}{2}}
$$

For $K h<<1, \tanh K h \approx K h$ and Equation (38) gives

$$
C=(g h)^{\frac{1}{2}}
$$

This is the speed acquired by a particle falling a distance $h / 2$ from rest.

The second limit for $K h \gg>1$ or $h \gg>\frac{1}{K}$ gives tanh $K h=1$. Then

$$
C=\left(\frac{g}{K}\right)^{\frac{1}{2}}=\left(\frac{\lambda g}{2 \pi}\right)^{\frac{1}{2}}
$$

where $\lambda$ is the wavelength. When we take $\lambda$ to be the bed diameter

$$
C=\left(\frac{D g}{2 \pi}\right)^{\frac{1}{2}}=0.3989(g D) \frac{1}{2}
$$

versus the experimental slug velocity (Hovmand and Davidson, 1971)

$$
C_{\text {slug }}=0.35(g D) \frac{1}{2} \text {. }
$$

\section{Reduction to Wave Equation}

Further analysis of fluidization oscillations following gravity wave theory is not very useful due to the assumption of incompressibility of bulk density made in the previous section. However, the one dimensional compressible analysis can be easily extended to more than one dimension by again neglecting $\mathrm{v}_{\mathrm{s}}$ compared with $\mathrm{C}_{\mathrm{s}}$ and assuming developed flow. The generalization of Equation (17) with the approximation made in the one dimensional analysis gives a wave equation with a source.

$$
\frac{\partial^{2} \rho_{B}}{\partial t^{2}}=C_{s}^{2} \nabla^{2} \rho_{B}+\left[\frac{\left(3 \varepsilon_{s} / \varepsilon+2\right) \varepsilon_{s}^{2} g \rho_{s}}{\varepsilon_{s o} x_{o}}\right]
$$

The solution to this equation is the approximate source solution given by Equation (28) plus the solution to the wave equation with the source in the brackets set to zero. The solution of the homogeneous wave equation, when put into the canonical form, has the form

$$
\rho_{\mathrm{B}, \text { homogeneou s }}=f_{1}\left(x-C_{s} t\right)+f_{2}\left(x+C_{s} t\right)
$$

which shows that the waves move with the pseudo-sonic velocity $\mathrm{C}_{\mathrm{s}}$ in opposite directions. This is the theory behind the empirical correlation

$$
f_{C F B}=\frac{C_{s}-v_{s}}{L_{\text {emirical }}}
$$

shown in Figure 15 . The pseudo-sonic velocity $\mathrm{C}_{s}$ was taken relative to the solids velocity, as shown by the exact characteristics analysis.

The classical theory of wave propagation can be applied to this problem in the direction perpendicular to flow. Equation (13) shows that at the walls, $\mathrm{y}=0$ and $\mathrm{y}=\mathrm{L}$ the gradient of bulk 
density is zero. Then separation of variables of the homogeneous portion of the wave equation is as follows. Let

$$
\rho_{B}=T(t) Y(y)
$$

The ordinary differential equations become as follows, where prime denotes the derivative

$$
\begin{aligned}
& \frac{T^{\prime \prime}}{T}=C_{s}^{2} \frac{Y^{\prime \prime}}{Y}=-\omega^{2} \\
& T^{\prime \prime}+\omega^{2} T=0 \text { and } Y^{\prime \prime}+\frac{\omega^{2}}{C_{S}^{2}} Y=0
\end{aligned}
$$

with the boundary conditions

$$
Y^{\prime}(0)=Y^{\prime}(L)=0
$$

which give

$$
Y=A \cos \left(\frac{\omega_{n}}{C_{s}}\right) y
$$

and the eigenvalues

$$
\frac{\omega_{n} L}{C_{s}}=\pi n, n=1,2,3, \ldots
$$

Hence with the zero gradient boundary conditions the fundamental frequency is:

$$
\omega_{1}=\frac{\pi C_{s}}{L}
$$

or

$$
\omega_{1}=\pi f_{C F B}
$$

Figure 15 gives a length $L=\pi L_{\text {empirical }}$ of about 6 meters which is the length of the CFB. Note that the boundary conditions at the top and bottom of the bed cannot be given exactly in terms of bulk density only. Hence the length in the direction of flow is not precisely known for wave propagation. This analysis, however, greatly aids in interpreting the numerical solution of the complete equations of motion.

\section{Non Dissipating System at Resonant Frequency}

A most important characteristic of fluidized bed is that they never reach a true steady state. In dense beds this unsteadiness is visually observed as bubbles that form near the bottom of the bed, rise and then erupt at the surface, just like boiling water in a pot. In risers the unsteadiness is visually observed and computed (Tsuo and Gidapow, 1989; Sun and Gidaspow, 1999) as clusters of particles that form at the top, descend to the bottom of the bed and are transported back up in the center of the pipe. If the intensity of oscillations is not strong, as in dilute riser flow, or if the restitution coefficient is made too small, the computer code gives a steady state which may or may not represent the correct time averaged behavior. Hence an approximate analytical behavior needs to be investigated. Classical wave theory aids in the understanding.

The Navier-Stokes equations for compressible fluids can be decomposed into a wave equation for a potential with damping due to the fluid viscosity and into a stream function 
equation (Tolstoy, 1973; Morse and Feshbach, 1953). For zero viscosity that is for a high Reynolds number, the result is an undamped wave equation for a potential which by substitution

$$
\Phi(x, y, z) e^{-i \omega t}
$$

can be transformed into the classical Helmholtz equation for the eigenfunction $\Phi_{n}$

$$
\begin{gathered}
\nabla^{2} \Phi_{n}+k_{n}^{2} \Phi_{n}=0 \\
k_{n}=\omega_{n} / C_{s}
\end{gathered}
$$

The corresponding equation for a unit source solution, the Green's function $G_{k}$ is

$$
\nabla^{2} G_{k}+k_{\text {source }}^{2}=-4 \pi \delta\left(\vec{r}-\vec{r}_{\text {source }}\right)
$$

A standard Green's function construction (Morse and Feshbach, 1953) gives

$$
G_{k}\left(\vec{r} ; \vec{r}_{\text {source }}\right)=4 \pi \sum_{n=1}^{\infty} \frac{\Phi_{n}(\vec{r}) \Phi_{n}\left(\vec{r}_{\text {source }}\right)}{k_{n}^{2}-k^{2} \text { source }}
$$

In Equation (54) when

$$
k_{n}=k_{\text {source }}
$$

we have a singularity. These are the infinities when a non dissipative vibrating system is driven at one of its resonant frequencies. For fluidization, the porosity goes to infinity.

\section{Resonant Height}

The brief review of resonance for a non dissipative system shows that at resonance we equate the frequency of the source to the natural frequency of the system, as given by Equation (55). For the fluidized bed we equate the frequency given by Equations (51) and (44) to the gravity wave frequency, Equation (29). For the fundamental frequency, $\omega$, with $C_{s}$ expressed relative to the velocity of the solids, the result is

$$
\frac{C_{s} \pi}{L}=\left(\frac{g}{L}\right)^{\frac{1}{2}}\left[\frac{\left(3 \varepsilon_{s} / \varepsilon+2\right) \varepsilon_{s}}{\varepsilon_{s o}}\right]^{\frac{1}{2}}
$$

The resonant length, $\mathrm{L}_{\text {resonant }}$, neglecting second order terms in volume fractions, gives the simple result

$$
L_{\text {resonant }}=\frac{\pi^{2} C_{s}^{2}}{2 g \varepsilon_{s} / \varepsilon_{s o}}
$$

To make a quick estimate, it is best to express the pseudo-sonic velocity, $\mathrm{C}_{\mathrm{s}}$ in terms of the granular temperature, $\theta$ using the ideal equation of state for particles (Gidaspow and Huilin, 1998), $P_{s}=\varepsilon_{s} \rho_{s} \theta$ which is valid near $5 \%$ solids or less.

$$
C_{s}^{2}=\theta
$$

Then the resonant length becomes

$$
L_{\text {resonant }}^{\text {dilute }}=\frac{\pi^{2} \theta}{2 g \varepsilon_{s} / \varepsilon_{s o}}
$$

For dense bubbling beds the collisional pressure $P_{s}=4 \varepsilon_{s}^{2} \rho_{s} g_{o} \theta$ can be used where $\mathrm{g}_{\mathrm{o}}$ is the radial distribution function at contact. The result is 


$$
L_{\text {resonant }}=\frac{4 \pi^{2} g_{o} \theta}{g / \varepsilon_{\text {so }}}
$$

For bubbling beds Cody's data (Cody and Buyevich, 1998) gives a granular temperature of 10 $(\mathrm{cm} / \mathrm{s})^{2}$. With $\mathrm{g}_{0}=5$, Equation (60) shows that resonance occurs at a length of $2 \mathrm{~cm}$. Resonance may be an alternative way to interpret bubble formation.

For the Synthol reactor discussed in the introduction, Equation (59) gives a length of about 10 meters. Hence a smaller pilot plant had no violent vibrations, while the commercial unit encountered resonance.

\section{An Analytical Solution For Granular Temperature}

Values of granular temperature vary by at least four order of magnitude, from about 1 $(\mathrm{m} / \mathrm{s})^{2}$ in a riser for FCC particles to less than $1(\mathrm{~cm} / \mathrm{s})^{2}$ for $45 \mu m$ catalyst in a liquid-solid fluidized bed (Gidaspow and Huilin, 1998b). Cody and Goldfarb's (1998) values of granular temperature in a bubbling bed at a ratio of fluid velocity to the velocity of minimum fluidization of two are about $15(\mathrm{~cm} / \mathrm{s})^{2}$ for a $50 \mu \mathrm{m}$ size particle, rise to $35(\mathrm{~cm} / \mathrm{s})^{2}$ for about $90 \mu \mathrm{m}$ particle and then decrease to $5(\mathrm{~cm} / \mathrm{s})^{2}$ for a $150 \mu \mathrm{m}$ size and then finally increase with particle size. Such a behavior is known to exist for heat transfer coefficients in bubbling beds and has never been explained successfully. Hence we only present an analysis that explains the order of magnitude difference between various measurements, since a full explanation in not yet available.

In developed flow in a riser with flow of elastic particles, the granular temperature balance (Gidaspow, 1994) involves a balance between conduction and generation. In cylindrical coordinates it is as follows for a constant conductivity, $\kappa$ and particle viscosity, $\mu_{s}$.

$$
\frac{\kappa}{r} \frac{d}{d r}\left(r \frac{d \theta}{d r}\right)=-\mu_{s}\left(\frac{\partial u_{s}}{\partial y}\right)^{2}
$$

As a limit we had assumed that all dissipation occurs at the wall. We prescribe the wall granular temperature at pipe surface; $r=R$

$$
\theta(R)=\theta_{w}
$$

The solids velocity, $u_{s}$ can be approximated as the difference between the gas and the terminal velocity leading to a lower shear rate for larger particles and a possible explanation for the maximum in Cody and Goldfarb's data. However, here we assume homogeneous flow, as is roughly correct for flow of FCC particles in the CFB.

We had estimated the FCC viscosity (Miller and Gidaspow, 1992) from the mixture momentum balance,

$$
\frac{\mu_{s}}{r} \frac{d}{d r}\left(r \frac{d u_{m}}{d r}\right)=\frac{d P}{d z}-\rho_{m} g
$$

and the measurement of the solids radial velocity profile. For small slip the mixture velocity $u_{m}$ and the solids velocity $u_{s}$ are nearly equal. Then Equation (63) can be used to obtain the velocity gradient in Equation (61). Unfortunately the mixture density is a function of the radius $r$. One can, however, divide the flow into two regions, the core and the dense annulus. 
Neglecting the thin annulus downflow region, integration of Equation (63) then gives the usual Poiseuille flow. Integration of Equation (61) then gives a fourth-power dependence of granular temperature on radius, like the thermal temperature rise in Poiseuille flow (Schlichting, 1960). In terms of the mean velocity $\bar{u}$, the relation between the maximum granular temperature, $\theta_{\max }$ and $\bar{u}$ then is the same as the relation between the thermal temperature and the mean velocity.

$$
\theta_{\max }-\theta_{w}=\left(\frac{\mu_{s}}{\kappa}\right) \bar{u}^{2}
$$

Equation (64) shows that the granular temperature is of the order of the fluid velocity squared. Figure 10 fully supports this analysis. Equation (64) shows the reasonable result that at low fluid velocities, the granular temperature will be correspondingly low. It provides a first order estimate of the granular temperature and the pseudo-sonic velocity needed in the present analysis.

\section{Vortices Due to Standing Waves}

Joshi and Sharma (1979) solved a stream function equation with vorticity for bubble column and pointed out the possibility of multiple circulation cells. Wu and Gidaspow (1999) solved the separate phase conservation of mass, momentum, species and energy equations for a slurry bubble column reactor using granular flow kinetic theory and observed multiple circulation cells in addition to the basic upflow in the center and downflow at the walls. The understanding and modification of flow patterns by, for example, proper placement of heat exchangers into the column is needed for an improved reactor design. The origin of the multiple circulation cells may be in the vortices formed by the stationary porosity waves.

The classical Rayleigh kundt's tube solutions, depicted in Fig. 16, can be applied to fluidization by replacing the sonic velocity with pseudo-sonic velocity, $C_{s}$. Tolstoy (1973) shows how such solutions are obtained starting with the Navier-Stokes' equations. The standing waves are the solutions that depend on the position only.

Outside the boundary layer, there exists a velocity in the $\mathrm{x}$ direction given by

$$
V_{x}=\frac{3 V_{o}^{2}}{8 C_{s}} \sin 2 \alpha x
$$

where

$$
\alpha=\frac{\omega}{C_{s}}
$$

We see that the periodic solution (65) depends upon the value of the prescribed frequency, which is the gravity wave frequency derived earlier; and on the pseudo-sonic velocity, $C_{s}$. Figure 17 gives a representation of the flow patterns for some typical values for the riser and for a denser bed. The riser flow pattern is similar to that measured and computed using the complete set of Navier-Stokes' equations with granular flow theory (Neri and Gidaspow, 1999). Equation (66), however, permits a quick estimate of length using the prescribed forced frequency, $\omega$, and the pseudo-sonic velocity, $C_{s}$. Such patterns may also be achieved by vibrations, where $\omega$ can be varied independently. 


\begin{tabular}{|c|c|}
\hline \multicolumn{2}{|c|}{ Nomenclature } \\
\hline e & Restitution coefficient \\
\hline$f$ & Frequency of oscillation \\
\hline g & Gravitational acceleration \\
\hline $\mathrm{g}_{\mathrm{o}}$ & Radial distribution function \\
\hline $\mathrm{h}$ & Bed height \\
\hline k & Particles thermal conductivity \\
\hline $\mathrm{k}_{\mathrm{n}}$ & Wave number \\
\hline $\mathrm{r}$ & Radial coordinate \\
\hline$\vec{r}$ & Space vector \\
\hline $\mathrm{t}$ & Time \\
\hline $\mathrm{v}$ & Velocity \\
\hline$<v>$ & Average fluctuating velocity of particles \\
\hline $\mathrm{X}$ & Direction of flow \\
\hline $\mathrm{y}$ & Perpendicular direction to flow \\
\hline $\mathrm{Z}$ & Axial coordinate \\
\hline $\mathrm{C}$ & Wave velocity \\
\hline $\mathrm{C}_{\mathrm{s}}$ & Pseudo-sonic velocity of particles \\
\hline $\mathrm{C}_{\mathrm{p}}$ & Heat capacity of particles \\
\hline $\mathrm{D}$ & Pipe diameter \\
\hline $\mathrm{F}$ & Flux \\
\hline $\mathrm{G}_{\mathrm{k}}$ & Greens' function \\
\hline K & Separation constant \\
\hline $\mathrm{L}$ & Bed diameter \\
\hline $\mathrm{P}$ & Pressure \\
\hline $\mathrm{R}$ & Pipe diameter \\
\hline $\operatorname{Re}$ & Reynolds number \\
\hline $\mathrm{U}_{\mathrm{o}}$ & Inlet superficial gas velocity \\
\hline \multicolumn{2}{|c|}{ Greek Letters } \\
\hline$\alpha$ & Wave number \\
\hline$\beta$ & Drag coefficient \\
\hline$\delta$ & Dirac delta function \\
\hline$\varepsilon$ & Volume fraction \\
\hline$\theta$ & Granular temperature \\
\hline$\kappa$ & Granular temperature conductivity \\
\hline$\lambda$ & Wavelength \\
\hline$\mu$ & Viscosity \\
\hline$\rho$ & Density \\
\hline$\phi$ & Sphericity \\
\hline$\omega$ & Angular frequency \\
\hline
\end{tabular}


Velocity potential

$\begin{array}{ll}\text { Subscripts } & \\ \mathrm{g} & \text { Gas } \\ \mathrm{m} & \text { Mixture } \\ \mathrm{o} & \text { Initial value } \\ \mathrm{p} & \text { Due to pressure } \\ \mathrm{p} & \text { Particle } \\ \mathrm{s} & \text { Solid } \\ \mathrm{w} & \text { Wall property } \\ \mathrm{B} & \text { Bulk } \\ \varepsilon & \text { Due to porosity }\end{array}$

\section{Acknowledgment}

This study was supported by the National Science Foundation Fluid, Particulate and Hydraulic System Grant No. CTS-96-10053, by a Dow Corning Corporation gift and by Department of Energy Grant No. DE-PS26-98FT98200.

\section{References}

Anderson K., Sundaresan S. and Jackson R. 1995, Instabilities and the formation of bubbles in fluidized beds, J. Fluid Mech., 303, 327-366.

Anderson T. B. and Jackson R. 1969, A fluid mechanical description of fluidized beds, comparison of theory and experiment, I \& EC Fundamentals, 8, 137-144.

Baeynes J. and Geldart D. 1974, An investigation into slugging fluidized beds, Chem. Eng. Science, 29, 255-265.

Bagnold R. A. 1954, Experiments on a gravity free dispersion of large solid spheres in a Newtonian fluid under shear, Proc. Roy. Soc., A255, 49-63.

Baumgarten P. K. and Pigford R. L. 1960, Density fluctuations in fluidized beds, AIChE J., 6, 115-121.

Benyahia S., Arastoopour H. and Knowlton T.M. 1998, Prediction of solids and gas flow behavior in a riser using a computational multiphase flow approach, Proc. 9 th Eng. Found. Conf. Fluidization, Durango, Colorado.

Bouillard J. X. and Miller A. 1994, Experimental investigations of chaotic hydrodynamic attractors in circulating fluidized bed, 4th Int. Conf. on CFB, Engineering Fundation, 80-85.

Buyevich Y. A. and Cody G.D. 1998, Particle fluctuations in homogeneous fluidized beds, Prep. for Brighton World Congress on Particle Tech., 3, Brighton, UK, Paper 207.

Campbell C. S. and Wang D. G. 1991, Particle pressure in gas fluidized beds, J. Fluid Mech., 227, 495-508.

Carlos C. R. and Richardson J. F. 1986, Solid movement in liquid fluidzed beds I: particle velocity distribution, Chem. Eng. Sci., 23, 813-824.

Chen J. C., Polashenski W. and Tuzla K. 1994, Normal solid stress in fluidized beds, AIChE Annular Meeting, San Francisco, 14-19. 
Cody G. D. and Goldfarb D. J. 1998, Bifurcation in particle granular temperature of monodispersed glass spheres at the Geldart A/B transition, Fluidization IX, edited by L. S. Fan and T. M. Knowlton, New York: Engineering Foundation, 53-60.

Culik F. E. C. 1994, Some recent results for nonlinear acoustics in combustion chambers, AIAA J., 32, 146-169.

Davidson J. F. 1961, Symposium on fluidization: discussion, Trans. Inst. Chem. Engrs., 39, 230-232

Ding J. and Gidaspow D. 1990, A bubbling fluidization model using kinetic theory of granular flow, AIChE J. 36, 523-538.

Elmore W.C. and Heald M.A. 1969, Physics of Waves, New York, Mc Graw-Hill. 1969.

Gidaspow D. and Huilin L., 1996, Collisional viscosity of FCC particles in a CFB, AIChE. J. 42, 2503-2510.

Gidaspow D. and Huilin L., 1998a, Equation of state and radial distribution function of FCC particles in a CFB, AIChE. J. 44, 279-293.

Gidaspow D. and Huilin L., 1998b, A comparison of gas-solid and liquid-solid fluidization using kinetic theory and statistical mechanics, Fluidization IX, edited by L. S. Fan and T. M. Knowlton, New York: Engineering Foundation, 662-668.

Gidaspow D. 1994, Multiphase flow and fluidization: Continuum and kinetic theory descriptions, Boston: Academic Press Inc.

Gidaspow D., Gamwo I., Tsuo Y. P. and Ding J. 1989, Two dimensional fluidized bed experiments, report to Argonne National Laboratory Cont. No. 82312401.

Hovmand S. and Davidson J. F. 1971, Pilot plant and laboratory scale fluidized reactors at high gas velocities; the relevance of slug flow, Fluidization, edited by J. F. Davidson and D. Harrison, Academic Press, 193-257.

Jackson R. 1985, Hydrodynamic stability of fluid-particle systems, in Fludization, edited by J. F. Davidson, R. Clift and D. Harrison, Academic press, 47-72.

Jackson R. 1993, Progress toward a mechanics of dense suspensions of solid particles, AIChE Symp. Ser., 90, 1-14.

Jin Y., Zhu J.X. and Yu Z.Q. 1997, Novel configurations and variants, in Circulating Fluidized Beds, edited by J.R. Grace, A.A. Avidan and T.M. Knowlton, Blackie Academic \& Professionals, London, 525-567.

Johnson P. C. and Jackson R., 1987 Frictional-Collisional Constitutive Relations for Granular Materials with Application to Plane Shearing, J. Fluid Mech., 176, 67-93.

Joshi J. B. and Sharma M. M. 1979, A circulation cell model for bubble columns, Trans. I. Chem. E., 57, 244-251.

Kuippers J. A. M., Hoomans B. P. B. and van Swaaij W. P. M. 1998, Hydrodynamic models of gas-fluidized beds and their role for design and operation of fluidized bed reactors, Fluidization IX, edited by L. S. Fan and T. M. Knowlton, New York: Engineering Foundation, 15-30.

Lun C. K. K., Savage S. B., Jeffrey D. J. and Chepurniy N. 1984, Kinetic theories for granular flow: inelastic particles in Couette flow of singly inelastic particles in a general flow field, $J$. Fluid Mech., 140, 223-256. 
Lyczkowsky R.W., Gamwo I.K., Dobran F., Ali H., Chao B.T., Chen M.M. and Gidaspow D. 1993, Validation of computed solids hydrodynamics and pressure oscillations in a bubbling atmospheric fluidized bed, Powder Technology, 76, 65.

Matsen J. M. 1997, Design and scale up of CFB catalytic reactors, in Circulating Fluidized Beds, edited by J. R. Grace, A. A. Avidan and T. M. Knowlton, Blackie Academic and Professionals, 498.

Miller A. and Gidaspow D. 1992, Dense, vertical gas-solid flow in a pipe, AIChE J., 11, 1801-1813.

Miller A. 1991, Dense vertical gas-solid flow in a pipe, Ph D. Diss., Illinois Institute of Technology, Chicago.

Morse P.M. and Feshbach H. 1953, Methods of Theoretical Physics, New York, Mc GrawHill.

Neri A. and Gidaspow D. 1999, Riser hydrodynamics: simulation using kinetic theory, submitted to AIChE $J$.

Neri A. 1998, Multiphase flow modeling and simulation of explosive volcanic eruptions, Ph.D. thesis, Illinois Institute of Technology, Chicago.

Neri A., Gidaspow D., Macedonio G. and Barberi F. 1998, Simulation of explosive volcanic eruptions by using multiphase flow models, AIChE annual meeting preprints, Vol. II, Particte Technology Forum, Miami Beach, 527-533.

Ocone R. \& Astarita G. 1994, On waves of particulate phase pressure in granular materials, $J$. Rheol., 38, 129-139.

Plasynski S. I., Klinzing G. E. and Mathur M. P. 1993, Pressure fluctuations investigation for high pressure vertical pneumatic transport, 4th Int. Conf. on CFB, Engineering Foundation, 260-265.

Samuelsberg A. and Hjertager B.H. 1996a, An experimental and numerical study of flow patterns in a circulating fluidized bed reactor, Int. J. Multiphase Flow, 22, 575-591.

Samuelsberg A. and Hjertager B.H. 1996b, Computational modeling of gas particle flow in a riser, AIChE J., 42, 1536-1546.

Savage S. B. 1988, Streaming motions in a bed of vibrationally fluidized dry granular material, J. Fluid Mech., 194, 457-478.

Schlichting H. 1960, Boundary Layer Theory, Mc Graw Hill, New York.

Seo Y. C. 1985, Fluidization of single and binary size particles, Ph.D. thesis, Illinois Institute of Technology, Chicago.

Shingles T. and Mc Donald A. F. 1997, Commercial experience with Synthal CFB reactors, in Circulating Fluidized Beds, edited by J. R. Grace, A. A. Avidan and T. M. Knowlton, Blackie Academic and Professionals, 43.

Sinclair J. L. and Jackson R. 1989, Gas-solid flows in a vertical pipe with particle-particle interaction, AIChE J., 35, 1473-1486.

Sinclair J. L. 1997, Hydrodynamic modeling, in Circulating Fluidized Beds, edited by J. R. Grace, A. A. Avidan and T. M. Knowlton, Blackie Academic and Professionals, 149.

Squires A. M., Kwauk M. and Avidan A. A. 1985, Fluid beds: at last, challenging two entrenched practices, Science, 230, 1329-1337. 
Sun B. and Gidaspow D. 1999, Computation of circulating fluidized bed riser flow for the Fluidization VIII benchmark test, Ind. Eng. Chem. Res., 38, 787-792.

Sun B. and Koves W.J. 1998, Application of numerical hydrodynamic model in FCC design, Particle Technology Forum, AIChE meeting, Miami Beach, 2, 469-476.

Therdthianwong A. and Gidaspow D. 1994, Hydrodynamics and $\mathrm{SO}_{2}$ sorption in a CFB loop, in Circulating Fluidized Bed Technology IV, edited by A.A. Avidan, proceedings of the AIChE 4 th International Conference on Circulating Fluidized Beds, New York, 551-558.

Thompson A. S. 1978, Instabilities in a coal burning fluidized bed, Oak Ridge National Laboratory Report, Tennessee, ORNL/HUD/MIUS-3B.

Tolstoy I., 1973, Wave Propagation, New York, Mc Graw-Hill.

Tsinontides S. C. and Jackson R. 1993, The mechanics of gas fluidized beds with an interval of stable fluidization, J. Fluid Mech., 255, 237-274.

Tsuo Y.P. and Gidaspow D. 1990, Computation of flow patterns in circulating fluidized beds, AIChE J., 36, 885-896.

Verloop J. and Heertjes P. M. 1974, Periodic pressure fluctuations in fluidized beds, Chem. Eng. Science, 29, 1035-1042.

Weimer A. W., Gyure D. C. and Clough D. E. 1985, Application of gamma-radiation density gauge for determining hydrodynamic properties of fluidized beds, Powder Technology, 2 , 179-194.

Wu Y. and Gidaspow D. 1999, Hydrodynamic simulation of methanol synthesis in gas-liquid slurry bubble column reactors, to appear in Chem. Eng. Science. 
Table A Summary of Experimental Data

\begin{tabular}{|c|c|c|c|c|c|c|c|c||}
\hline $\begin{array}{c}\mathrm{U}_{\mathrm{g}} \\
\mathrm{m} / \mathrm{s}\end{array}$ & $\begin{array}{c}\mathrm{W}_{\mathrm{s}} \\
\mathrm{kg} / \mathrm{m}^{2} \mathrm{~s}\end{array}$ & $\boldsymbol{\varepsilon}_{\mathrm{s}}$ & $\begin{array}{c}\sigma_{z} \\
\mathrm{~cm} / \mathrm{s}\end{array}$ & $\begin{array}{c}\sigma_{r} \\
\mathrm{~cm} / \mathrm{s}\end{array}$ & $\begin{array}{c}\boldsymbol{\theta} \\
(\mathrm{m} / \mathrm{s})^{2}\end{array}$ & $\begin{array}{c}\mathrm{V}_{\mathrm{p}} \\
\mathrm{m} / \mathrm{s}\end{array}$ & $\begin{array}{c}\mathrm{P}_{\mathrm{s}} \\
\mathrm{P}_{\mathrm{a}}\end{array}$ & $\begin{array}{c}\text { Dominant } \\
\text { Frequency } \\
(\mathrm{Hz})\end{array}$ \\
\hline 2.67 & 34.1 & $\begin{array}{c}0.113 \\
6\end{array}$ & $\begin{array}{c}247.3 \\
5\end{array}$ & 20.36 & 2.067 & 2.31 & 430.07 & 0.1953 \\
\hline 2.67 & 27.8 & $\begin{array}{c}0.109 \\
8\end{array}$ & $\begin{array}{c}223.1 \\
9\end{array}$ & 18.74 & 1.684 & 2.03 & 424.63 & 0.1269 \\
\hline 2.67 & 18.3 & $\begin{array}{c}0.070 \\
9\end{array}$ & $\begin{array}{c}225.0 \\
4\end{array}$ & 14.28 & 1.824 & 1.68 & 174.94 & 0.0572 \\
\hline 2.14 & 27.8 & $\begin{array}{c}0.096 \\
5\end{array}$ & $\begin{array}{c}232.0 \\
3\end{array}$ & 19.13 & 1.819 & 1.74 & 290.85 & 0.0976 \\
\hline 2.14 & 21.3 & $\begin{array}{c}0.057 \\
2\end{array}$ & $\begin{array}{c}218.3 \\
2\end{array}$ & 14.05 & 1.602 & 1.69 & 154.25 & 0.0651 \\
\hline 1.61 & 27.8 & $\begin{array}{c}0.087 \\
9\end{array}$ & $\begin{array}{c}239.5 \\
7\end{array}$ & 18.06 & 1.935 & 1.34 & 277.76 & 0.0879 \\
\hline
\end{tabular}




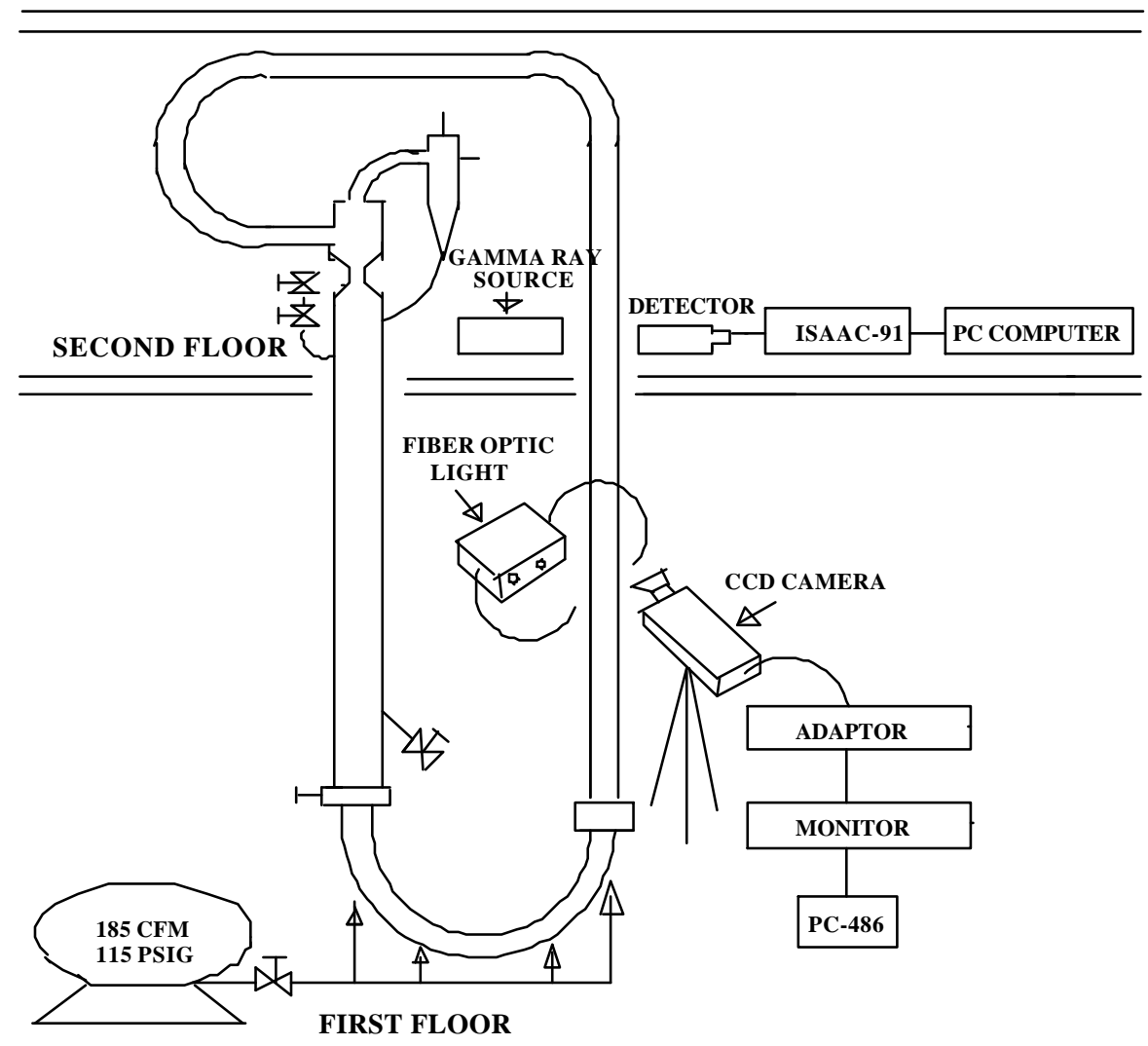

Fig. 1a IIT Circulating Fluidized Bed With Particle Pressure Transducer, CCD Camera and Gamma Ray Densitometer 


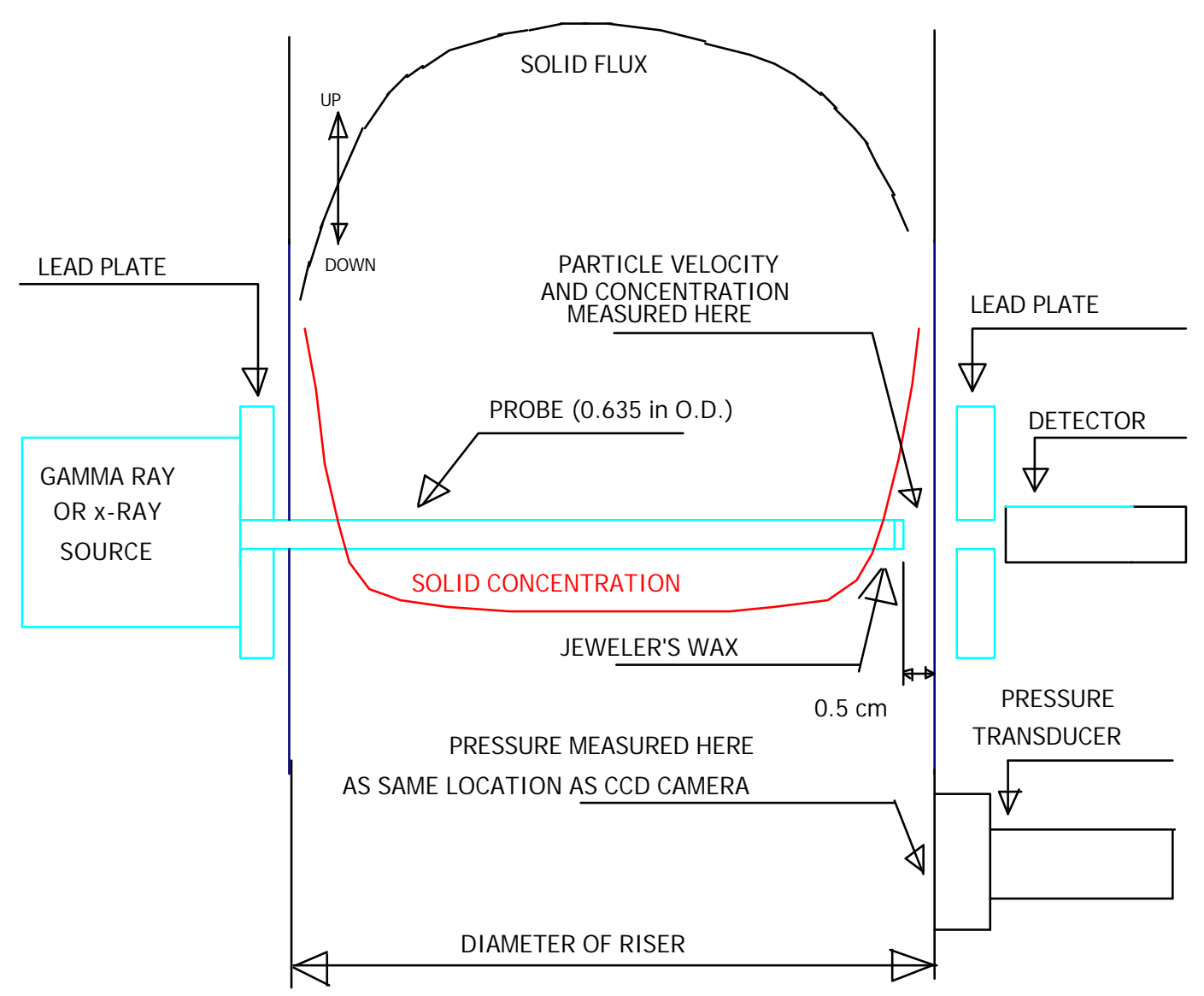

Fig . 1b Sketch of Determination of Particle Concentrations in This Study ( Miller and Gidaspow , 1992) 


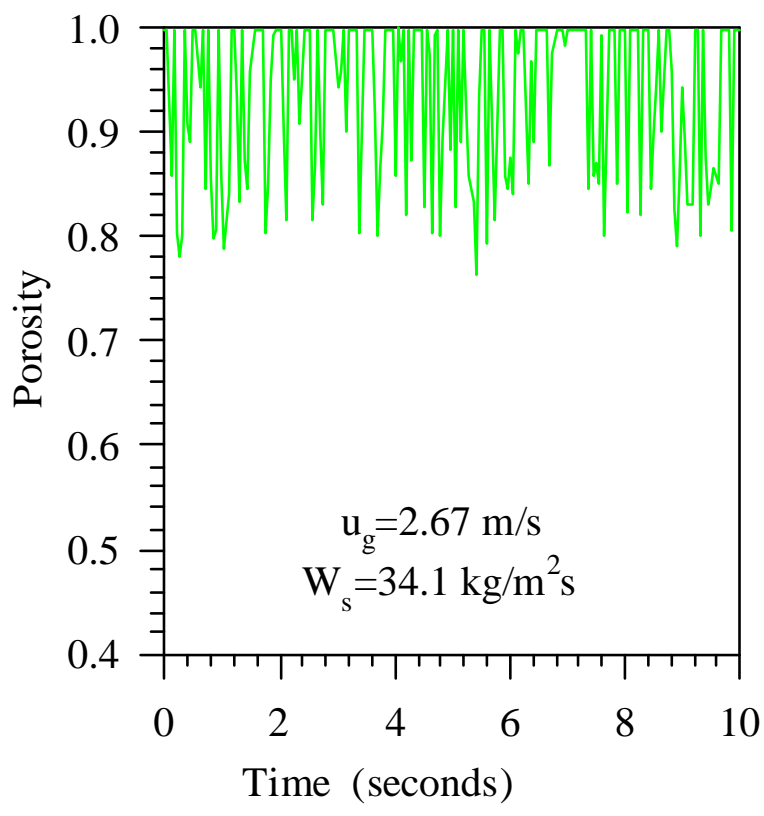

Fig. 2 Experimental Instantaneous Porosity

Fluctuations in The Dilute Region

(Second Floor, Fig. 1a)

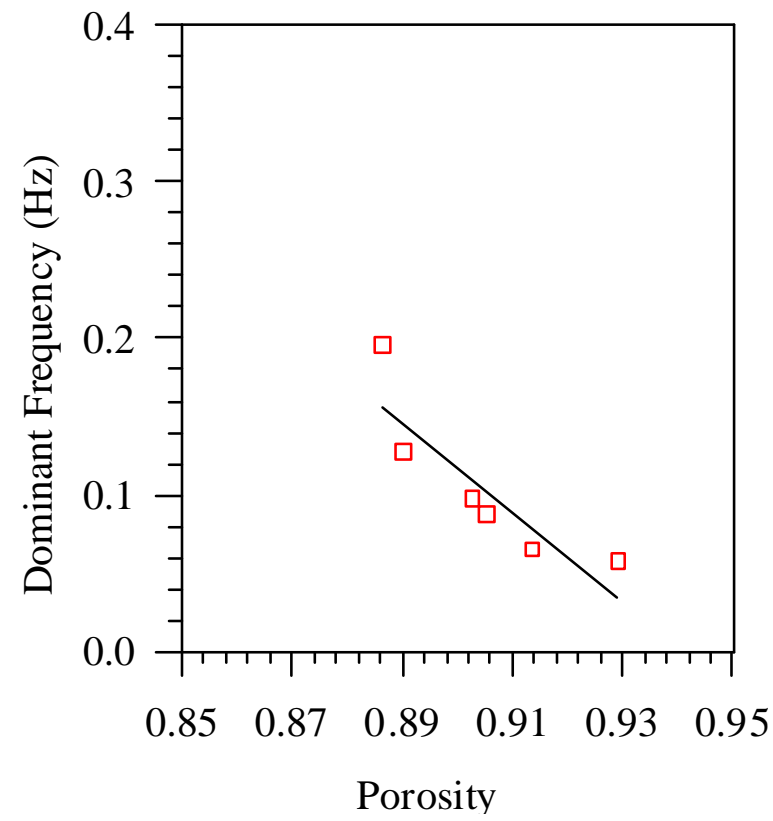

Fig. 5 Dominant Frequency in the Dilute Phase Region

Fig. 1a)

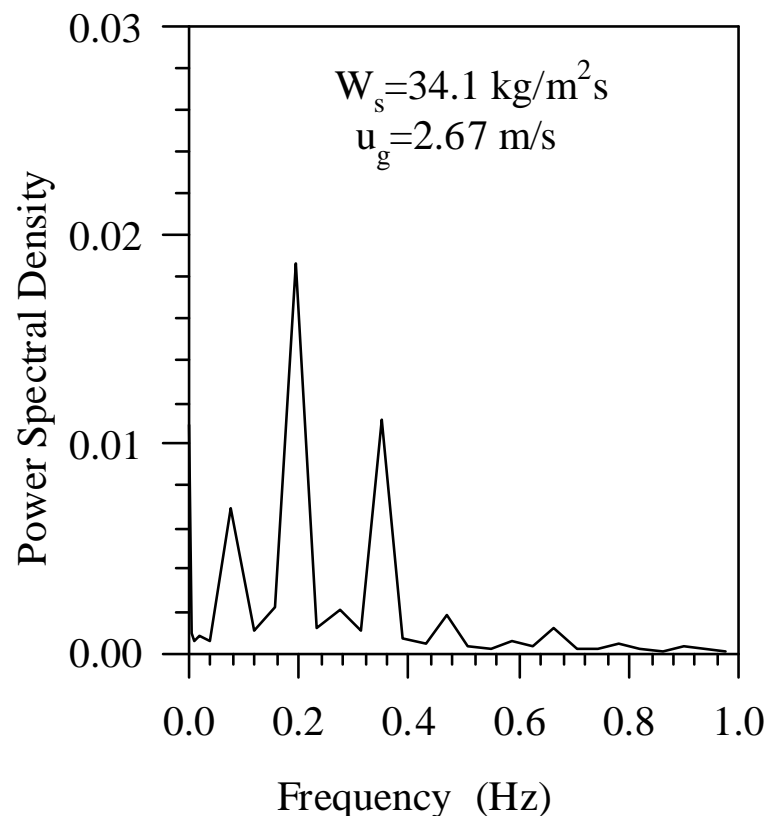

Fig. 3 Power Spectrum Density of Porosity

Fluctuations in The Dilute Region

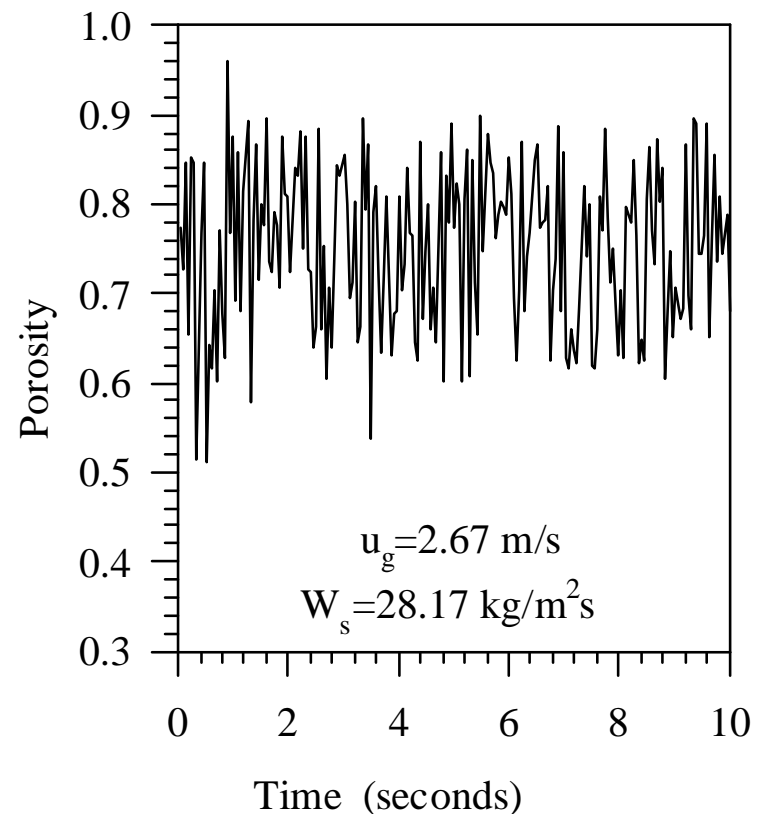

Fig. 6 Experimental Instantaneous Porosity

Fluctuations in the Dense Regime

$\left(\mathrm{U}_{\mathrm{g}}=2.67 \mathrm{~m} / \mathrm{s}, \mathrm{W}_{\mathrm{s}}=28.17 \mathrm{~kg} / \mathrm{m}^{2} \mathrm{~s}\right.$; First Floor, 


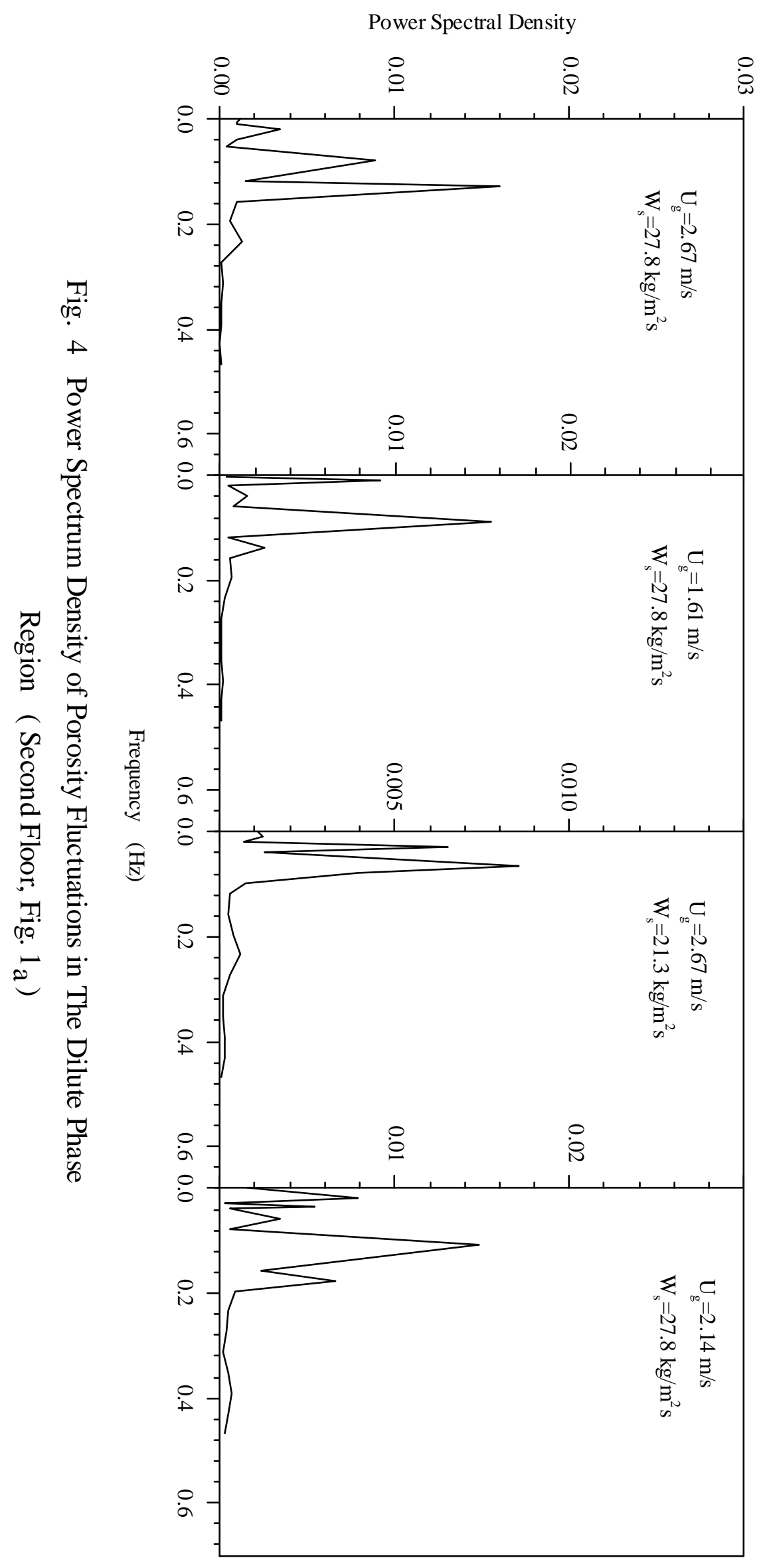




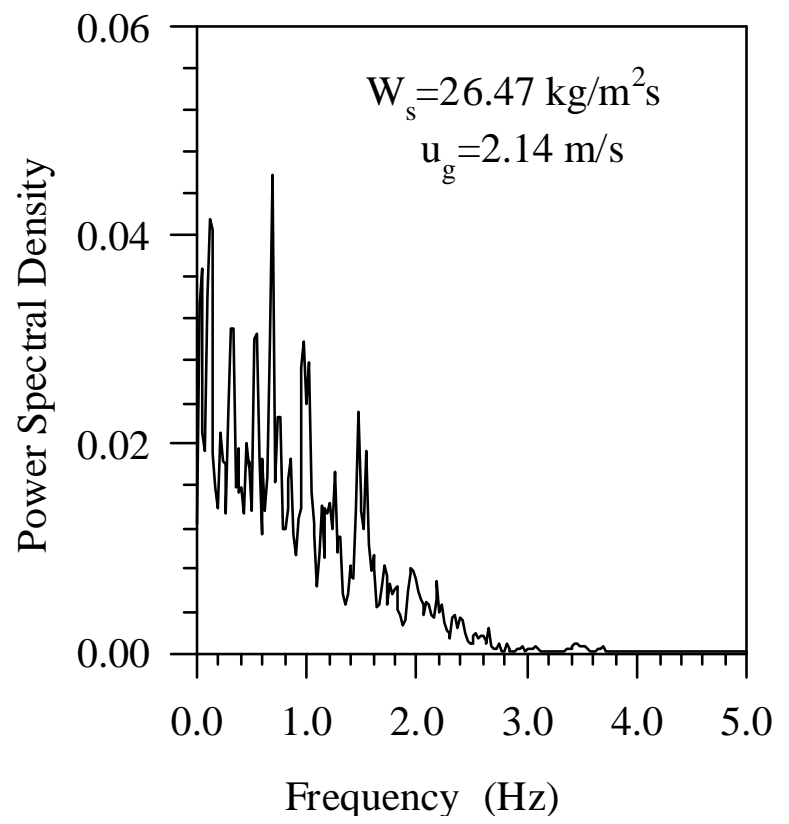

Fig. 7 Power Spectrum Density of Porosity

Fluctuations in the Dense Regime

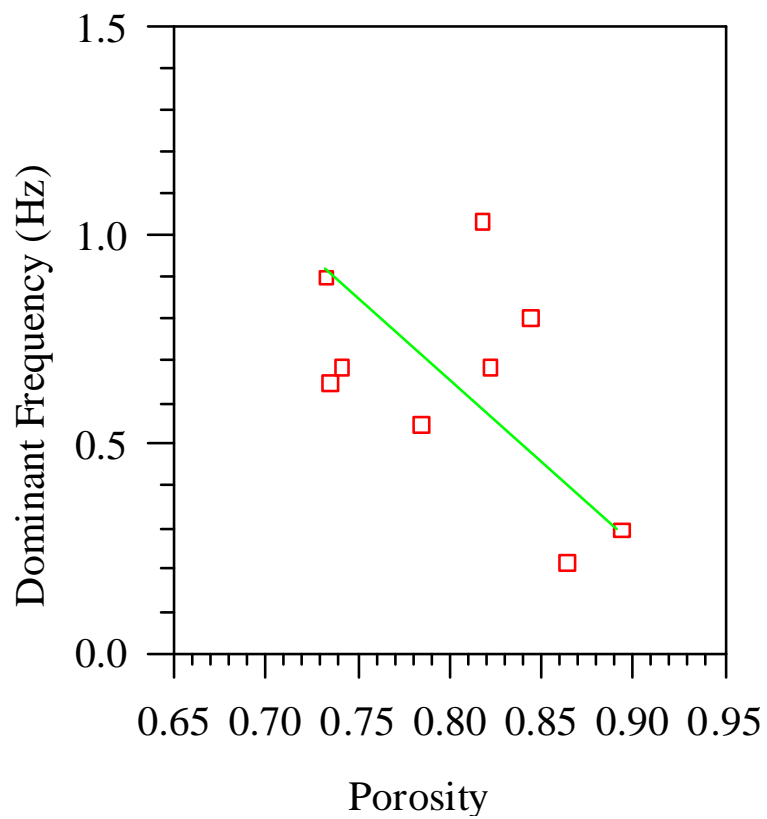

Fig. 8 Dominant Frequency in the Dense Phase Region $\left(\mathrm{U}_{\mathrm{g}}=2.14 \mathrm{~m} / \mathrm{s}, \mathrm{W}_{\mathrm{S}}=26.47 \mathrm{~kg} / \mathrm{m}^{2} \mathrm{~s}\right.$; First Floor, Fig. $\left.1_{\mathrm{a}}\right)$

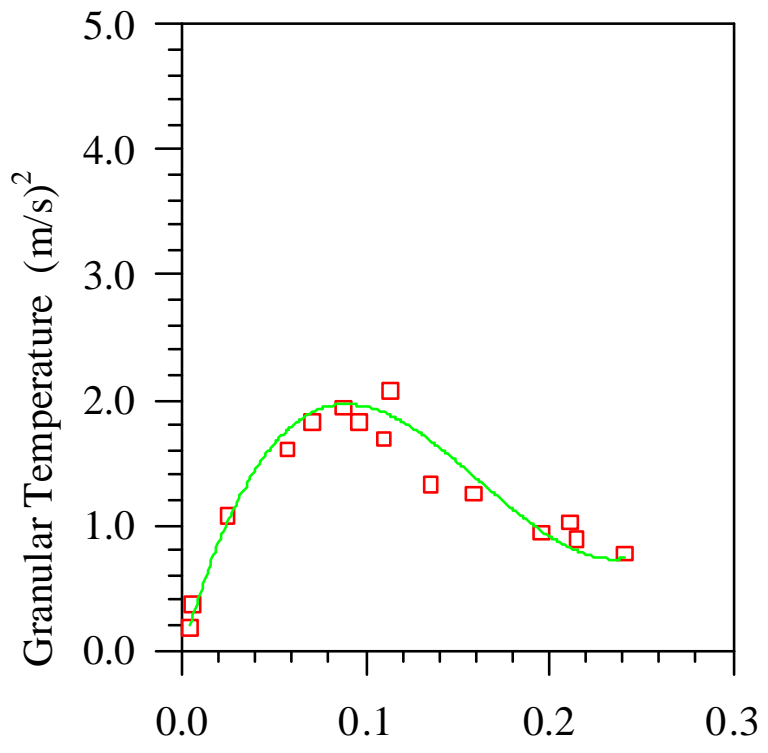

Solid Volume Fraction

Fig. 9 Granular Temperature for $75 \mu \mathrm{m}$ FCC

Particles in the IIT CFB

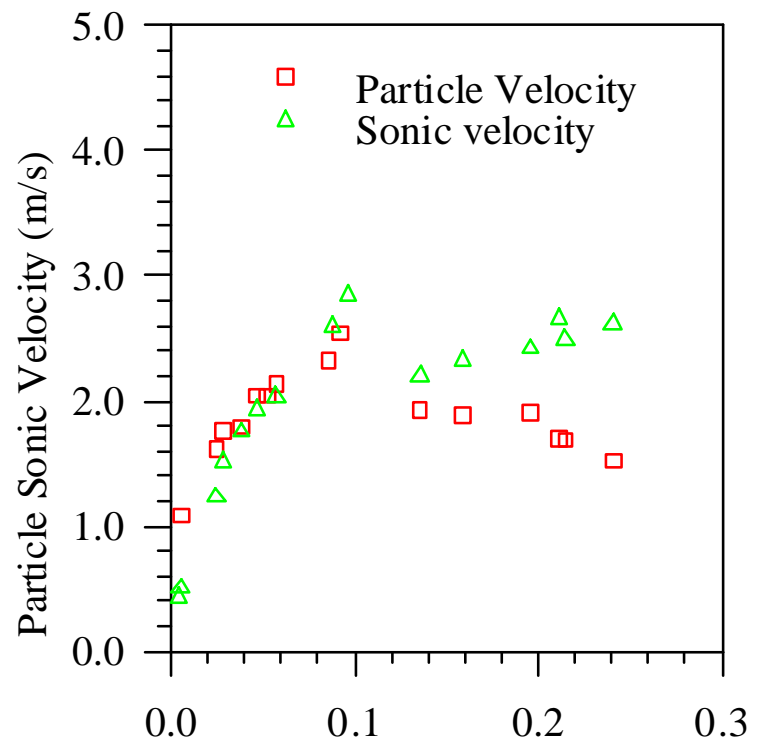

Solid Volume Fraction
Fig. 10 Particulate Sonic Velocities and Average Particle Velocities for $75 \mu \mathrm{m}$ FCC Particles in the IIT CFB 


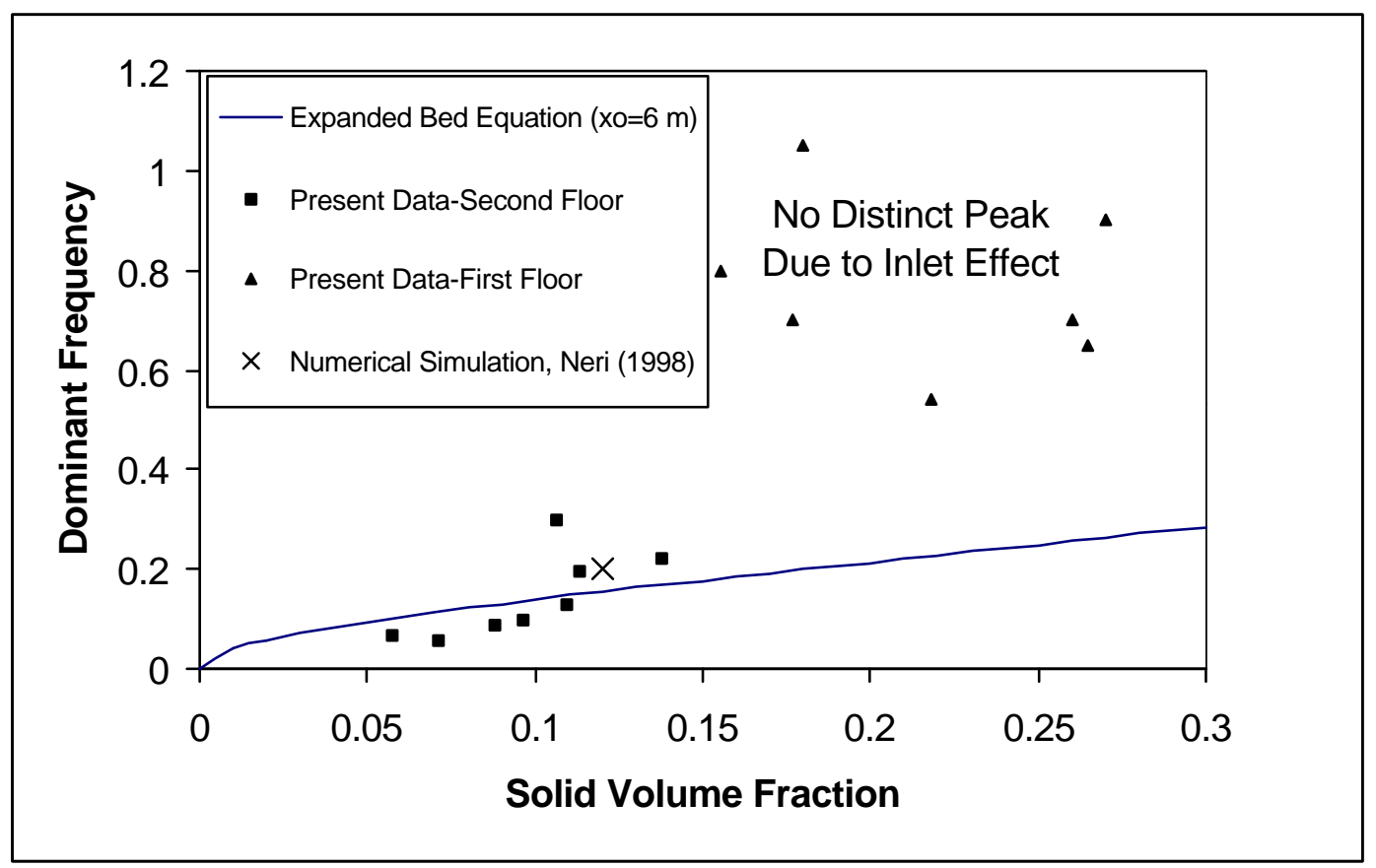

Figure 11- A Comparison of Riser Dominant Frequency, $f$ to the

$$
\begin{gathered}
\text { Analytical Solution } \\
f=\frac{1}{2 \pi}\left(\frac{g}{x_{o}}\right)^{\frac{1}{2}}\left[\frac{\left(3 \varepsilon_{s} / \varepsilon+2\right) \varepsilon_{s}}{\varepsilon_{s o}}\right]^{\frac{1}{2}} ; \quad \varepsilon_{\mathrm{so}}=0.5
\end{gathered}
$$



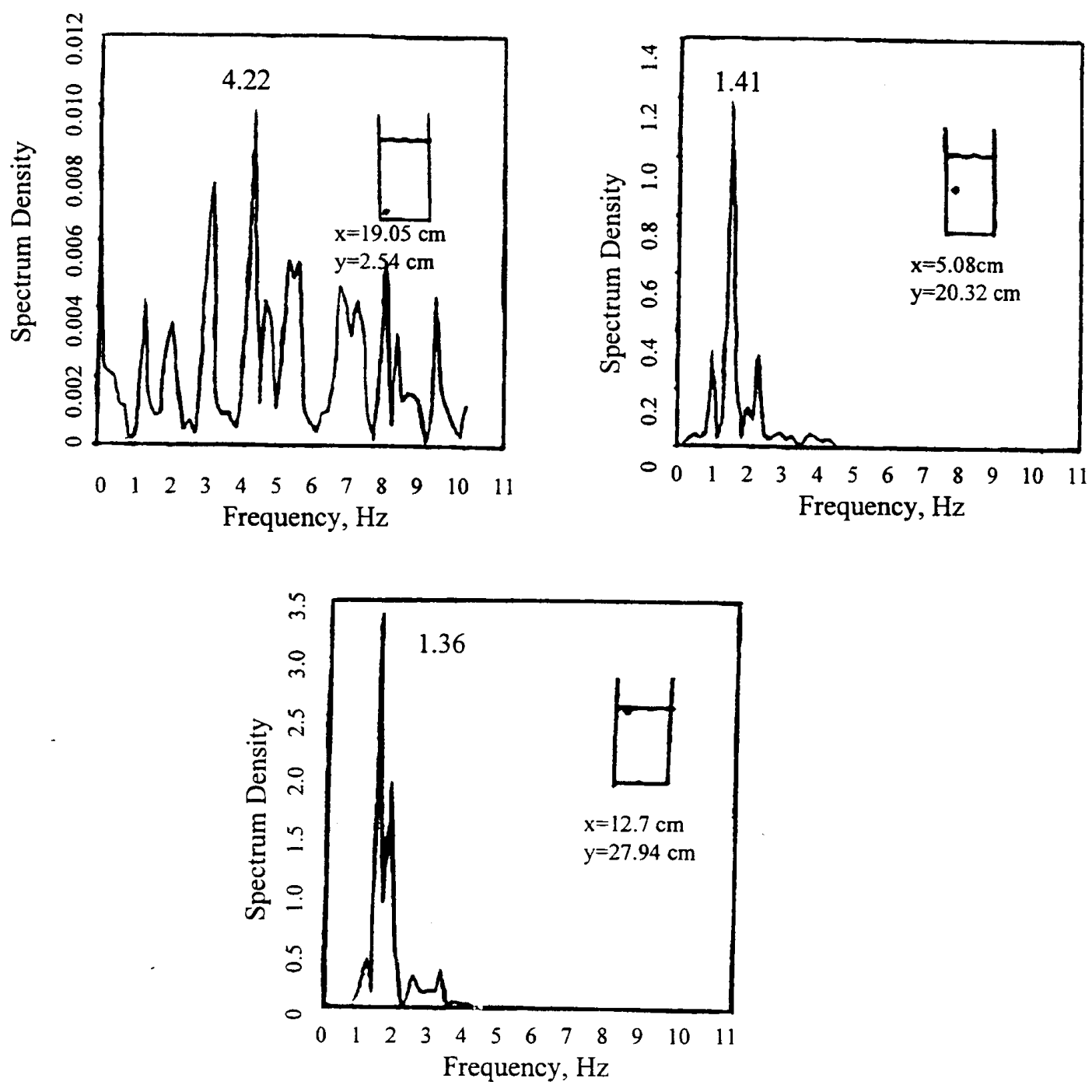

Figure 12 - Power Spectrum for Porosity Measured with a Gamma-ray Densitometer in the Two-Dimensional Bubbling Bed Described in Gidaspow's Book (Gidaspow, et al 1989 ) 


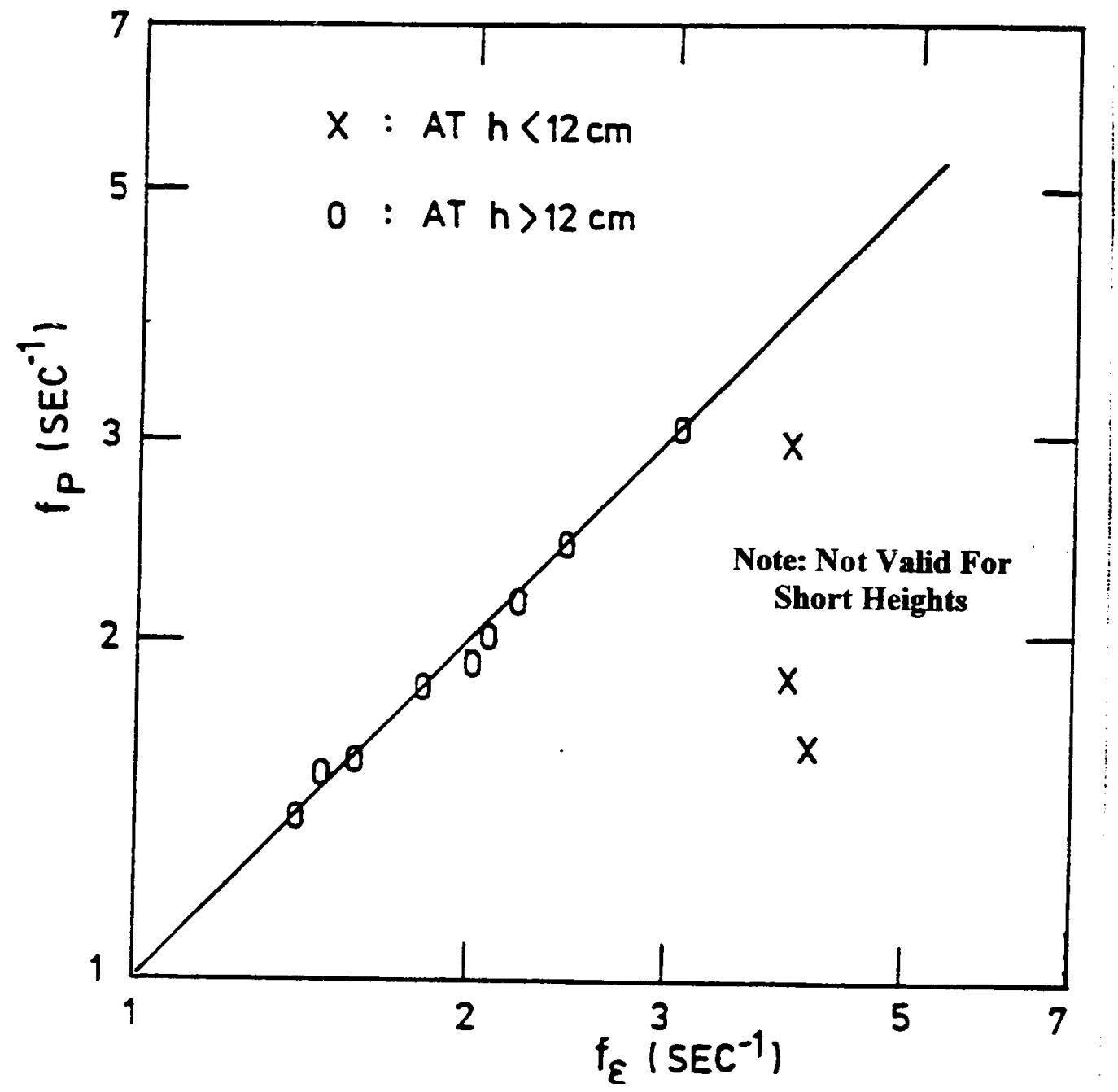

Figure 13. A Comparison of the Frequencies of Porosity Fluctuations to Pressure Fluctuations in a Two Dimensional Fluidized Bed with a Jet as Described in Gidaspow”s Book (Seo, 1985) 


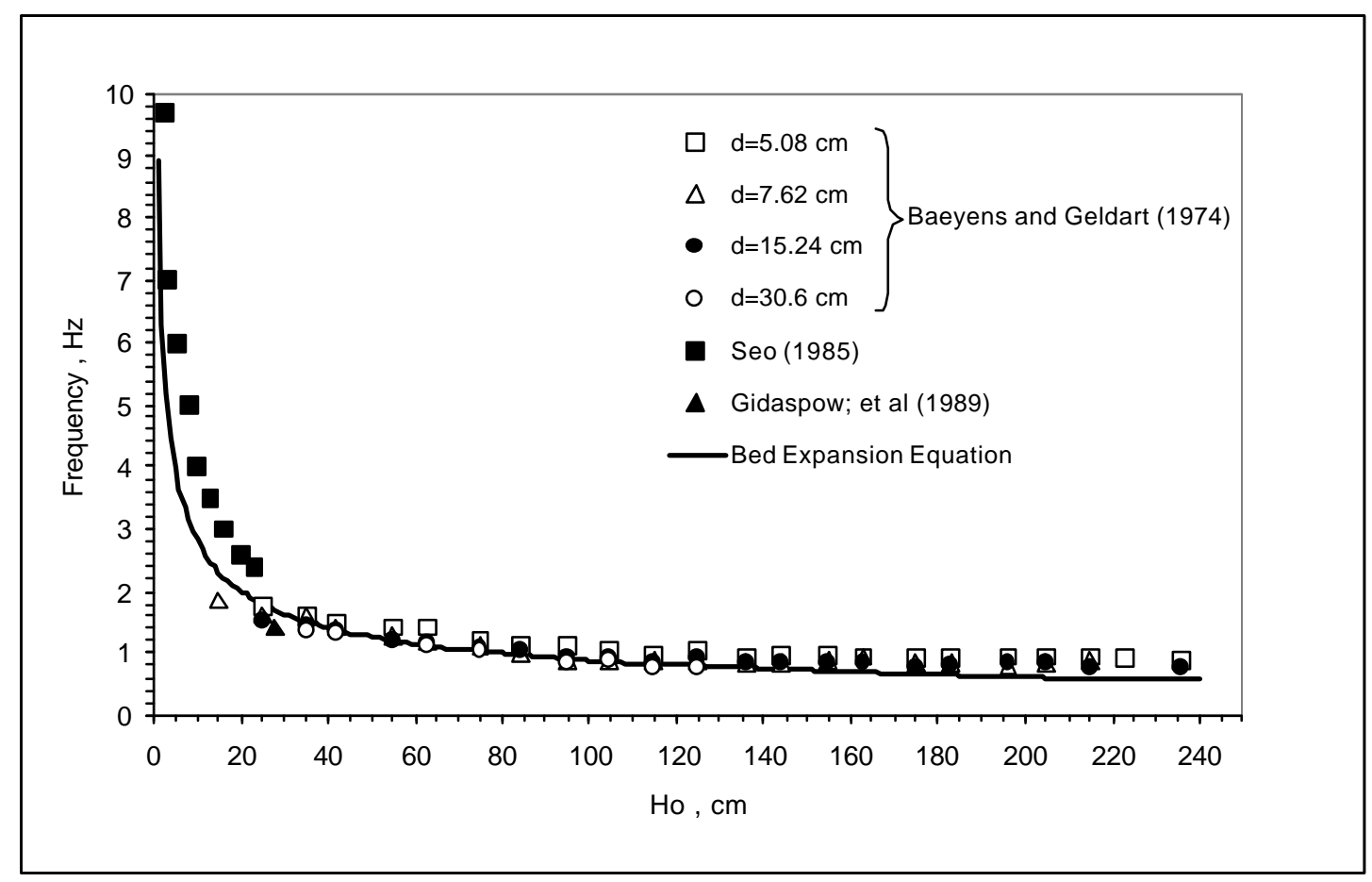

Figure 14. A Comparison of Dominant Bubbling Bed

Frequency Data to the Analytical Solution

$$
f=\frac{1}{2 \pi}\left(\frac{g}{x_{o}}\right)^{\frac{1}{2}}\left[\frac{\left(3 \varepsilon_{s} / \varepsilon+2\right) \varepsilon_{s}}{\varepsilon_{s o}}\right]^{\frac{1}{2}}
$$




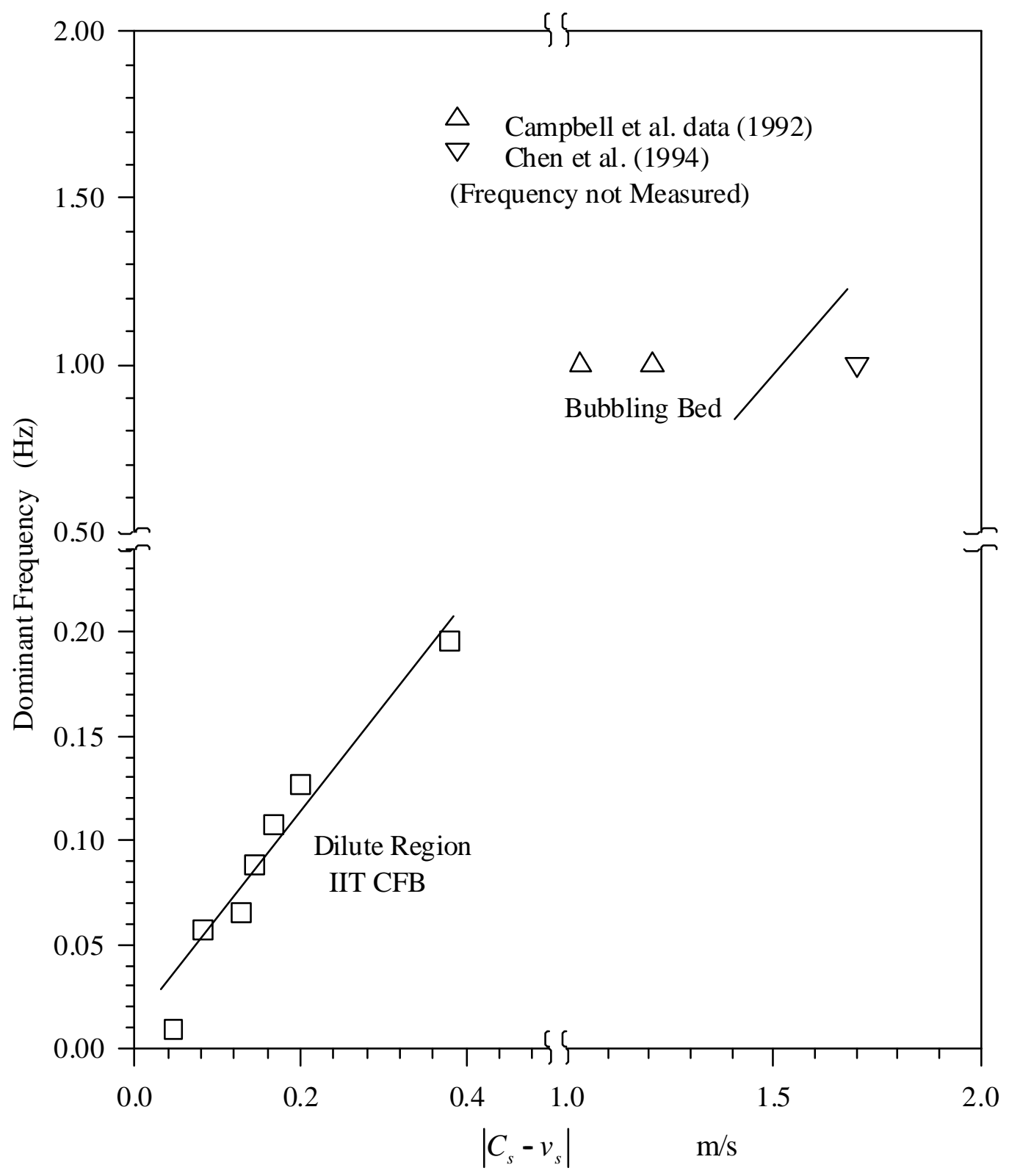

Figure 15 Kinetic Theory Explanation of Low Frequencies in The IIT CFB 


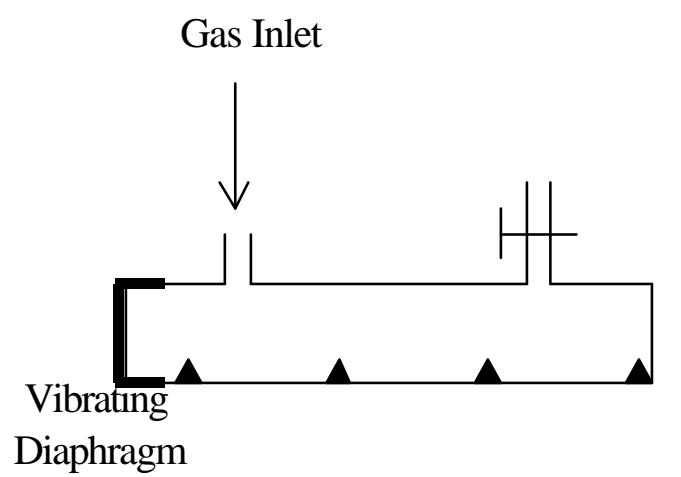

\section{Standing Wave Solution in Two Dimensions}

for a Narrow Tube (Tolstoy, 1973)

$V_{x}=\frac{3 V_{o}^{2}}{8 C_{s}} \sin 2 \alpha x \quad \alpha=\frac{\omega}{C_{s}}$

Figure 16. Kundt's Tube Solution 


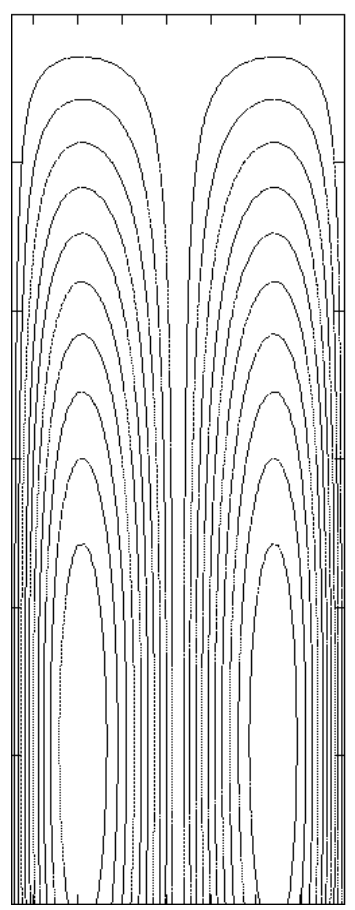

IIT Riser $(\mathrm{d}=7.5 \mathrm{~cm}, \mathrm{~h}=6 \mathrm{~m})$ $\mathrm{C}_{\mathrm{s}}=1.9 \mathrm{~m} / \mathrm{s}, \omega=0.3 \mathrm{~Hz}$

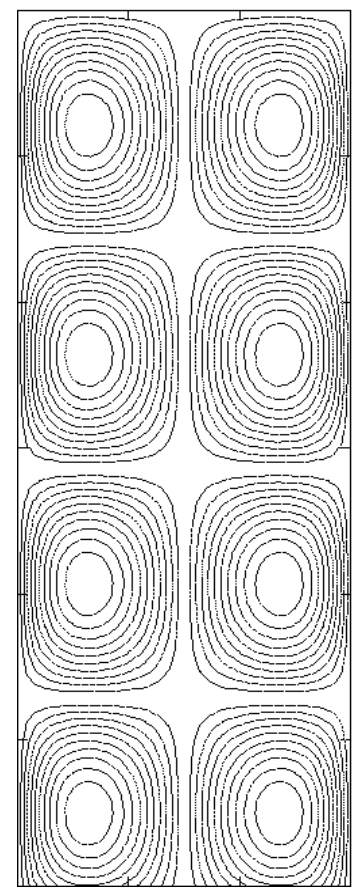

A Fluidized Bed (l=1.5 m, h=6 m) $\mathrm{C}_{\mathrm{s}}=1 \mathrm{~m} / \mathrm{s}, \omega=1 \mathrm{~Hz}$

Figure 17. Flow Patterns Obtained from Standing Waves Analysis 


\title{
Turbulence of Particles in a CFB and Slurry Bubble Columns Using Kinetic Theory
}

\author{
Dimitri Gidaspow, Xiaolin Wu and M. Reza Mostofi \\ Department of Chemical and Environmental Engineering \\ Illinois Institute of Technology, Chicago, IL 60616 \\ Fax: 312-567-8874, E-mail: gidaspow@iit.edu
}

To be presented at the AIChE 1999 Annual Meeting, Dallas Texas, November 31999

The objective of this research is to understand turbulence in circulating fluidized beds (CFB) and bubble column reactors for the purpose of improving multiphase models, such as described in Gidaspow's book, which can be used for reactor design. Recently Buyevich and Cody (1998) found that the granular temperature of particles in bubbling fluidized beds is a maximum at a diameter of about 90 microns and have given an explanation for this observation. The heat transfer coefficient has a similar behaviour. To find an optimum particle size and to confirm and extend Cody's observations, the granular temperature was measured in the IIT CFB for 450 micron glass beads. The granular temperature was measured in the two-story IIT CFB ( Gidaspow and Huilin, 1996) using the CCD camera method described earlier. Figures 1 and 2 show the typical axial and tangential velocity distributions measured with the camera. The local volume fraction was also measured with the camera using the method of Gidaspow and Huilin (1998a) that was shown to give densities close to those determined with an X-ray densitometer. From the standard deviations, such as those seen in Figures 1 and 2, the granular temperature was obtained, assuming equality of tangential and radial standard deviations. Figure 3 shows the granular temperature behavior for the 450 micron glass beads. The shape of the curve is similar to that for 75 micron FCC particles (Gidaspow and Huilin, 1996), but the granular temperature is one order of magnitude lower. This surprising result can be explained on the basis of a balance of production of granular temperature due to shear and dissipation due to inelasticity, which shows that (Gidaspow, 1994, Eq 10. 12)

Granular temperature $=$ constant $\times(\text { shear rate } \times \text { particle diameter })^{2}$

The shear rate for 450 micron beads was measured to be $13 \mathrm{sec}^{-1}$ at a volume fraction of 0.04 by means of a probe. This shear rate is only roughly one twentieth that of FCC particles. This shear rate is much lower for 450 micron beads due to the higher slip. Hence the shear rate decreased faster than the diameter increased, leading to the surprisingly lower turbulence. 
The velocity measurements also allowed us to compute the Reynolds stress from the product of the deviations of the velocities in the two directions. Fig. 4 depicts the results. Since the tangential velocity has a larger error than the velocity in the direction of flow, there is more error in the Reynolds stress than in the granular temperature. The ratio of the Reynolds stress to the granular temperature gives us an estimate of the restitution coefficient. We need this value as an input into our kinetic theory based hydrodynamic model. Most of the values are in the range of 0.99 to 0.999 .

Figure 5 shows the viscosity of the 450 micron beads. It was computed in two ways: 1 . Using the kinetic theory formula, Eq. 5 in Gidaspow and Huilin(1996) with the radial distribution function at contact given by the Bagnold formula, Eq 7. 2. From the equation,

Reynolds stress $\times$ particle density $\times$ solids volume fraction $=$ viscosity $\times$ shear gradient.

Similarly to the results reported at the 1998 Miami Beach annual AlChE meeting (Gidaspow, et al 1998) the viscosity calculated from the Reynolds stress and from the granular temperature agree with each other. As expected, the viscosity of the large beads is higher than the FCC viscosity. However, the viscosity of the 450 micron beads in air in our CFB is an order of magnitude higher than the viscosity of the beads in water reported in the Miami Beach PTF Proceedings (Gidaspow, et al 1998) due to the lower granular temperature in water. See Fig. 6. Fig. 7 compares the velocity gradients in the CFB in air and in water in the fluidized bed with a central jet. The higher granular temperature and the viscosity in air cannot be explained based on the lower shear rate. The difference must be due to the lower air viscosity compared with water. Particles oscillate much faster in air than in water for the same shear rate.

These results are useful for understanding turbulence in slurry bubble column reactors. Fig. 8 shows a comparison of our computed granular temperature using the model and code reported by Wu and Gidaspow (1999) to experimental data for 45 micron Air Products methanol catalyst particles. We had used the restitution coefficient obtained from our experiment in the

simulation. Fig 9 shows the computed solids viscosity. It is quite small due to the low granular temperature and the small catalyst size. In Fig. 8, it is the flow of gases that produced the turbulence. The granular temperature of the catalyst particles in water was almost an order of magnitude lower ( Gidaspow and Huilin, 1998b).

\section{Acknowledgment}

This study was supported by the National Science Foundation Fluid, Particulate and Hydraulic System Grant No. CTS-9610053 and by the Department of Energy Grant No. DE-PS2698FT98200.

\section{References}

Buyevich Y. A. and Cody G.D. 1998, Particle fluctuations in homogeneous fluidized beds, Prep. for Brighton World Congress on Particle Tech., 3, Brighton, UK, Paper 207.

Gidaspow D. and Huilin L., 1996, Collisional viscosity of FCC particles in a CFB, AIChE. J. 42, 2503-2510.

Gidaspow D. and Huilin L., 1998a, Equation of state and radial distribution function of FCC particles in a CFB, AIChE. J. 44, 279-293.

Gidaspow D. and Huilin L., 1998b, A comparison of gas-solid and liquid-solid fluidization using kinetic theory and statistical mechanics, Fluidization IX, edited by L. S. Fan and T. M. Knowlton, New York: Engineering Foundation, 662-668.

Gidaspow D. 1994, Multiphase flow and fluidization: Continuum and kinetic theory descriptions, Boston: Academic Press Inc.

Gidaspow D., Guo Y. and Mostofi M. R. 1998, Turbulence in liquid-solid fluidization, AIChE annual meeting preprints, Vol. II, Particte Technology Forum, Miami Beach, 15-20. 
Wu Y. and Gidaspow D. 1999, Hydrodynamic simulation of methanol synthesis in gas-liquid slurry bubble column reactors, to appear in Chem. Eng. Science. 


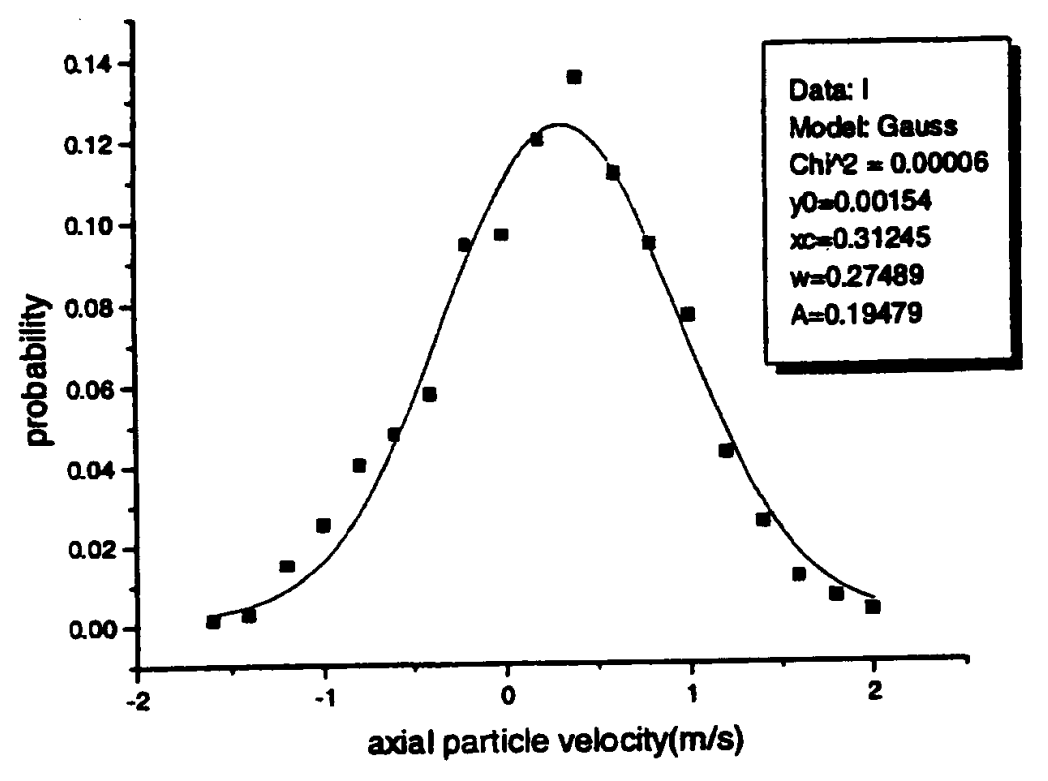

Figure 1. Axial Particle Velocity Distribution For $450 \mu \mathrm{m}$ Glass Beads

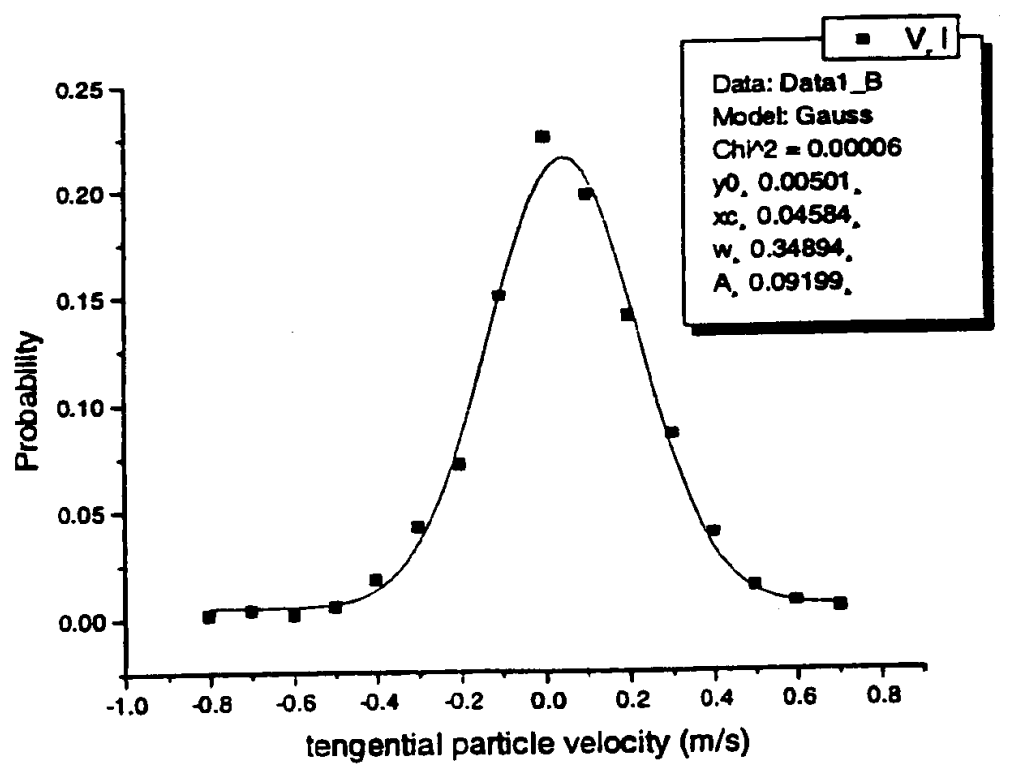

Figure 2. Tangential Particle Velocity Distribution For $450 \mu \mathrm{m}$ Glass Beads 


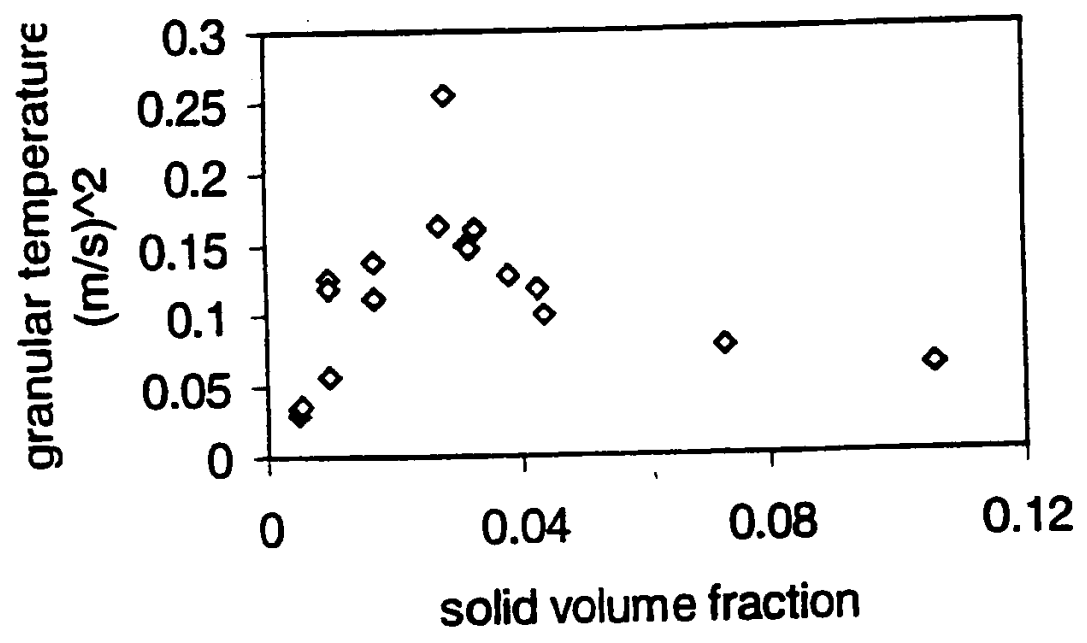

Figure 3. Granular Temperature, $\theta=\frac{1}{3}\left(2 \sigma_{\theta}^{2}+\sigma_{3}^{2}\right)$

For $450 \mu \mathrm{m}$ Glass Beads

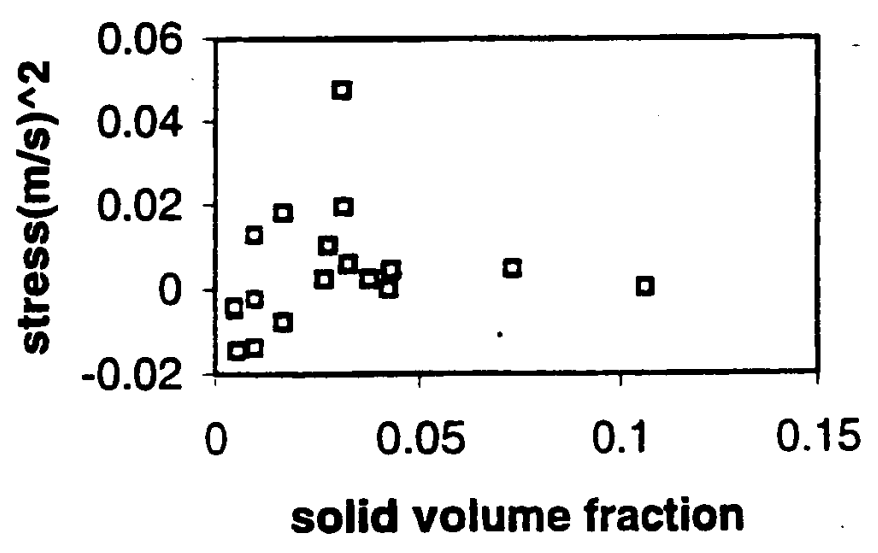

Figure 4. Reynolds Stress, $\overline{v_{\theta}^{\prime} v_{:}^{\prime}}=\frac{1}{N} \sum_{n=1}^{N}\left(v_{\theta}-\bar{v}_{\theta}\right)\left(v_{z}-\bar{v}_{z}\right)$

For $450 \mu \mathrm{m}$ Glass Beads 


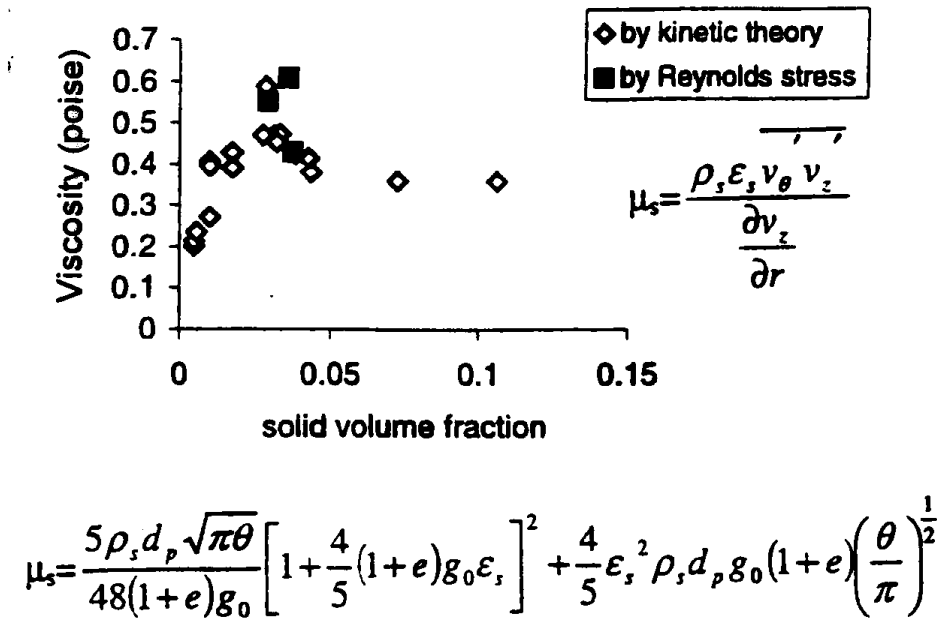

Figure 5. Solids Viscosity For $450 \mu \mathrm{m}$ Glass Beads

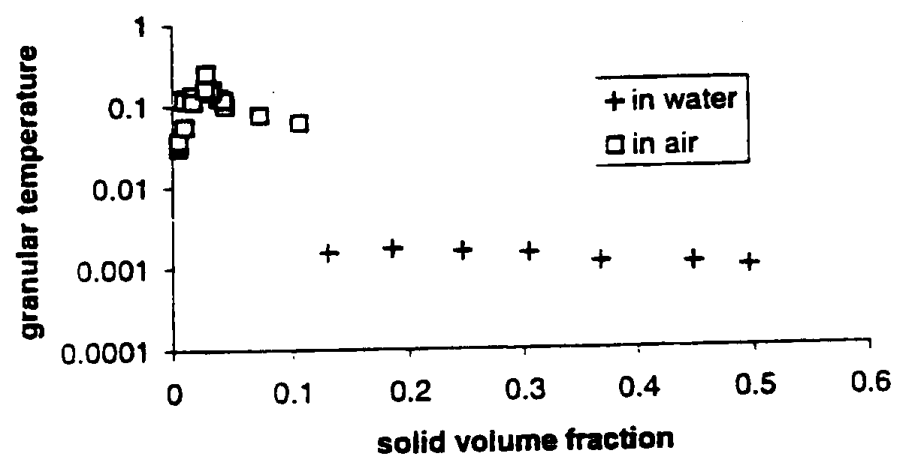

Figure 6. A Comparison of Granular Temperature of $450 \mu \mathrm{m}$ Glass Beads in Air in the IIT CFB and in a Water Fluidized Bed (Gidaspow, et al 1998)

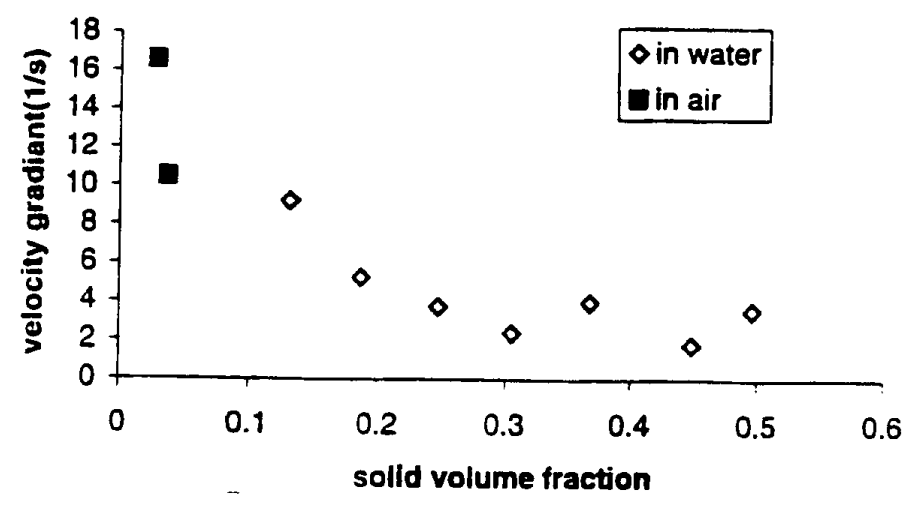

Figure 7. Velocity Gradient of $450 \mu \mathrm{m}$ Glass Beads in Different Media 


\title{
Measurement of Thermal Conductivity of FCC Particles
}

\author{
Dimtri Gidaspow Professor, Principal Investigator \\ Lu Huilin, Research Assistant
}

\section{Department of Chemical and Environmental Engineering Illinois Institute of Technology}

\section{Introduction}

Various models for heat transfer coefficients in CFB require the knowledge of thermal conductivity of the fluid-particle suspension (Zabrodsky, 1966; Wu, et al, 1987\& 1989; Wu and Gidaspow, 1999). The cluster penetration model (Glicksman, 1988; Basu and Fraser, 1991) shows that the wall to bed heat transfer coefficient is proportional to the square root of the cluster conductivity. The hydrodynamic model of Syamlal and Gidaspow (1985) shows a similar strong dependence on the conductivity. Kuipers, et al (1992) have confirmed and extended the computations.

A heat transfer module was inserted into the two-story CFB at IIT. From time average radial temperature distributions at two axial positions, the thermal conductivity of FCC particles was calculated using an energy balance for the mixture. This procedure was very similar to the method of computation of FCC viscosity from measurement of radial velocity profiles (Miller and Gidaspow, 1992). Similarly to the viscosity the conductivity is a function of the volume fraction of FCC particles. At $5 \%$ particles the kinematic viscosity is $0.15 \mathrm{~cm}^{2} / \mathrm{s}$, while the thermal diffusivity is only $0.036 \mathrm{~cm}^{2} / \mathrm{s}$. Hence the Prandtl number has a reasonable value of 4.2 . 


\section{Experimental Equipment}

\section{Circulating fluidized bed}

The circulating fluidized bed (CFB) test unit shown in Figure 1 was used. Air enters the CFB through the bottom U section with FCC catalyst particles of a diameter of $75 \mu \mathrm{m}$, density of $1654 \mathrm{~kg} / \mathrm{m}^{3}$ and specific heat of $2.6 \mathrm{KJ} / \mathrm{Kg} . \mathrm{K}$. The set-up is that used by Miller and Gidaspow (1992). A section of the acrylic pipe was replaced with a heat transfer module.

\section{Heat Transfer Module}

Two electrical heaters with wire coils, internal and compensator heater, were used as the heat source, shown in Figure 2. The wire coils were arranged uniformly so that heat was liberated quite uniformly along the height. The diameter of wire coil is $1.0 \mathrm{~mm}$ and $0.4 \mathrm{~mm}$ for internal and compensator heater, respectively. The heating length of heater is $1.016 \mathrm{~m}$. Both heaters are separated by a polyurethane foam strip. Fiberglass was used to separate the wire coils from both the riser pipe and insulation. Inside of the insulation between the two heaters, two thermocouples (type T) were installed in order to control the energy added to the compensator. The signals of these thermocouples are fed to temperature controllers (Ysi, Model 72) which maintain a temperature difference equal to zero, avoiding heat loss. Power fed to the internal electrical heater was controlled by a powerstat, which can be adjusted to the required voltage.

Measurement of particle temperature is difficult because it is not possible to attach a thermocouple without impairing the mobility of the particles. Usually, temperatures in fluidized beds are measured with thermocouples in direct or indirect contact with particles. Protected thermocouples at low temperature conditions are not only inaccurate, but also have a low response characteristic. Unshielded thermocouples measure some mean temperature lying between the gas temperature and the particle temperature. 
Temperatures were measured by two unshielded copper-constant thermocouples each separated $0.45 \mathrm{~m}$. Moving the thermocouples back and forward along the radial coordinate, a radial temperature profile can be determined. Transient temperature data using these thermocouples were collected. The $\mathrm{mV}$ signals from the thermocouples passed through an amplifier and then to an analog-digital converter (11 channels) made by Interactive Strutures Inc. The digital signals were stored by a computer.

Experiments were done under steady state conditions. Results of a calibration test show that the steady state was reached 1.5-2.0 hours after switching on the heater. For a steady state the two thermocouples across the insulation had to give equal temperature.

\section{Extraction Probe}

Flux profiles in the CFB were measured with the extraction probe shown in Figure 3. The probe consisted of a brass tube that has an outside diameter of $0.635 \mathrm{~cm}$ and a $0.4724 \mathrm{~cm}$ inside diameter. The tube is bent at a 90-degree angle to align its opening parallel to the flowing gas-solids mixture. After extraction by the probe, the gas/solids mixture is separated by a filter. The filter is equipped with a removable solids collection chamber that is fabricated of clear PVC for visual observation. Air leaving the filter flows through a fine secondary filter to protect the downstream rotameter and a vacuum pump. The flow rate of air exiting the extraction probe was adjusted by a globe valve that is located downstream of the rotameter.

At any particular position within the $\mathrm{CFB}$, the time-averaged solid flux consisted of an upward and downward component. The magnitude of the upward flux minus the magnitude of the downward flux is equal to the net upward flux which should be equal to external solids flux. The upward and downward fluxes are measured with the inlet of the extraction probe pointing in the upstream and downstream directions, respectively. Because the CFB operates in an oscillatory state, all flux measurements were time-averaged over periods that ranged from 1,5 to 8 minutes. Flux components were calculated by dividing the weight of solids collected in the filtration chamber by the area of the tip of the probe and sample time. 
Van Breugel et al. (1969) suggested in their study that the extraction probe should be operated under isokinetic conditions, that means the velocity in the probe nozzle should be equal to that of the surrounding stream. However, the CFB operates with a rapid fluctuating velocity, making it very difficult to operate the probe isokinetically. Similar to Gajdos and Bierl (1978), we have found that the flux withdrawn by the extraction probe does not vary significantly when the probe gas extraction velocity is altered within the range of gas velocity anticipated at the local positions in the CFB. This is probably due to the overwhelming size of the momentum of the solids compared to that of the gas. The magnitude of both flux components at the riser wall with varying extraction velocity in the range of $2.0-12.0 \mathrm{~m} / \mathrm{s}$ is shown in Figure 4 . This behavior shows that the downward minus upward flux is approximately constant at the riser wall. Downward flux at the center of the riser was negligible in comparison to the corresponding upward flux for all measured conditions.

Near the riser wall it is necessary to measure both the downward and upward fluxes to obtain the net flux. Flow-restrictive plugging, however, would sometimes occur when the extracting velocity of the probe operated within the range of low gas velocity. There is little difference in the magnitude of the upward and downward fluxes. Therefore, in this investigation the net flux has been taken to be the difference between the two components of the flux measured at the same extracting velocity. The error analysis indicated that the main error for the thermal conductivity and heat transfer coefficient was caused by the error of measuring the solid mass flux. To compensate for the experimental error, the readings were averaged over two extracting velocities. Under such conditions the error between net upward flux and the external flux was estimated to be less than $18.2 \%$.

\section{Model}


The steady state differential equation for equal solid and gas temperature can be derived for the differential element shown in Figure 5. It is:

$$
\left(W_{s} C_{p}+G_{g} C_{g}\right) \frac{\partial T}{\partial z}=K_{r}\left(\frac{\partial^{2} T}{\partial r^{2}}+\frac{1}{r} \frac{\partial T}{\partial r}\right)
$$

The assumption of symmetry gives:

$$
\left.\frac{\partial T(Z, 0)}{\partial r}\right|_{r=0}=0
$$

The following equation for the mean thermal conductivity is obtained after integrating Eq. (1):

$$
\int_{0}^{R}\left(W_{s} C_{p}+G_{g} C_{g}\right) \frac{\partial T}{\partial z} r d r=\left.R K_{r} \frac{\partial T}{\partial r}\right|_{r=R}
$$

The temperature profiles and solid mass flux profiles are obtained by approximating the data with a least-squares polynomial that visually best fits the profiles. The polynomial ranged in order from 5 th to 8 th degree.

The mean overall heat transfer coefficient, $h$, was obtained by taking an overall heat balance across the whole riser. If $\mathrm{Q}$ is the net heat flux, the heat transfer coefficient can be estimated by:

$Q=h A \Delta T$

where $\mathrm{A}$ is the heat transfer surface based on the internal diameter of the riser, and $\Delta \mathrm{T}$ is the logarithmic temperature difference.

\section{Experimental Data}

\section{Radial Temperature Profile}

Typical local instantaneous temperatures are shown in Figure 6. In general, variation of instantaneous temperature indicated the degree of mixing and exchange between particles, 
particle and gas. It is seen that the degree of such mixing near the wall is more intense than that in the core region. The flow characteristic is approaching plug flow in the core region.

Radial temperature profiles experimentally obtained in present test are shown in Figure 7. In general, the radial temperature gradient is near straight line in the core region and very steep near the wall of the riser.

\section{Solid Flux Profile}

Solid flux profiles were obtained using the extraction probe. The profiles are quasiparabolic with an upward-moving mass flux at the center and downward flux at the wall. In Figure 8, the radial mass flux is plotted at a constant superficial velocity. The radial mass flux at the center of the riser increases with increasing feed flux. At the wall the solids are flowing downward. The magnitude of the flux increases with increasing values of the feed flux. The core is defined as the region in the center of the riser in which the net solid mass flux is moving upward. It is seen that the radius of the core decreases with increasing values of mass flux.

The influence of the superficial velocity on the radial flux profiles is shown in Figure 9. The core radius increases with increasing superficial velocity. The solid mass flux at the centerline decreased with increasing superficial velocity. The magnitude of the solids mass flux at the wall flowing downward increases as the superficial velocity decreases. The profiles of radial mass flux are near parabolic.

\section{Thermal Conductivity}

The plot of the effective thermal conductivity versus the superficial velocity is presented in Figure 10. The effective thermal conductivity increases slightly with increasing superficial velocity. The influence of the solid mass flux on the effective thermal conductivity is presented in Figure 11. The value of the effective thermal conductivity increases with increasing solid mass flux. This is due to the particle concentration near the wall. It may be seen that the individual values of the thermal conductivity evaluated from each radial temperature profile become 
independent of axial position in this present system, when the axial distance is large. Therefore, it may be reasonable to obtain the thermal conductivity from the temperature profiles under these testing conditions.

The effective thermal conductivity versus cross sectional averaged solid volume fraction is shown in Figure 12. It is seen that the effective thermal conductivity increases with increasing solid volume fraction in the dilute region of the circulating fluidized beds. The least squares fitted equation is:

$K_{r}=[5.9427+366.218(1-\varepsilon)] 10^{-2}$

Let us assume that

$K_{r}=K_{g, o}+K_{s}$

where $\mathrm{K}_{\mathrm{go}}$ is the gas thermal conductivity.

Figure 13 shows the variation of the effective particle thermal conductivity $\mathrm{K}_{\mathrm{s}}$ with the solid volume fraction. It is seen that the effective particle thermal conductivity increases with increasing solid volume fraction. The expression obtained by least squares fitting of data is: $K_{s}=[3.1995+366.098(1-\varepsilon)] 10^{-2}$

\section{Heat Transfer Coefficient}

Figure 14 shows the variation of heat transfer coefficient with superficial velocity. Within the range of superficial velocity tested, the data shows that the heat transfer coefficient increases slightly with increasing superficial velocity. There is a very substantial augmentation of the heat transfer coefficient with superficial velocity. According to Grace (Grace, 1986), the independence of heat transfer of the superficial velocity is due to the small contribution of the gas convective component to the heat transfer coefficient. The variation of the gas convetive component due to a change in gas velocity for a flow of gas alone is indeed small compared to 
the measured variations at higher solid mass flux. Figure 15 shows the influence of solid mass flux on the heat transfer coefficient. It is evident from this figure that heat transfer coefficient is a strong function of the solid mass flux.

The plot of the heat transfer coefficient versus bulk density is shown in Figure 16. It is seen that the heat transfer coefficient increases with increasing density in the dilute region of the circulating fluidized bed. The least-squares correlation is as follows:

$h=87.466+1.5038 \rho_{b}$

where $\rho_{b}$ is bulk density of the riser.

\section{Error Analysis}

The expected error in the measured values of the effective thermal conductivity can be expressed as follows:

$\varepsilon_{K_{r}}=\left|\frac{\Delta K_{r}}{K_{r}}\right|^{2}=\left|\frac{\Delta W_{s}}{W_{s}}\right|^{2}+\left|\frac{\Delta G_{g}}{G_{g}}\right|^{2}+\left|\frac{\Delta T}{T}\right|^{2}+\left|\frac{\Delta r}{R}\right|^{2}+\left|\frac{\Delta Z}{L}\right|^{2}+$ End Effects

The accuracy of measured solid mass flux $\mathrm{W}_{\mathrm{s}}$ is usually within $\pm 18.2 \%$ using the extraction probe. The accuracy of gas mass flux, $\mathrm{G}_{\mathrm{g}}$ is estimated to be $\pm 4.5 \%$, metered by rotameters. The temperature measurement using the copper-constant thermocouple is within $\pm 1.0 \%$, while the accuracy of measuring $\mathrm{r}$ and $\mathrm{Z}$ are about $\pm 1.33 \%$ and $\pm 0.2 \%$, respectively. The end effects cannot be predicated accurately. The measured value of the thermal conductivity is then within $\pm 19 \%$. The main error is due to the measured solid mass flux.

The expected error for heat transfer coefficient can be written as follows:

$\varepsilon_{h}=\left|\frac{\Delta h}{h}\right|^{2}=\left|\frac{\Delta Q}{Q}\right|^{2}+\left|\frac{\Delta W_{s}}{W_{s}}\right|^{2}+\left|\frac{\Delta G_{g}}{G_{g}}\right|^{2}+\left|\frac{\Delta T}{T}\right|^{2}+\left|\frac{\Delta r}{R}\right|^{2}+\left|\frac{\Delta Z}{L}\right|^{2}+$ End Effects 
The accuracy of measuring the input power is within $\pm 3.5 \%$. The measured value of the heat transfer coefficient is then $\pm 19.4 \%$.

\section{Nomenclature}

\begin{tabular}{|c|c|c|}
\hline A & Heat transfer surface & $\mathrm{m}^{2}$ \\
\hline $\mathrm{C}_{\mathrm{p}}$ & Particle specific heat & $\mathrm{J} / \mathrm{Kg} \cdot \mathrm{K}$ \\
\hline $\mathrm{C}_{\mathrm{g}}$ & Gas specific heat & $\mathrm{J} / \mathrm{Kg} . \mathrm{K}$ \\
\hline h & Heat transfer coefficient & $\mathrm{W} / \mathrm{m}^{2} \cdot \mathrm{K}$ \\
\hline $\mathrm{G}_{\mathrm{g}}$ & Gas mass flux & $\mathrm{Kg} / \mathrm{m}^{2} \cdot \mathrm{s}$ \\
\hline $\mathrm{K}_{\mathrm{r}}$ & Effective thermal conductivity & $\mathrm{W} / \mathrm{m} \cdot \mathrm{K}$ \\
\hline $\mathrm{K}_{\mathrm{s}}$ & Effective particle thermal conductivity & $\mathrm{W} / \mathrm{m} . \mathrm{K}$ \\
\hline $\mathrm{K}_{\mathrm{g}}$ & Gas thermal conductivity & $\mathrm{W} / \mathrm{m} . \mathrm{K}$ \\
\hline $\mathrm{K}_{\mathrm{g}, \mathrm{o}}$ & Gas microscopic thermal conductivity & $\mathrm{W} / \mathrm{m} . \mathrm{K}$ \\
\hline $\mathrm{K}_{\mathrm{s}, \mathrm{o}}$ & Solid microscopic thermal conductivity & $\mathrm{W} / \mathrm{m} . \mathrm{K}$ \\
\hline $\mathrm{P}$ & Pressure & $\mathrm{N} / \mathrm{m}^{2}$ \\
\hline Q & Net heat flux & $\mathrm{W}$ \\
\hline $\mathrm{r}$ & Radial coordinate & --- \\
\hline $\mathrm{R}$ & Radius of riser & $\mathrm{m}$ \\
\hline $\mathrm{T}$ & Gas/particle mixture temperature & $\mathrm{K}$ \\
\hline $\mathrm{T}_{\mathrm{g}}$ & Gas temperature & $\mathrm{K}$ \\
\hline $\mathrm{T}_{\mathrm{s}}$ & Particle temperature & $\mathrm{K}$ \\
\hline $\mathrm{T}_{\mathrm{r}=\mathrm{R}}$ & Wall temperature & $\mathrm{K}$ \\
\hline $\mathrm{T}_{\mathrm{r}=0}$ & Centerline temperature & $\mathrm{K}$ \\
\hline $\mathrm{U}_{\mathrm{g}}$ & Gas velocity & $\mathrm{m} / \mathrm{s}$ \\
\hline $\mathrm{W}_{\mathrm{s}}$ & Solid mass flux & $\mathrm{Kg} / \mathrm{m}^{2} \cdot \mathrm{s}$ \\
\hline $\mathrm{Z}$ & Axial coordinate & --- \\
\hline
\end{tabular}

Greek letters: 


$\begin{array}{llc}\rho_{\mathrm{g}} & \text { Gas density } & \mathrm{Kg} / \mathrm{m}^{3} \\ \rho_{\mathrm{s}} & \text { Solid density } & \mathrm{Kg} / \mathrm{m}^{3} \\ \rho_{\mathrm{b}} & \text { Bulk density } & \mathrm{Kg} / \mathrm{m}^{3} \\ \varepsilon & \text { Porosity } & ---\end{array}$

\section{References}

Basu P. and K. Nag, An investigation into heat transfer in circulating fluidized beds. Int. J. Heat Mass Transfer, No. 30, pp. 2399-2409, 1987.

Basu P. and S.C. Fraser, Circulating Fluidized Bed Boilers: Design and Applications, Butterworth-Heinemann Inc., 1991.

Botterill J. S. M. and A. O. O. Denloye, A theoretical model of heat transfer to a packed or quiescent fluidized bed, Chemical Engineering Science, No. 4, pp. 509-515, 1978.

Ebert T. A., L. R. Glicksman and M. Lints, Determination of particles and gas convective heat transfer components in a circulating fluidized bed, Chemical Engineering Science, No. 12, pp. 179-188, 1993.

Ernst R. G. E. and R. J. Goldstein, Measurements in heat transfer, McGraw-Hill Book Company, 1976.

Gabor J. D., B. E. Stangeland and W. J. Mecham, Lateral transport in a fluidizedpacked bed: part p: heat transfer, AIChE J., No. 1, pp. 130-132, 1965.

Gajdos J. L. and T. W. Bierl, Studies in support of recirculating bed reactors for the processing of coal, Annual report, Prepared U. S. Dept. of Energy, FE-2449-8 (Sept.), 1978.

Gidaspow, D., Multiphase flow and fluidization: continuum and kinetic theory descriptions, Academic Press Inc. 1994.

Glicksman L.R., Circulating Fluidized Beds Heat Transfer, in Circulating Fluidized Bed Technology II, Ed. By P. Basu and J.F. Large, Pergamon Press, 1988.

Grace J. R., Heat transfer in circulating fluidized beds, First Int. Conf. on Circluating Fluidized Beds, Halifax, 1986.

Kuipers J.A.M., W. Prins and W.P.M. van Swaaij, Numerical Calculation of Wall-toBed Heat Transfer Coefficients in Gas-Fluidized Beds, AIChE J., No. 7, 1992. 
Miller A. and D. Gidaspow, Dense, vertical gas-solids flow in a pipe, AIChE J., No. 11, pp. 1801-1815, 1992.

Syamlal M. and D. Gidaspow, Hydrodynamics of fluidization: prediction of wall to bed heat transfer coefficients, AIChE. J., No. 1 pp. 127-135, 1985.

Van Breugel J. W., J. J. M. Stein and R. J. Devries, Isokinetic sampling in a dense gassolids stream, Joint Symp. on Fluid Mech, and Measurements in Two Phase Systems. The Institution of Mechanical Engineers, Leeds (Sept.), 1969.

Wu Y. and D. Gidaspow 1999, Hydrodynamic simulation of methanol synthesis in gasliquid slurry bubble column reactors, to appear in Chem. Eng. Science.

Wu R. L., C. J. LIM, J. Chouki and J. R.Grace, Heat transfer from a circulating fluidized bed to membrane water wall surfaces, AIChE J., No. 33, pp. 11, 1987.

Wu R. L., J. R. Grace, C. J. Lim and C. M. H. Brereton, Suspension-to-surface heat transfer in circulating fluidized bed combustor, AIChE J., No. 35, pp. 1685-1691, 1989.

Zabrodsky S. S., Hydrodynamics and heat transfer in fluidized beds, The M.I.T. press, 1966. 
Table 1

Experimental Conditions

\begin{tabular}{|c|c|c|c||}
\hline Run & Velocity $(\mathrm{m} / \mathrm{s})$ & Flux $\left(\mathrm{Kg} / \mathrm{m}^{2} . \mathrm{s}\right)$ & Voltage (V) \\
\hline No. 1 & 3.545 & 17.48 & 65.04 \\
\hline No. 2 & 3.529 & 23.03 & 55.46 \\
\hline No. 3 & 3.553 & 32.09 & 80.92 \\
\hline No. 4 & 2.365 & 17.36 & 67.85 \\
\hline No. 5 & 3.020 & 24.43 & 72.88 \\
\hline No. 6 & 2.982 & 26.37 & 72.28 \\
\hline No. 7 & 2.982 & 17.26 & 64.27 \\
\hline No. 8 & 3.580 & 16.85 & 45.45 \\
\hline No. 9 & 3.562 & 26.80 & 75.45 \\
\hline No. 10 & 3.010 & 27.12 & 65.45 \\
\hline No. 11 & 2.419 & 23.90 & 75.45 \\
\hline No. 12 & 2.408 & 10.39 & 67.78 \\
\hline No. 13 & 3.607 & 16.75 & 67.78 \\
\hline No. 14 & 3.587 & 11.67 & 46.55 \\
\hline
\end{tabular}

\begin{tabular}{||c|c|c|c|}
\hline Run & $\begin{array}{c}\text { External } \\
\text { solid Flux }\end{array}$ & $\begin{array}{c}\text { Net solid } \\
\text { Flux }\end{array}$ & Error(\%) \\
\hline No.1 & 17.48 & 16.299 & 6.76 \\
\hline No. 2 & 23.03 & 26.586 & -15.44 \\
\hline No. 3 & 32.09 & 35.516 & 10.68 \\
\hline No. 4 & 17.36 & 20.518 & -18.19 \\
\hline No. 5 & 24.43 & 27.015 & 3.70 \\
\hline No. 6 & 26.37 & 28.227 & -7.04 \\
\hline No. 7 & 17.26 & 14.272 & 17.31 \\
\hline No. 8 & 16.85 & 17.557 & -19 \\
\hline No. 9 & 26.80 & 22.896 & 14.57 \\
\hline No. 10 & 27.12 & 25.679 & 5.31 \\
\hline No. 11 & 23.90 & 22.390 & 6.32 \\
\hline No. 12 & 10.39 & 9.145 & 11.98 \\
\hline No. 13 & 16.75 & 19.237 & -14.85 \\
\hline No. 14 & 11.67 & 13.442 & -15.19 \\
\hline
\end{tabular}




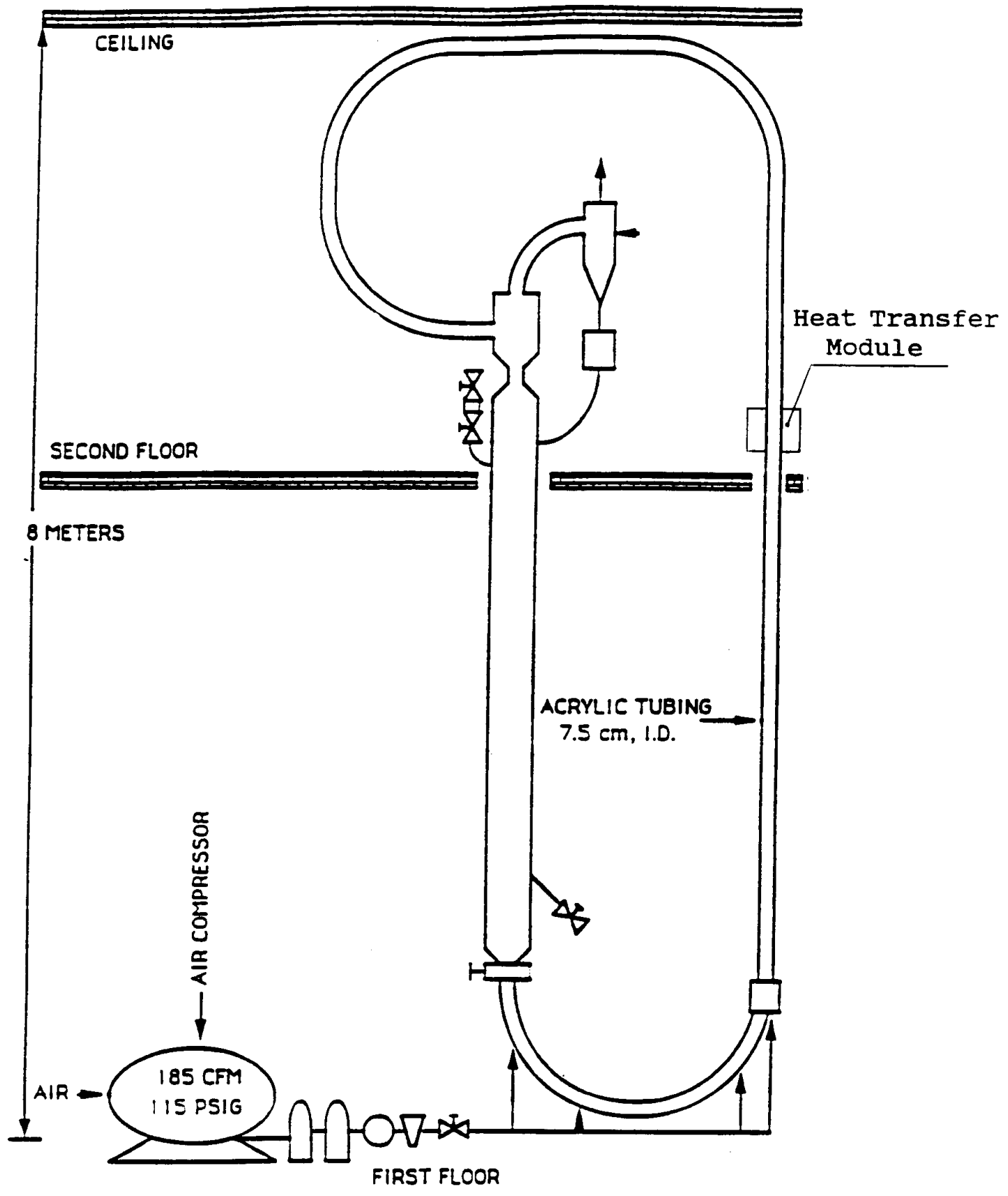

Figure 1 IIT Circulating Fluidized Bed System 

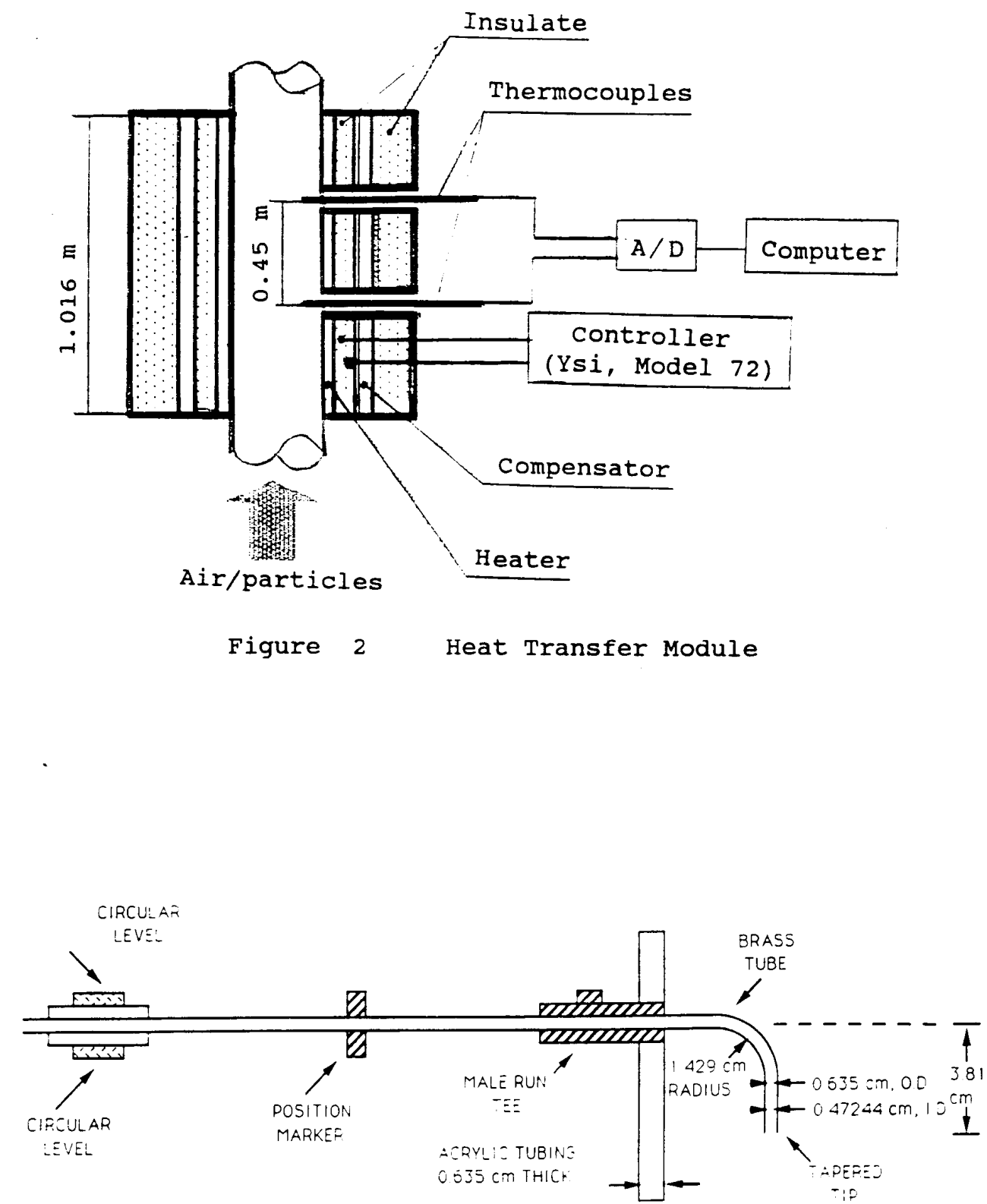

$2286 \mathrm{~cm}$

Figure 3 Extraction Probe 


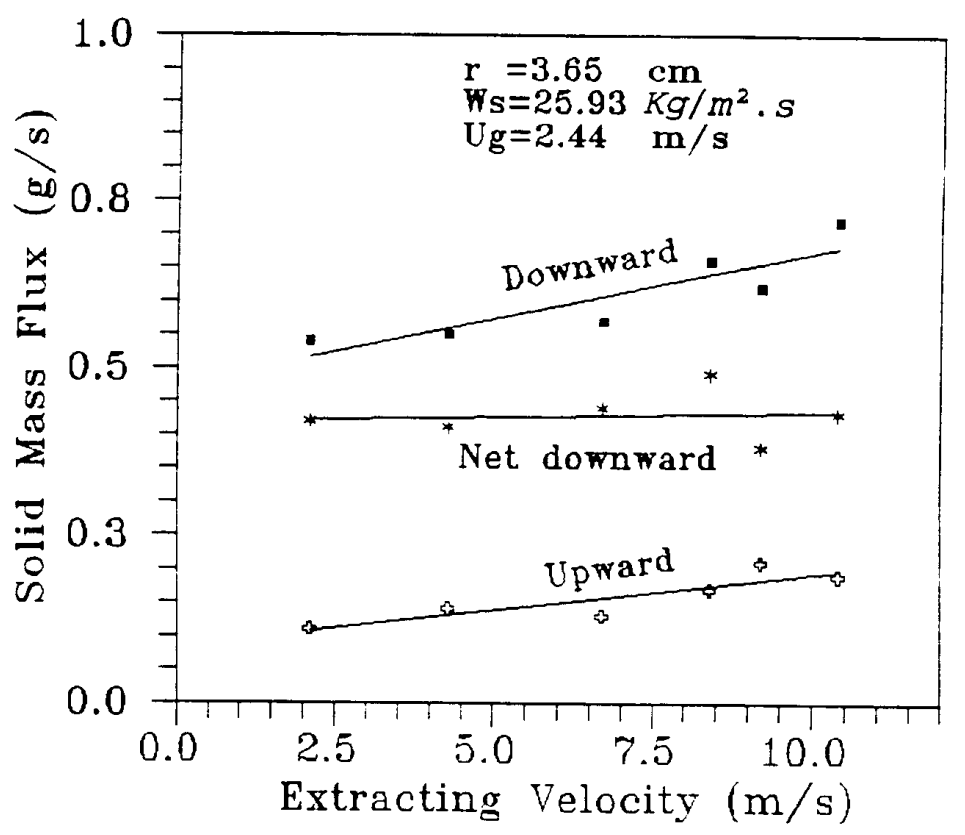

Figure 4 a Influence Extracting Velocity on The solid Mass Flux

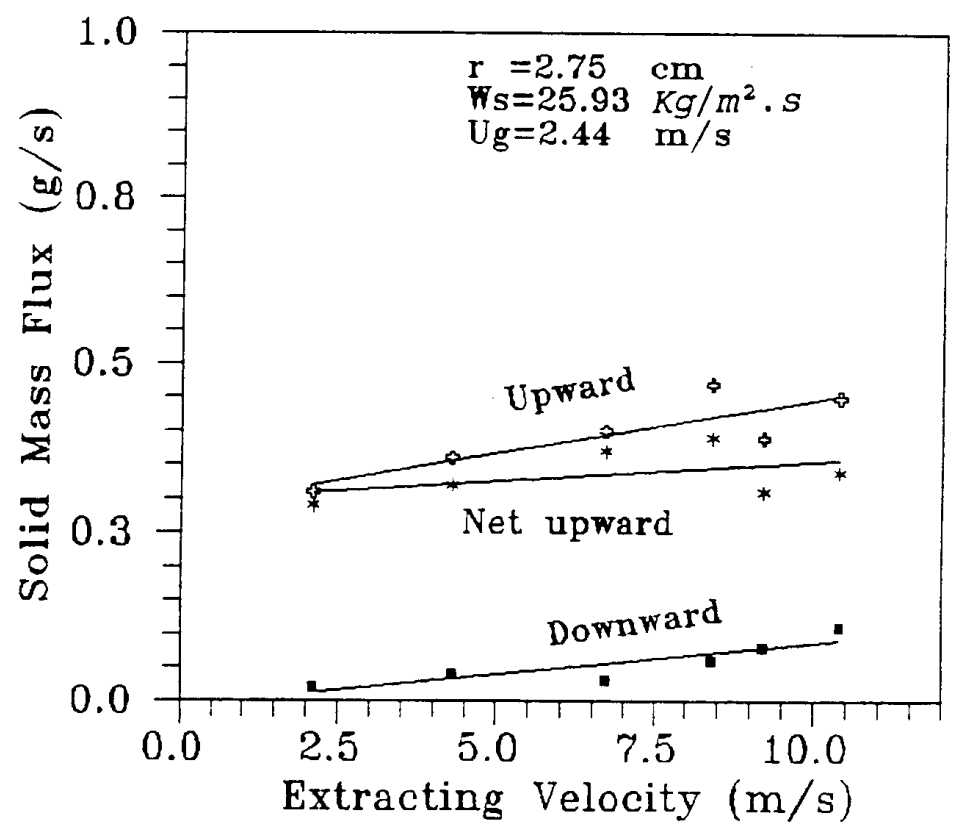

Figure $4 \mathrm{~b}$ Influence Extracting Velocity on The Solid Mass Flux 


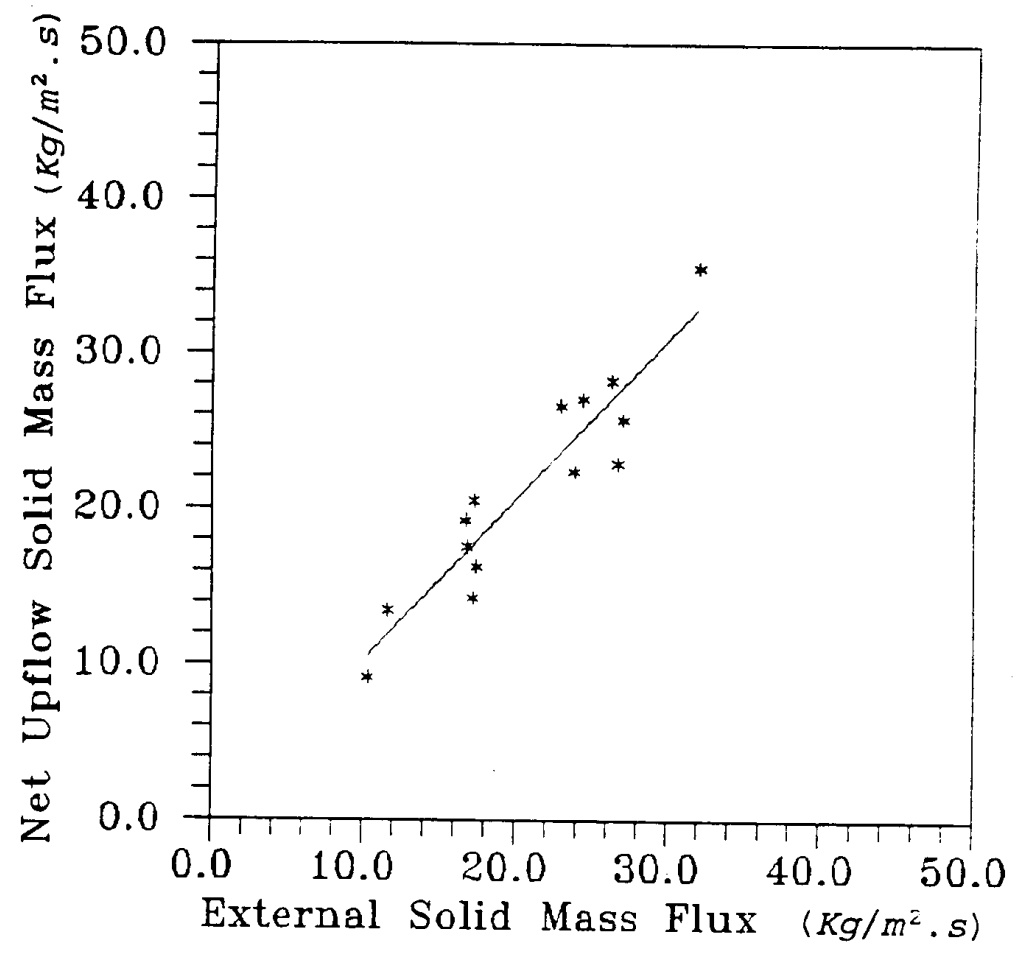

Figure $4 \mathrm{C}$ Comparision between Net Solid Mass Flux and External Solid Mass Flux

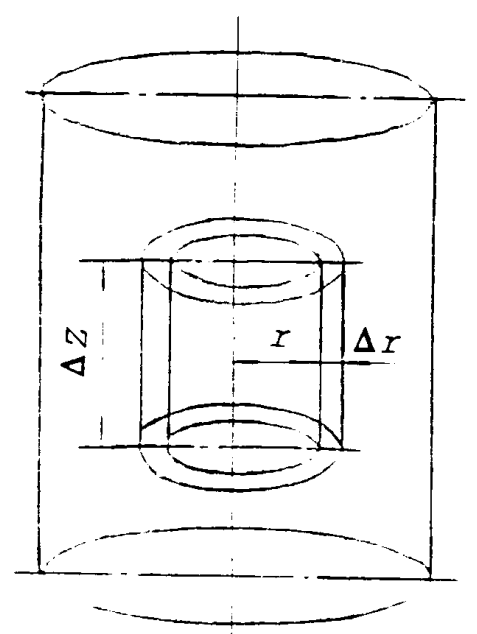

Figure 5 A Differential Annular section 


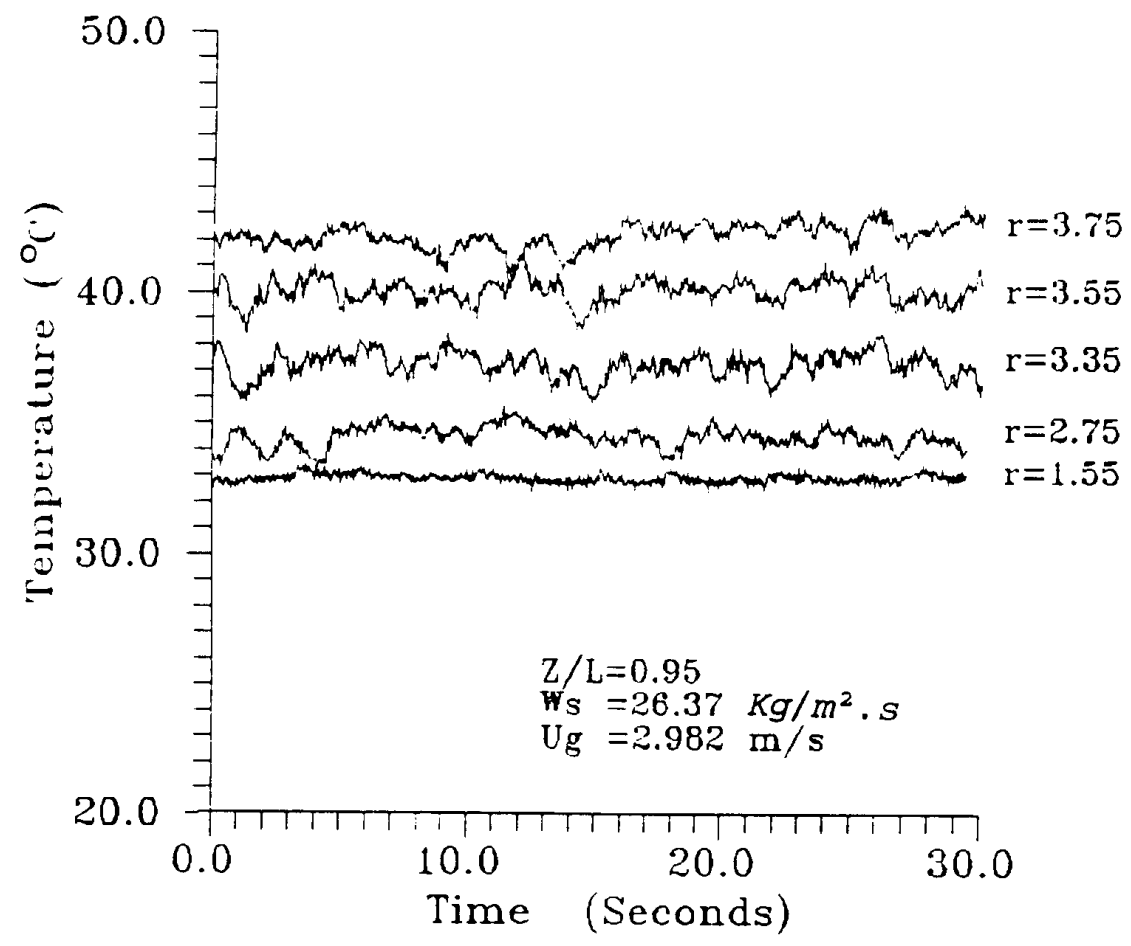

Figure $6 a$ Local Instantaneous Temperature Fluctuations

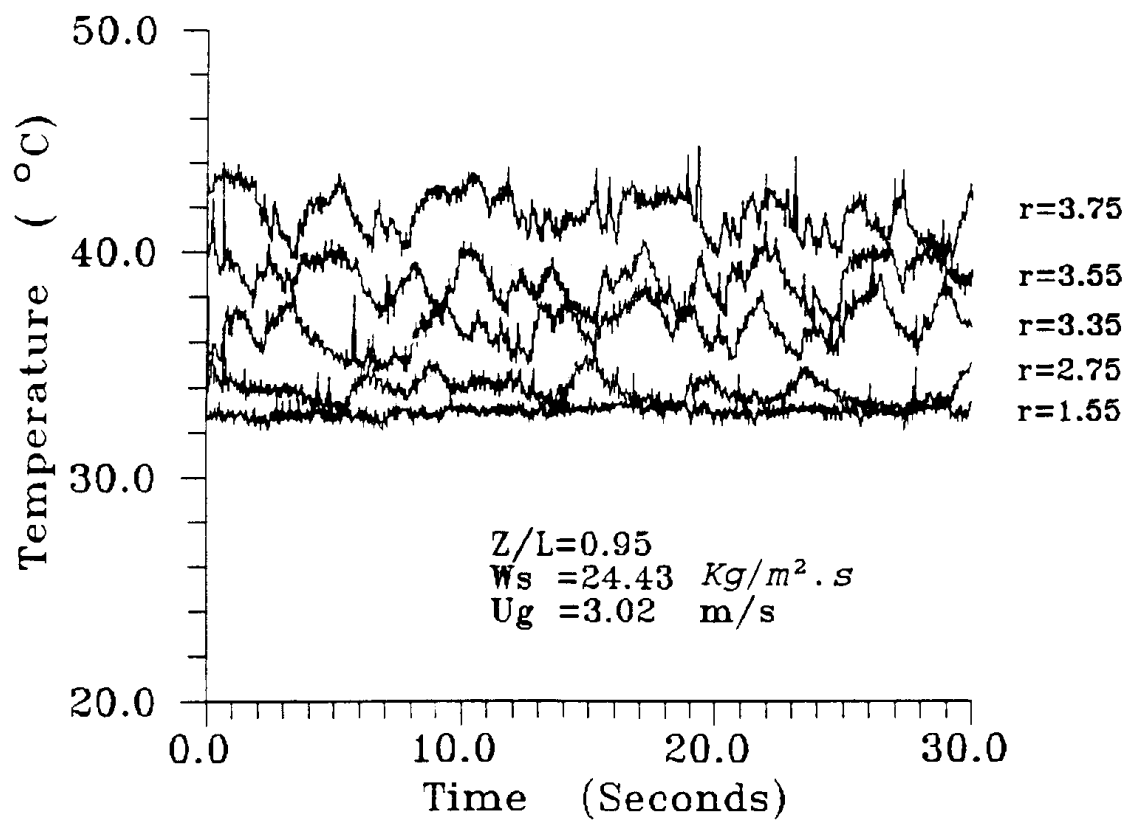

Figure $\sigma_{b}$ Local Instantaneous Temperature Fluctuations 


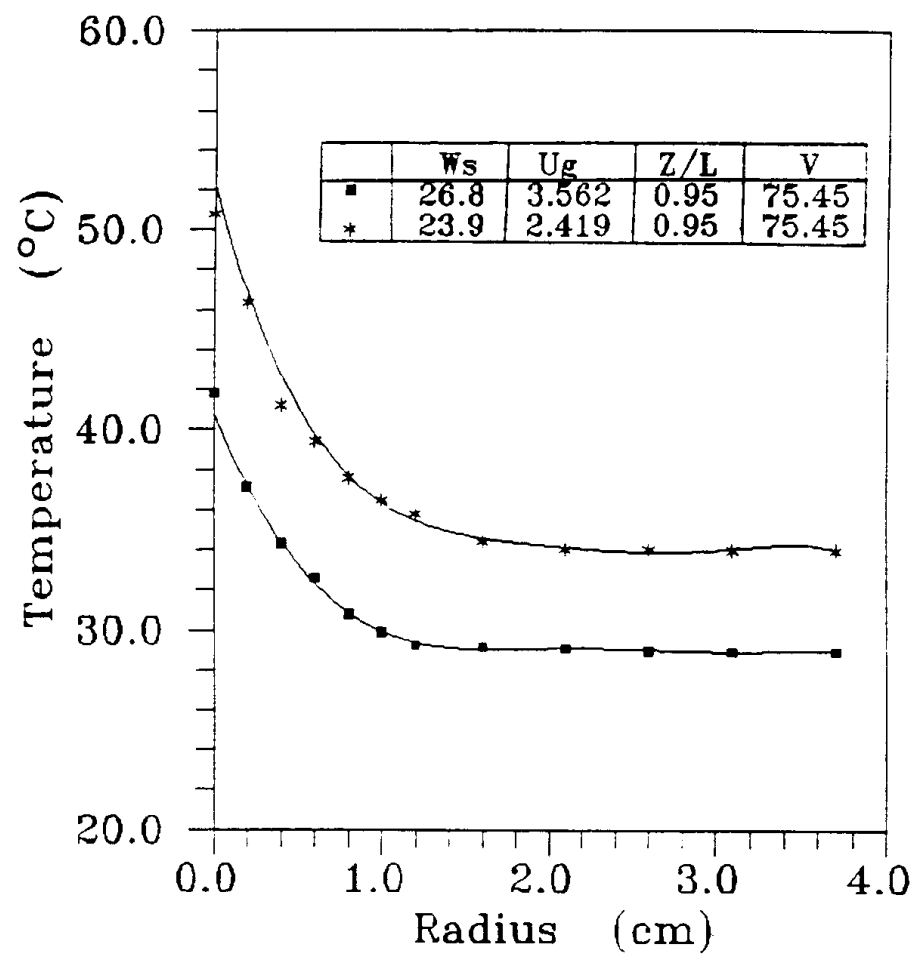

Figure 7a Radial Time-averaged Temperature Distributions

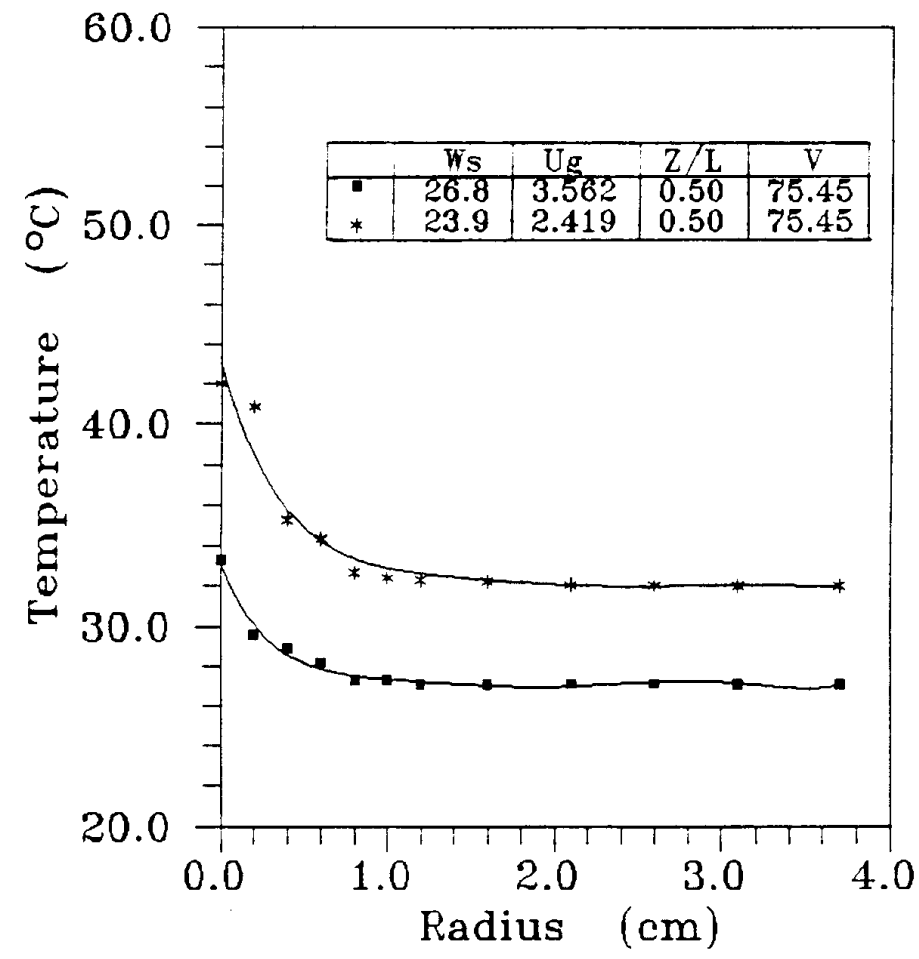

Figure $7_{b}$ Radial Time-averaged Temperature Distributions 


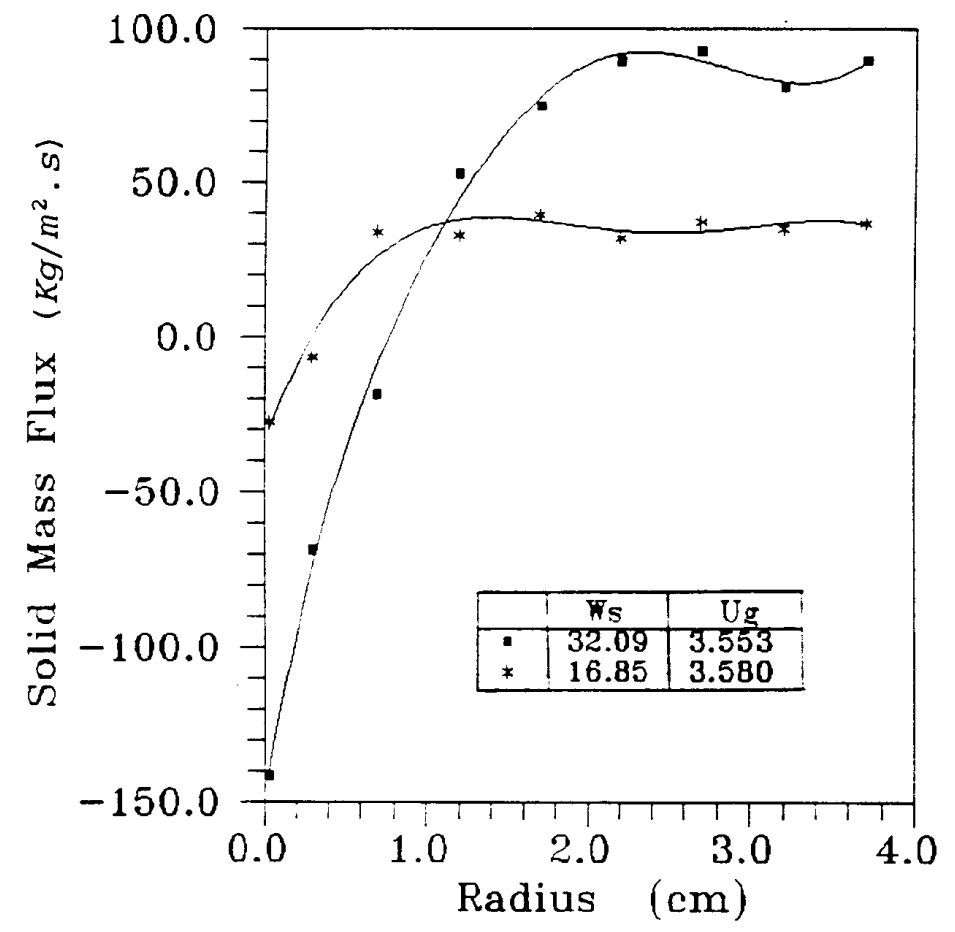

Figure 8 Radial Solid Mass Flux for Various Solid Feed Rates

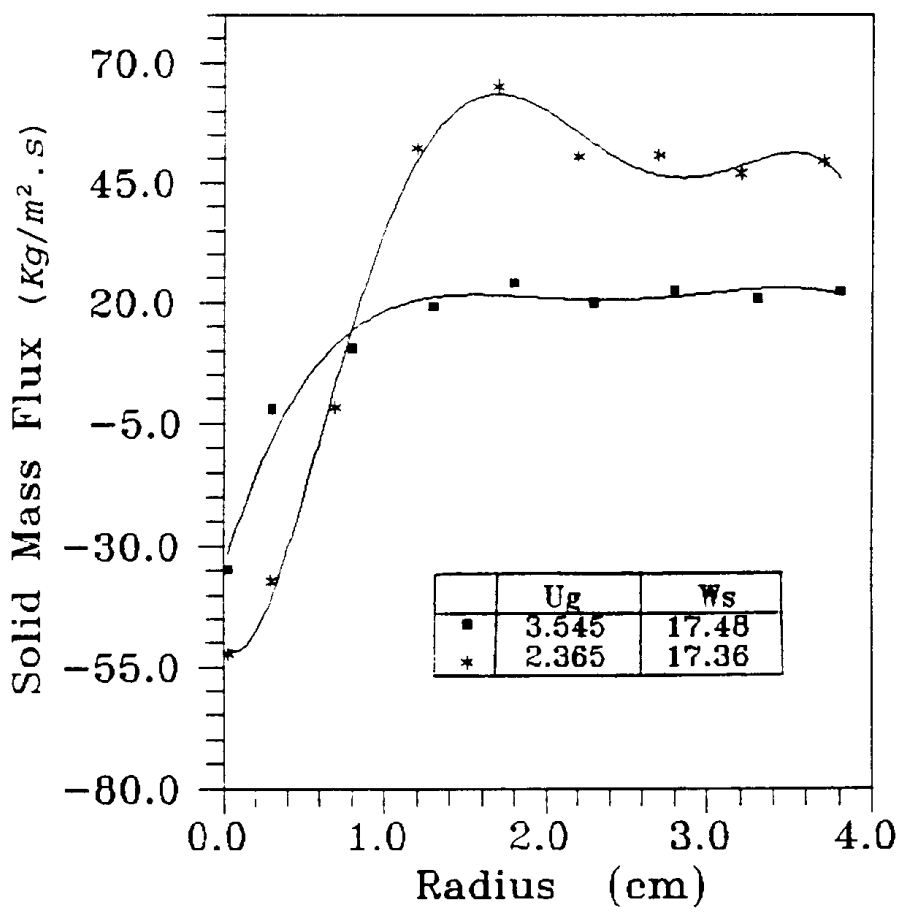

Figure 9 Radial Solid Mass Flux for Various Velocities 


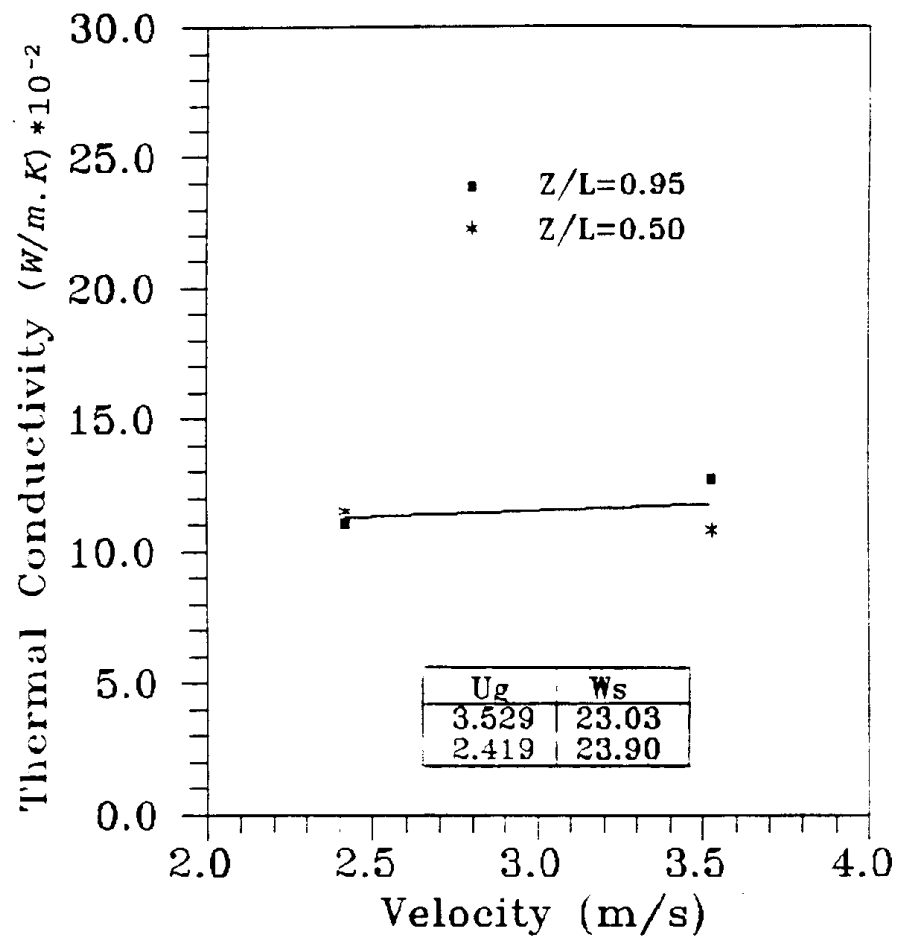

Figure 10 Effective Thermal Conductivity for Various Velocities

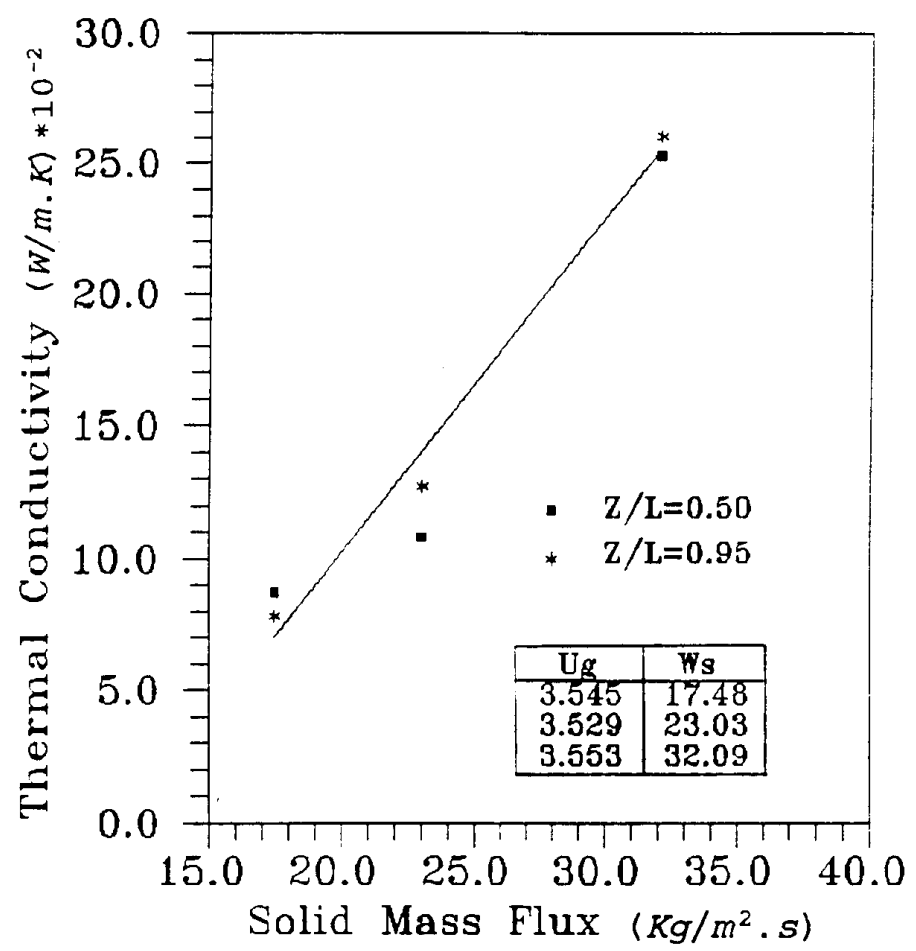

Figure 11 Effective Thermal Conductivity for Various Solid Fluxes 


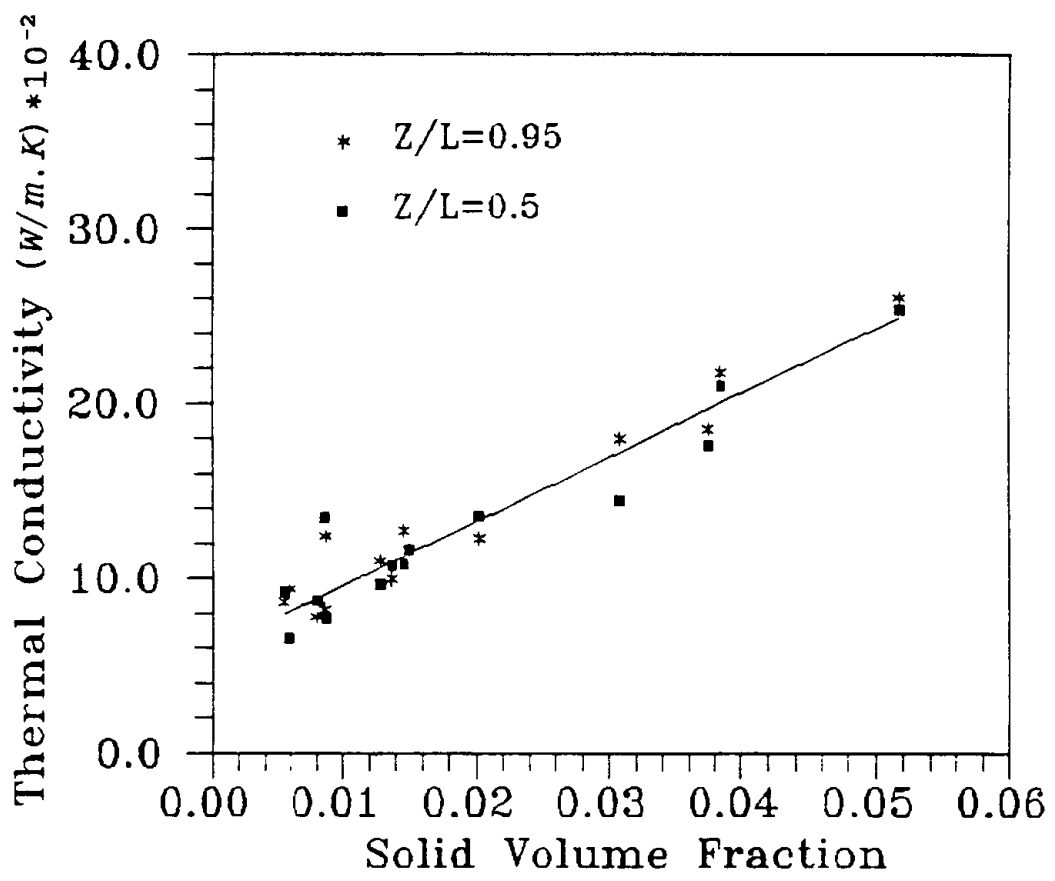

Figure 12 Thermal Conductivity Correction

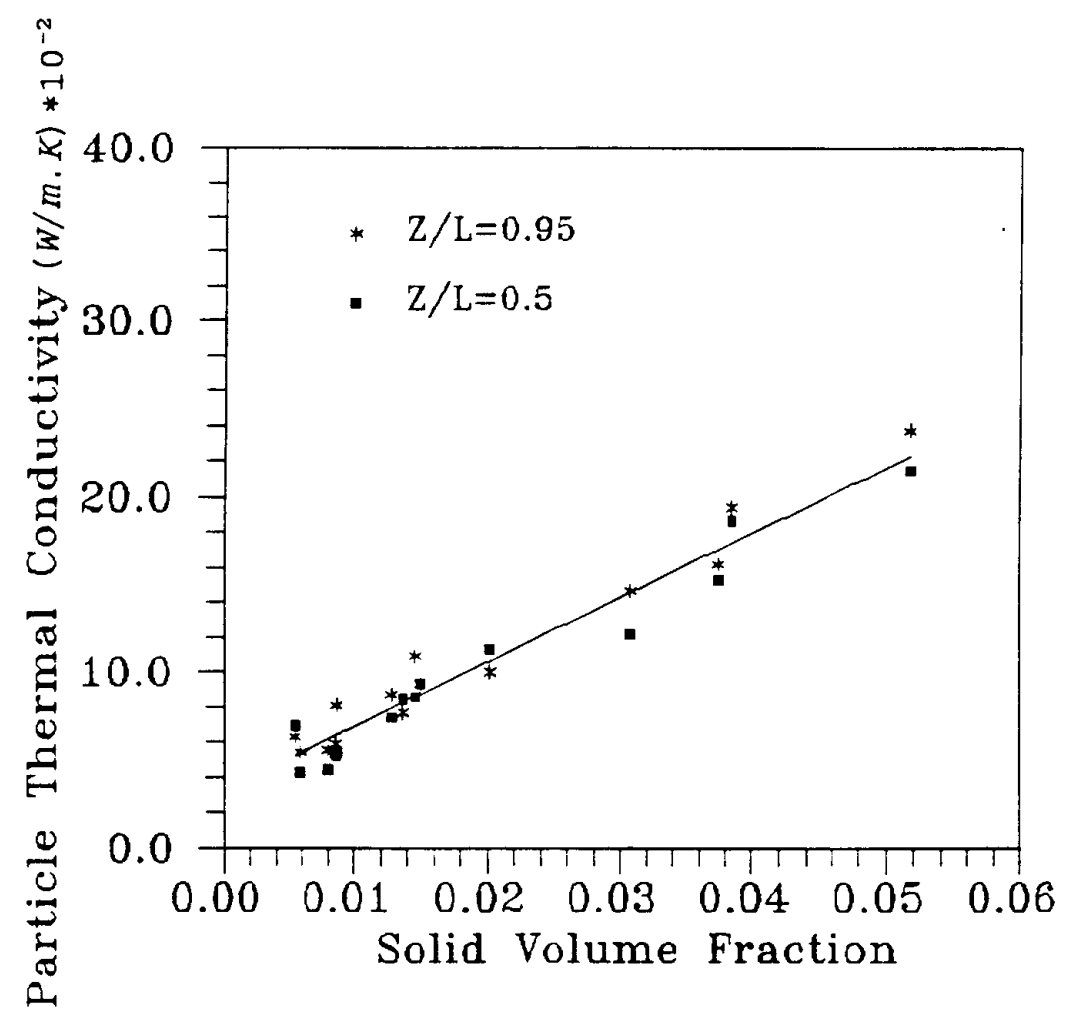

Figure 13 Particle Thermal Conductivity Correction 


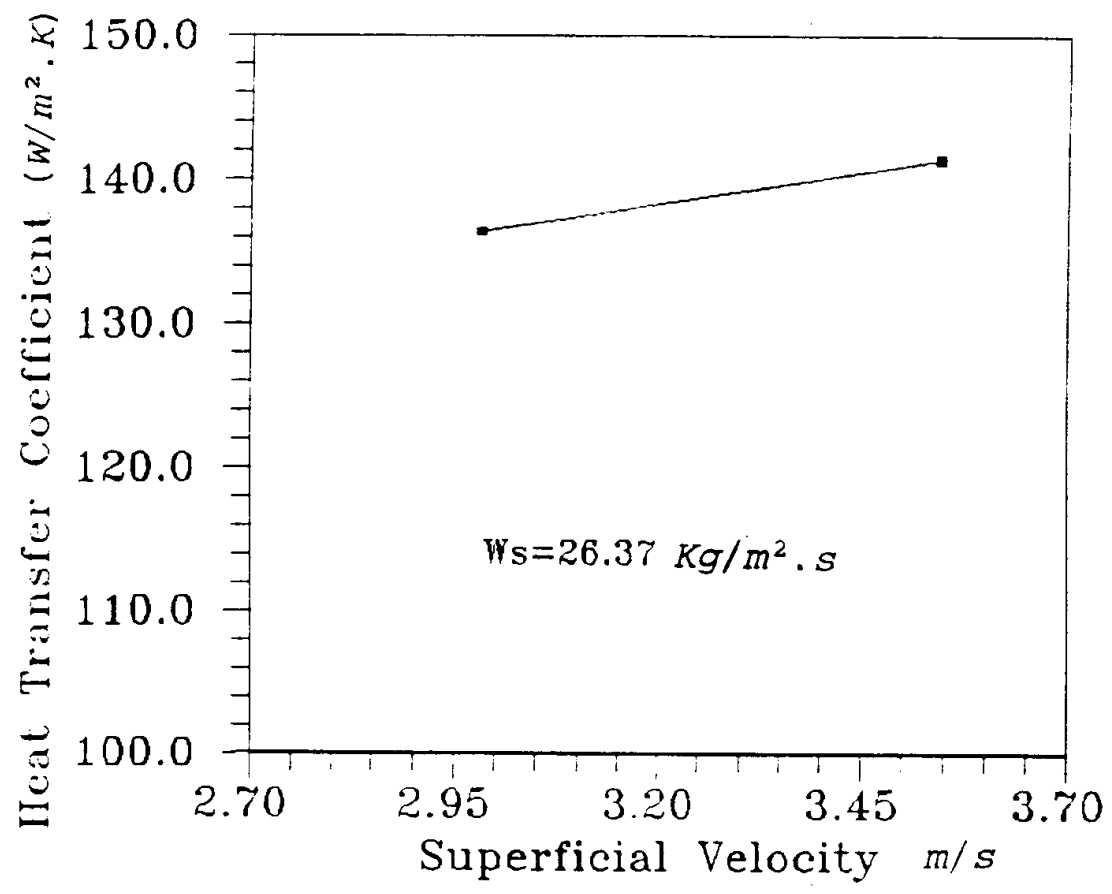

Figure 14 Effect of Velocity on Transfer Coefficient

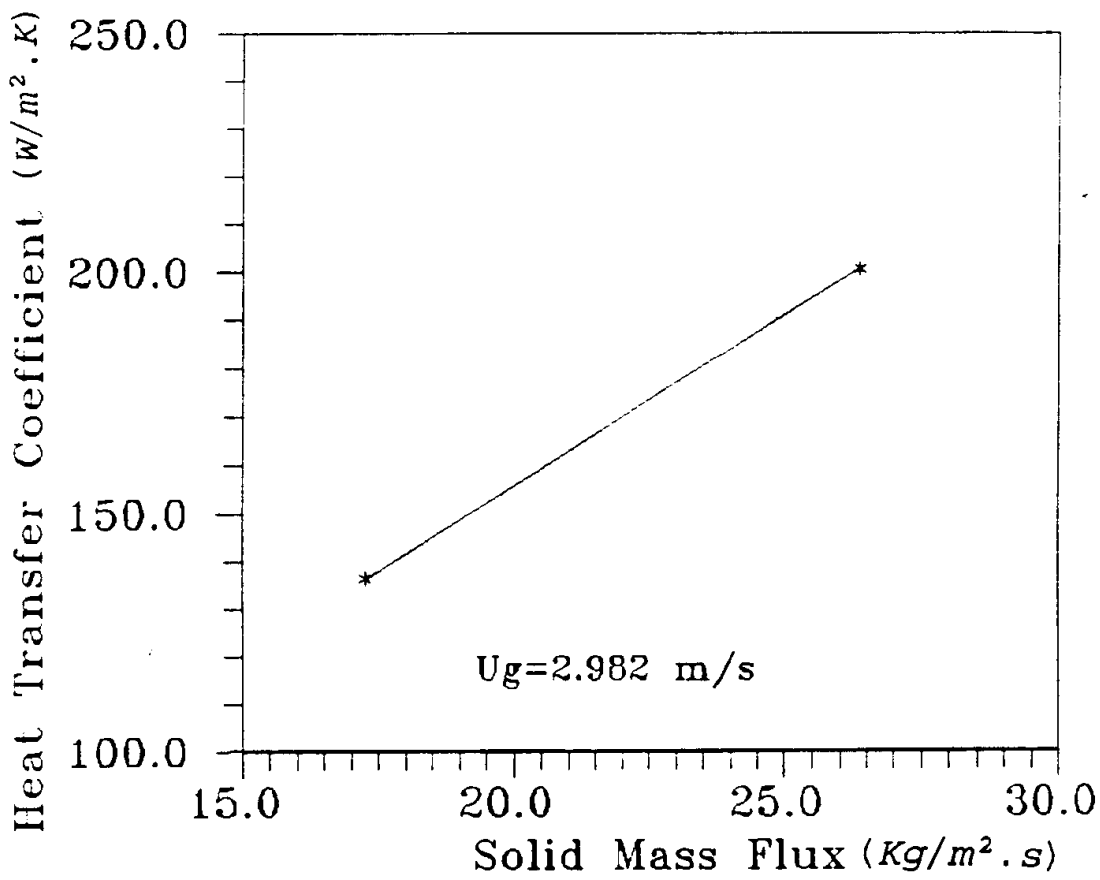

Figure 15 Effect of Solid Flux on the Heat Transfer Coefficient 


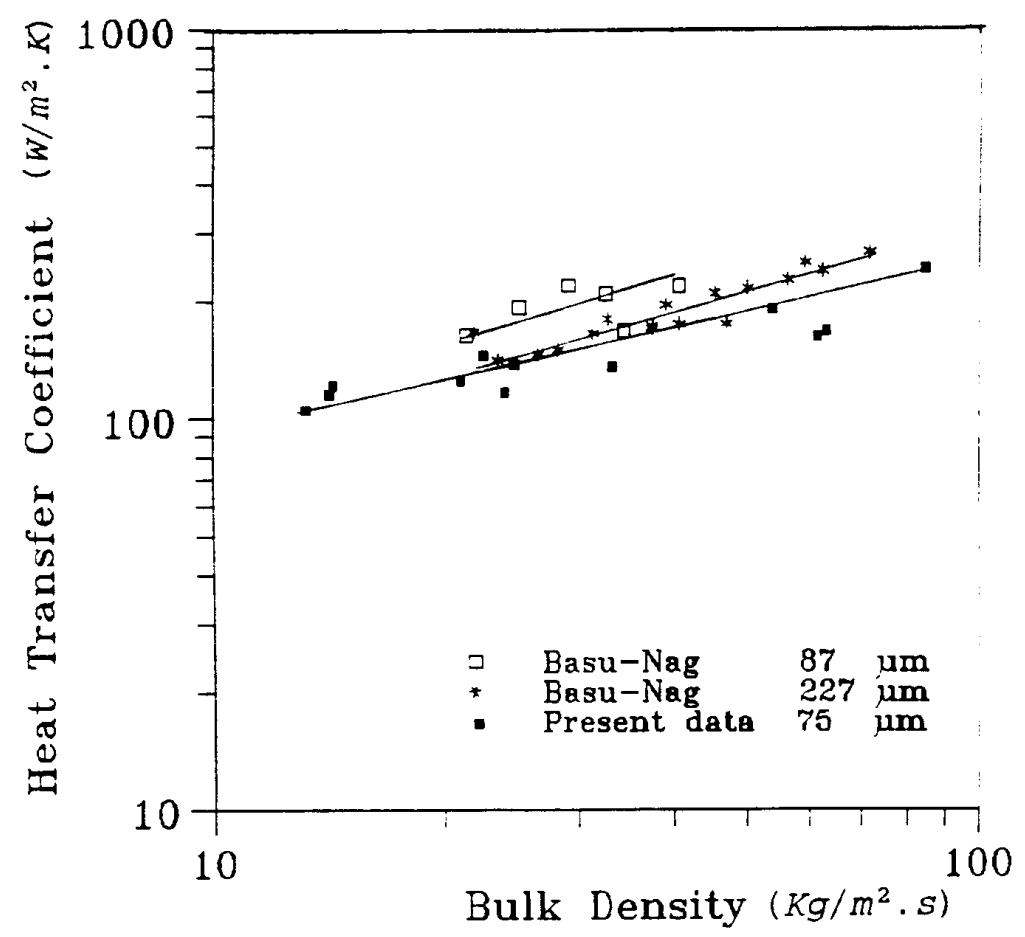

Figure 16 Effect of Bulk Density on the Heat Transfer Coefficient

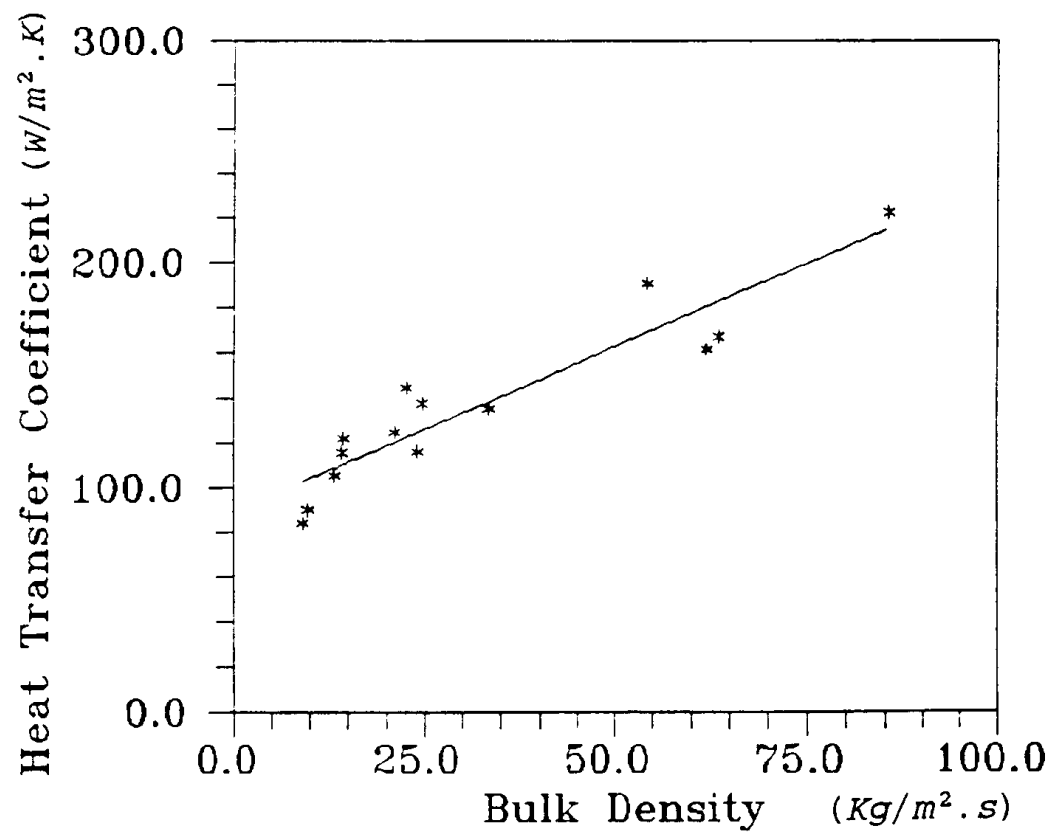

Figure 17 Effect of Bulk Density on the Heat Transfer Coefficient 


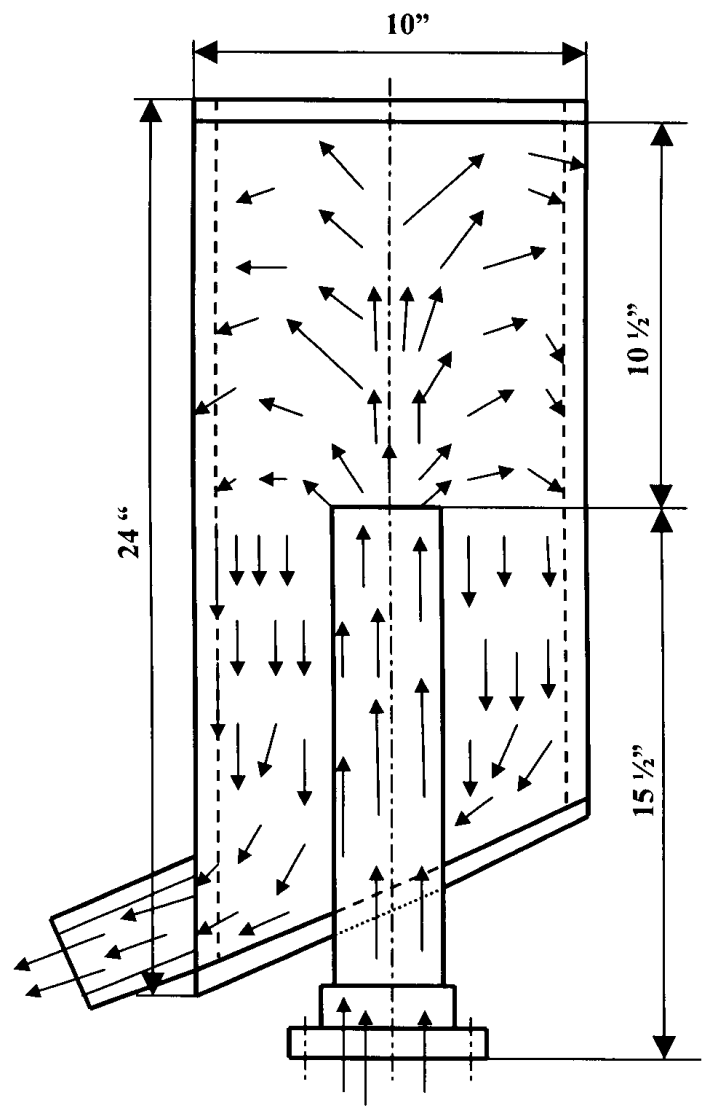

Figure 1a: The new top design of the circulating fluidized bed in IIT Chemical Engineering department.

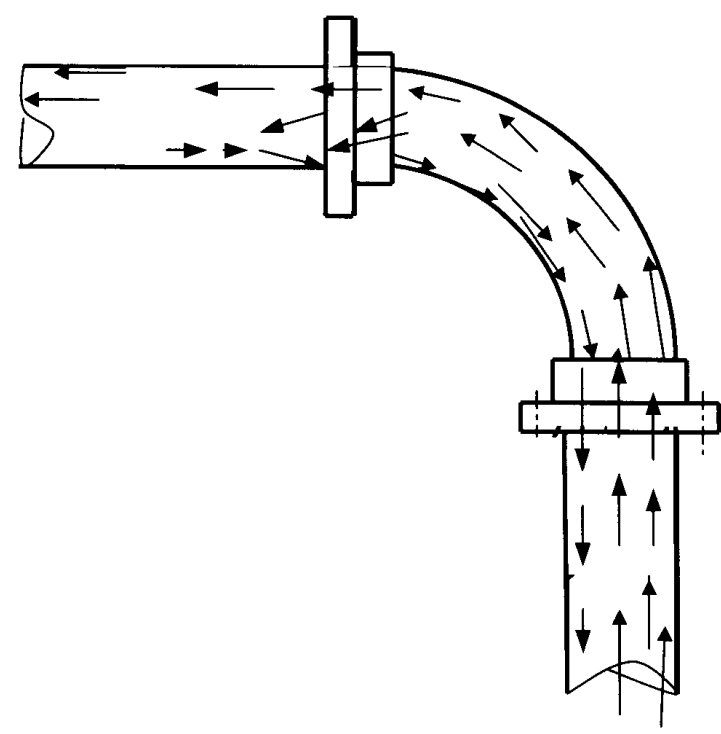

Figure 1b: The old top of the circulating fluidized bed in IIT Chemical Engineering department. 


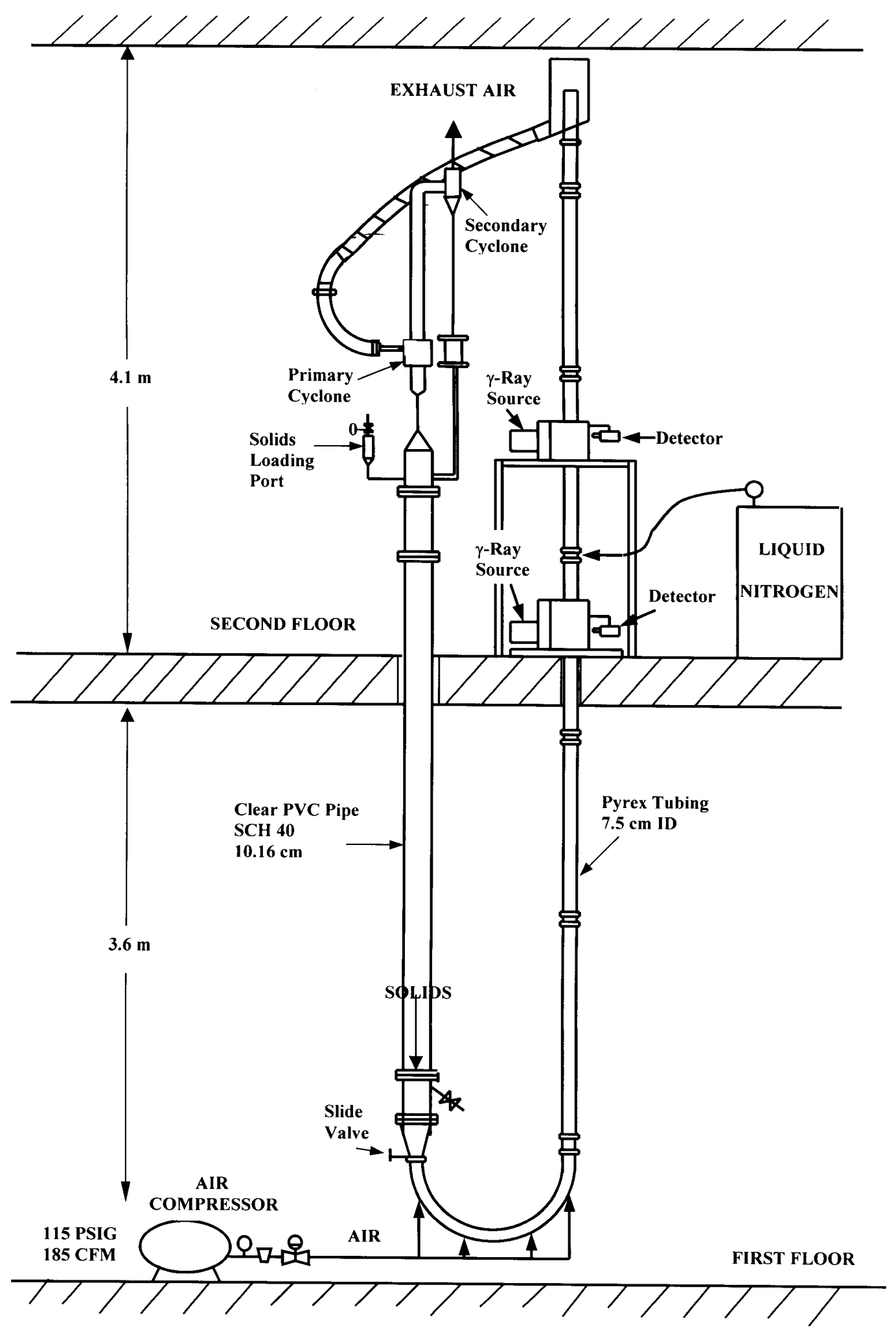

Figure 2: Circulating fluidized bed in IIT Chemical Engineering department to be operated as a three-phase column 


\section{MODEL FOR VAPORIZATION \\ D. Gidaspow}

Rate of vaporization $=$ Function of the collisional frequency. Assume the liquid droplet vaporizes as it collides with a hot particle.

$$
\# \text { collision per unit volume per unit time }=N_{12}=n_{1} n_{2} d_{12}^{2}\left(\frac{2 \pi \theta_{1} m_{0}}{m_{1} m_{2}}\right)^{\frac{1}{2}} g_{0}
$$

Let $\mathrm{m}_{\mathrm{DR}}=$ mass of droplet

The Rate of Vaporization (no heat or mass transfer resistance)

$$
\dot{\Gamma}=m_{D R} \times N_{12} \quad \mathrm{~kg} / \mathrm{m}^{3} \cdot \mathrm{s}
$$

For imperfect vaporization, multiply the mass in equation (2) by an efficiency of vaporization. Then equation ( 2 ) can be written as:

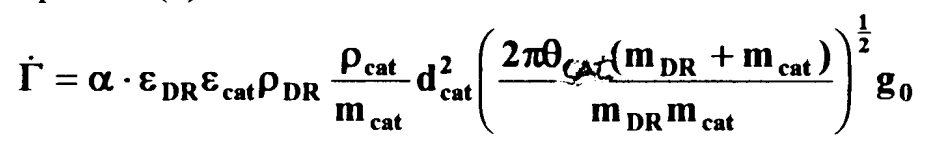

where $\alpha$ is the efficiency:

Optimum Volume fraction

Note that equation (3) gives the highest vaporization rate for $\epsilon_{D R}=0.5$ on a gas free basis.

Estimation of the rate of vaporization of liquid nitrogen in a FCC riser

$$
\begin{aligned}
& N_{12}=f_{\text {coll }} \cdot n_{D R}, \varepsilon_{s}=0.1, f_{\text {coll }}=10^{4}-10^{5} \frac{1}{\mathrm{sec}} \\
& \dot{\Gamma}=n_{D R} m_{D R} f_{\text {coll }}=\varepsilon_{D R} \rho_{D R} f_{\text {coll }} \\
& \dot{\Gamma}=0.1 \times 1000 \frac{\mathrm{kg}}{\mathrm{m}^{3}} \times 10^{4} \frac{1}{\mathrm{sec}}
\end{aligned}
$$

For nomenclature, see D. Gidaspow, "Multiphase Flow and Fluidization," Academic Press, 1994 


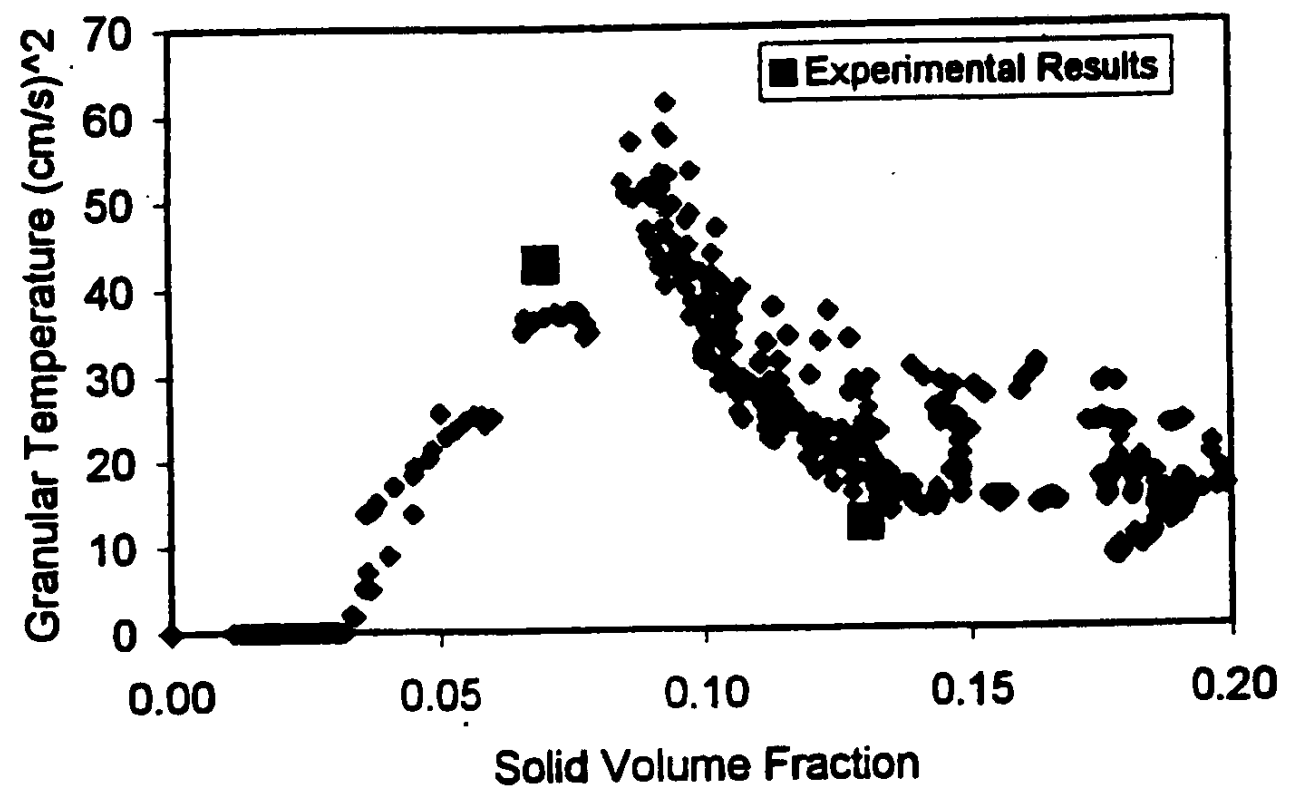

Figure 8. A Comparison of Computed Granular Temperature in a Slurry Bubble Column Reactor (Wu and Gidaspow, 1998) to Experiments with $45 \mu \mathrm{m}$ Catalyst

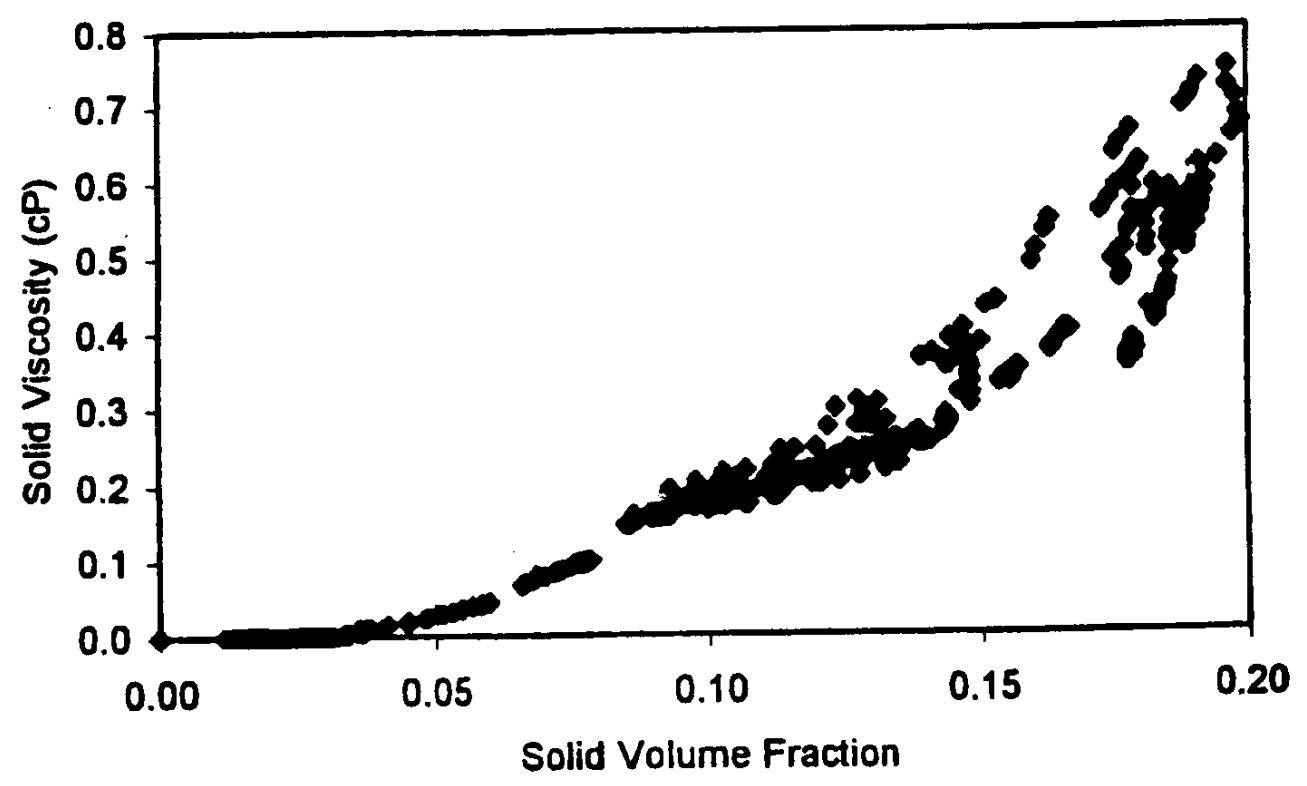

Figure 9. Computed Viscosity of $45 \mu \mathrm{m}$ Catalyst 